\title{
RELAÇÕES ENTRE AS CARACTERÍSTICAS INTERVALO DESMAME-CIO, DURAÇÃO DO CIO E MOMENTO DA OVULAÇÃO PELA ULTRA-SONOGRAFIA E DOSAGEM DE PROGESTERONA SÉRICA EM FÊMEAS DA ESPÉCIE SUÍNA.
}

Dissertação apresentada para a obtenção do título de Mestre junto à Faculdade de Medicina Veterinária e Zootecnia da Universidade de São Paulo.

Área de Concentração: REPRODUÇÃO ANIMAL

Orientador: Prof. Dr. Aníbal Sant' Anna Moretti

SÃO PAULO 


\section{FICHA CATALOGRÁFICA}

Preparada pela Biblioteca da

Faculdade de Medicina Veterinária e Zootecnia da Universidade de São Paulo

Viana, Carlos Henrique Cabral

Relações entre as características intervalo desmame-cio, duração do cio e momento da ovulação pela ultra-sonografia e dosagem de progesterona sérica em fêmeas da espécie suína / Carlos Henrique Cabral Viana -- São Paulo, 1998.

Dissertação (mestrado) -- Faculdade de Medicina Veterinária e Zootecnia da Universidade de São Paulo.

Departamento de Reprodução Animal. Área de concentração: Reprodução Animal.

Orientador: Prof. Dr. Anibal Sant'Anna Moretti.

Unitermos: 1.Estro 2.Ovulação 3.Progesterona 4.Ultra-sonografia 5.Suínos 
Exemplar atualizado de acordo com as sugestões da Banca Examinadora 
Ao meu irmão Paulo e meu avo Florindo que, embora ausentes, se fazem presente em lembranças todos dias.

Aos meus pais Manoel e Elza,

pelos exemplos de força, honestidade e humildade, incentivo, paciência e todo o amor que os pais podem dedicar a um filho

À minha avó Thereza pelo carinho e o prazer de sua presença junto a nós até os dias de hoje. 
Ao Prof. Dr. Anibal Sant'Anna Moretti pela orientação e confiança depositada.

Aos amigos Dr. Paulo Roberto Souza da Silveira e Édio Klein por toda ajuda, paciência, ensinamentos e, principalmente, amizade. 


\section{AGRADECIMENTOS}

Aos Professores Drs. José Antônio Visintin, Renato Campanarut Barnabe e Rubens Paes de Arruda pelo apoio incentivo e, acima de tudo, amizade.

À Prof. Dra. Tânia Goes de Pinho, pela orientação e paciência nas dosagens de progesterona.

Aos Pesquisadores e Funcionários do Centro Nacional de Pesquisa em Suínos e Aves pela parceria e confiança depositada.

Aos Veterinários, Técnicos e Funcionários da Sadia - Faxinal dos Guedes, pela oportunidade, confiança e esforços para possibilitar a execução deste trabalho.

Ao Prof. Paulo Henrique Mazza Rodrigues do Departamento de Nutrição e Criação Animal da FMVZ-USP, pela execução da análise estatística dos dados aqui apresentados. 
Aos revisores: Ronaldo Gonçalves Morato, José Antônio Visintin e Renato Valentin.

Aos funcionários da biblioteca da FMVZ-USP pela acessoria na confecção desta tese.

Aos professores, funcionários, pós-graduandos, bolsistas e estagiários do Departamento de Reprodução Animal, pelo constante apoio, estímulo e amizade.

A todos que, direta ou indiretamente, contribuíram para a realização deste trabalho. 


\section{SUMÁRIO}

\section{RESUMO}

\section{SUMMARY}

1 INTRODUÇÃO

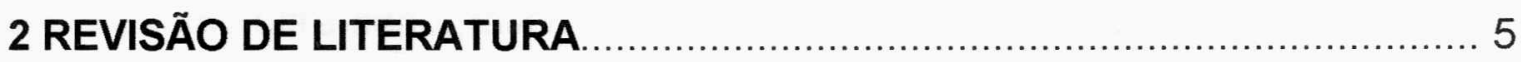

2.1 Aspectos Fisiológicos do Anestro Lactacional......................................... 6

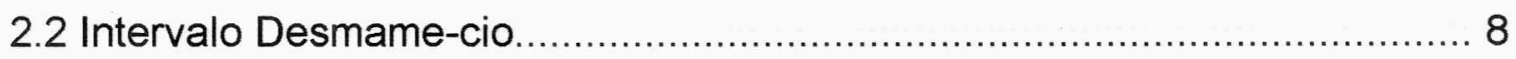

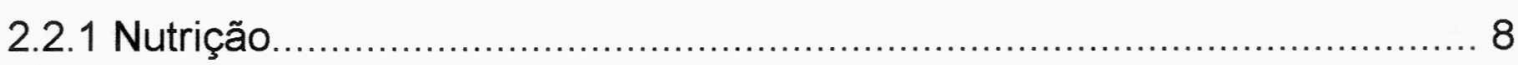

2.2.2 Período de lactação e tamanho de leitegada .......................................... 9

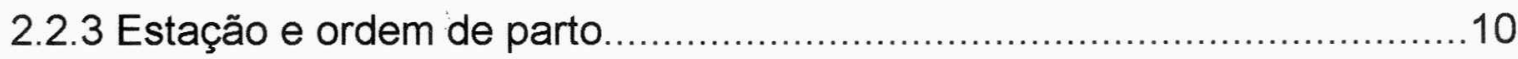

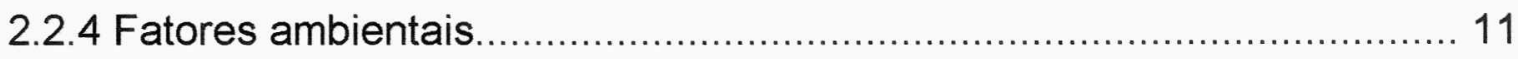

2.2.5 Raça

2.2.6 Duração e reflexos na fertilidade ....................................................... 12

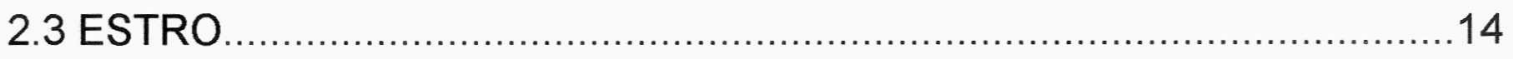

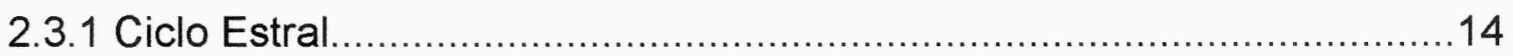

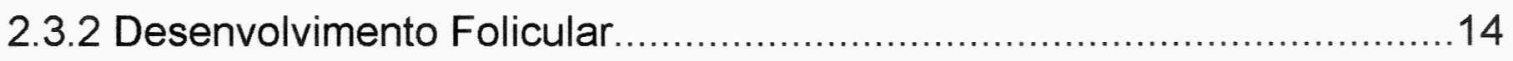

2.3.3 Perfis hormonais em relação ao estro e à ovulação...............................16

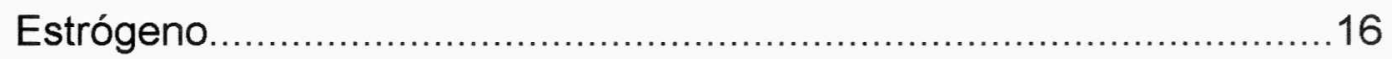

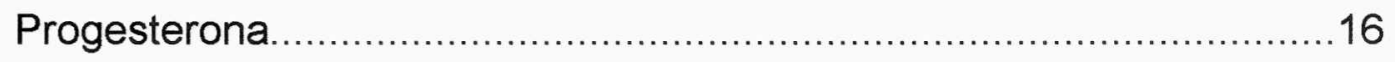

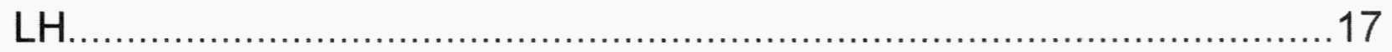

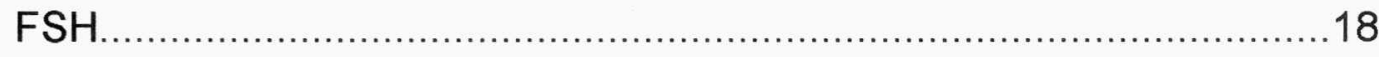

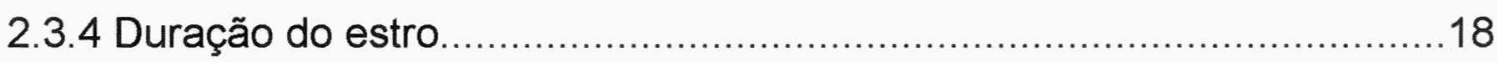

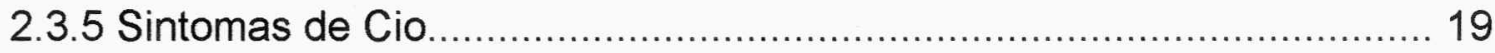




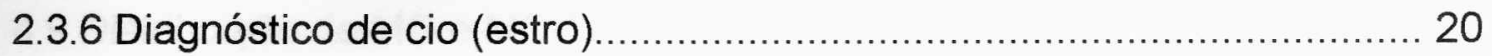

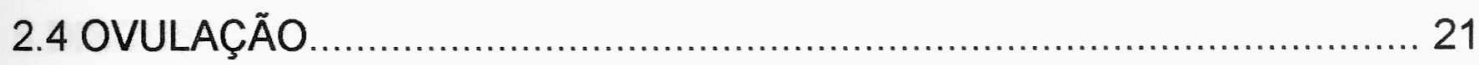

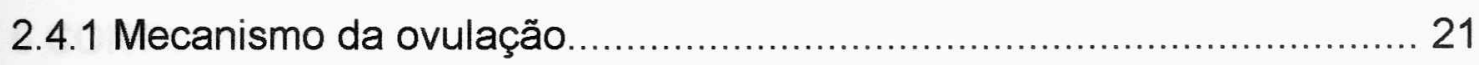

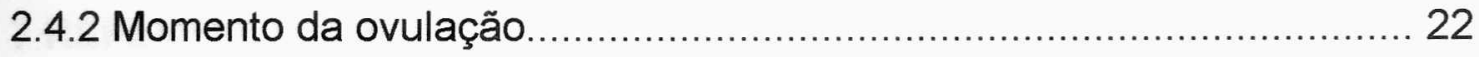

2.4.3 Exame ultra-sonográfico do ovário.................................................. 25

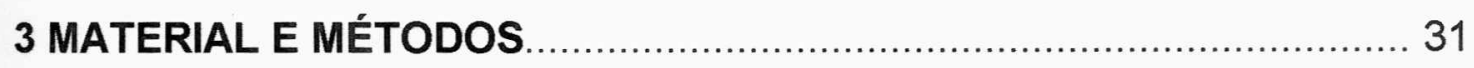

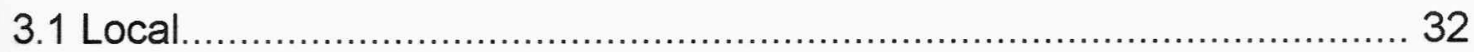

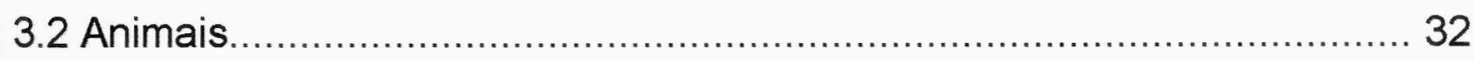

3.3 Determinação do intervalo desmame-cio (IDC) .................................... 33

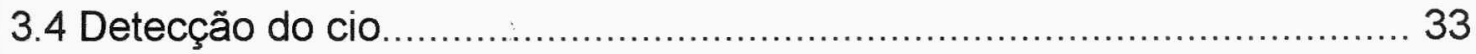

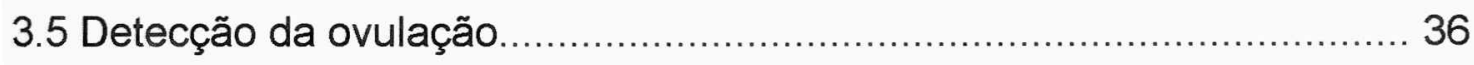

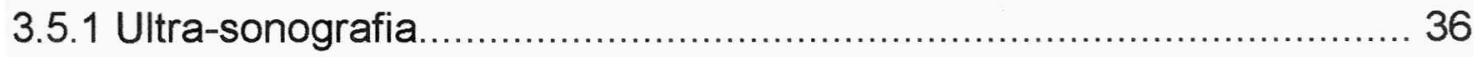

3.5.2 Dosagem sérica de progesterona ................................................. 39

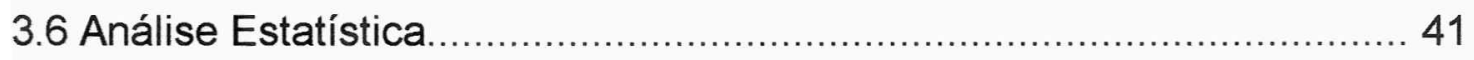

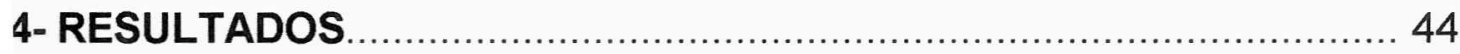

4.1- Distribuição das porcas de acordo com o IDC, DC e MO ..................... 45

1.2 Distribuição das porcas de acordo com horário de início do cio.............47

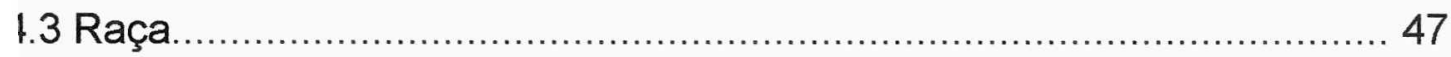

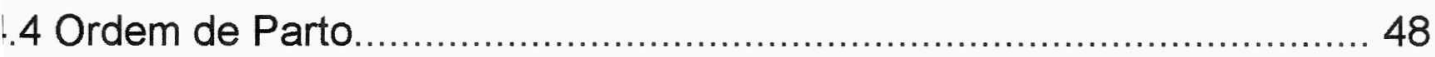

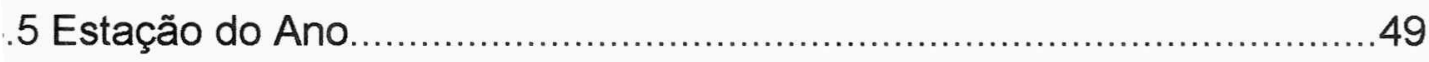

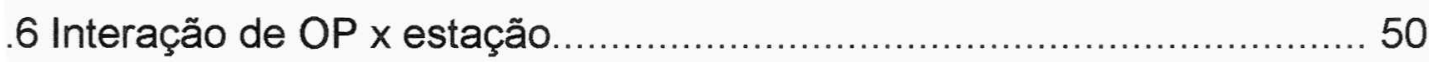

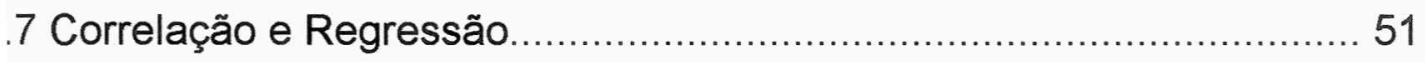

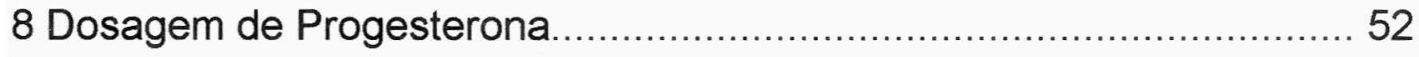


4.9 Distribuição de MO e MOP em intervalos 24 horas.

5 DISCUSSÃO

6 CONCLUSÕES.

91

7 REFERÊNCIAS BIBLIOGRÁFICAS

94 


\section{TABELAS}

TABELA 1 - Concentração de progesterona dos calibradores.

TABELA 2 - Distribuição das porcas de acordo com o intervalo desmame-cio (IDC), discriminado em dias e horas após o início do cio. 46

TABELA 3 - Distribuição das porcas de acordo com a duração do cio (DC) em horas.

TABELA 4 - Médias estimadas (LS means) do intervalo desmame-cio (IDC), da duração do cio (DC) e do momento da ovulação (MO) de acordo com as categorias da classe raça. 48

TABELA 5 - Médias estimadas (LS means) do intervalo desmame-cio (IDC), da duração do cio (DC) e do momento da ovulação (MO) de acordo com as categorias da classe ordem de parto.

TABELA 6 - Médias estimadas (LS means) do intervalo desmame-cio (IDC), da duração do cio (DC) e do momento da ovulação (MO) de acordo com as categorias da classe estação do ano 50

TABELA 7 - Médias estimadas (LS means) do momento da ovulação (MO) de acordo com a interação entre ordem de parto e estação do ano.... 51 
TABELA 8 - Níveis médios de progesterona de porcas com intervalo desmamecio (IDC) de 3, 4, 5 e 6 a 7 dias. 53

TABELA 9 - Numero e percentual de porcas nos diferentes grupos de intervalo desmame-cio (IDC), distribuídas em intervalos de 24 horas, onde estas provavelmente ovularam, de acordo com o momento da ovulação diagnosticada pela ultra-sonografia (MO). 55

TABELA 10 - Numero e percentual de porcas nos diferentes grupos de intervalo desmame-cio (IDC), distribuídas em intervalos de 24 horas, onde estas provavelmente ovularam, de acordo com o momento da ovulação estimado pelos níveis de progesterona (MOP). 56 


\section{FIGURAS}

FIGURA 1 - Diagnóstico de cio na presença do macho para a observação do reflexo de tolerância positivo. 35

FIGURA 2 - Disposição das fêmeas nas gaiolas para possibilitar o exame ultrasonográfico dos ovários

FIGURA 3 - Posição do transdutor em relação ao flanco da fêmea para a realização da ultra-sonografia. 38

FIGURA 4 - Distribuição das porcas de acordo com o intervalo desmame-cio (IDC) em horas 57

FIGURA 5 - Distribuição das porcas de acordo com a duração do cio (DC) em horas 58

FIGURA 6 - Distribuição das porcas de acordo com o momento da ovulação (MO) em horas após o início do cio 59

FIGURA 7 - Distribuição das porcas de acordo com o horário em que estas foram diagnosticadas em cio. 60 
FIGURA 8- Relações entre o intervalo desmame-cio (IDC) e a duração do cio (DC) 61

FIGURA 9 - Relações entre a duração do cio (DC) e o momento da ovulação (MO). 62

FIGURA 10 - Relações entre o intervalo desmame-cio (IDC) e o momento da ovulação (MO) 63

FIGURA 11 - Análise de regressão entre intervalo desmame-cio (IDC) e duração do cio (DC) com comparação de retas de acordo com a classe estação do ano. 64

FIGURA 12 - Análise de regressão entre intervalo desmame-cio (IDC) e momento da ovulação (MO) com comparação de retas de acordo com a classe estação do ano. 65

FIGURA 13 - Análise de regressão entre duração do cio (DC) e momento da ovulação (MO) com comparação de retas de acordo com a classe estação do ano. 66 
FIGURA 14 - Análise de regressão entre intervalo desmame-cio (IDC) e duração do cio (DC) com comparação de retas de acordo com a classe raça 67

FIGURA 15 - Análise de regressão entre intervalo desmame-cio (IDC) e momento da ovulação (MO) com comparação de retas de acordo com a classe raça 68

FIGURA 16 - Análise de regressão entre duração do cio (DC) e momento da ovulação (MO) com comparação de retas de acordo com a classe raça.

FIGURA 17 - Análise de regressão entre intervalo desmame-cio (IDC) e duração do cio (DC) com comparação de retas de acordo com a classe ordem de parto 70

FIGURA 18 - Análise de regressão entre intervalo desmame-cio (IDC) e momento da ovulação (MO) com comparação de retas de acordo com a classe ordem de parto. 71

FIGURA 19 - Análise de regressão entre duração do cio (DC) e momento da ovulação (MO) com comparação de retas de acordo com a classe ordem de parto 
FIGURA 20 - Valores médios, em horas, referentes à duração do cio (DC), momento da ovulação pela ultra-sonografia (MO) e momento da ovulação pela progesterona (MOP), de acordo com o intervalo desmame-cio (IDC) em dias 73

FIGURA 21 - Níveis médios de progesterona de acordo com os grupos de intervalo desmame-cio (IDC) em dias 74

FIGURA 22 - Percentual de porcas nos diferentes grupos de intervalo desmame-cio (IDC), distribuídas em intervalos de 24 horas, onde estas provavelmente ovularam, de acordo com o momento da ovulação diagnosticada pela ultra-sonografia (MO) 75

FIGURA 23 - Percentual de porcas nos diferentes grupos de intervalo desmame-cio (IDC), distribuídas em intervalos de 24 horas, onde estas provavelmente ovularam, de acordo com o momento da ovulação estimado pelos níveis de progesterona (MOP)... 76 
VIANA, C.H.C. Relações entre as características intervalo desmame-cio, duração do cio e momento da ovulação pela ultra-sonografia e dosagem de progesterona sérica em fêmeas da espécie suína (Relationships between the characteristics weaning-toestrus interval, estrus duration and moment of ovulation by ultrasonography and progesterone blood levels in sows). São Paulo, 1998. Tese (Mestrado). Faculdade de Medicina Veterinária e Zootecnia, Universidade de São Paulo.

O sucesso no emprego da inseminação artificial em suínos depende de inúmeros fatores, sendo o momento ideal de sua realização, um dos que mais influencia, o qual compreende um intervalo entre 0 e 24 horas antes da ovulação. Estudou-se as relações entre o intervalo desmame-cio (IDC), a duração do cio (DC) e o momento da ovulação (MO) e a influência da raça, ordem de parto e estação do ano sobre estas características e suas relações. Um total de 236 fêmeas, de uma unidade de produção de suínos no oeste Santa Catarina, foram observadas para a obtenção dos dados de IDC e DC, as quais eram testadas para o diagnóstico de cio 4 vezes ao dia, na presença do macho. A ovulação foi diagnosticada em 77 fêmeas, pela ultra-sonografia, por via trans-cutânea, em 3 exames diários com 8 horas de intervalo. As amostras de sangue para análise de progesterona, foram coletadas de 74 fêmeas, com 24 horas de intervalo, em 4 ocasiões para a determinação dos níveis: basal, 24, 48 e 72 horas após o início do cio, respectivamente, e submetidas a técnica de radioimunoensaio. A raça Landrace mostrou um IDC mais longo (113,62 horas) em comparação à Large White (linhagem 1) $(102,45$ horas) $(P<0,05)$, mas não houveram diferenças significativas destas em relação à Large White (linhagem 2). Fêmeas de $1^{\circ}$ parto apresentaram um IDC mais longo ( 117,44 horas) que às de $2^{\circ}$ parto $(100,47$ horas $)$ e acima deste $(104,78$ horas) $(P<0,05)$. Não houve influência da estação do ano sobre nenhuma das características. Houve interação entre estação do ano e ordem de parto sobre o MO, sendo que, nas fêmeas acima de $2^{\circ}$ parto, o $\mathrm{MO}$ médio estimado foi de 51,76 horas na estação 1 e de 36,56 horas na estação $2(P<0,05)$. Houve correlação negativa entre intervalo desmame-cio e duração do cio $(r=-0,4657 ; P=0,0001)$ e entre intervalo desmame-cio e momento da ovulação ( $r=-0,3955 ; P=0,0004)$, no entanto, não houve correlação entre duração do cio e momento da ovulação $(r=0,2201 ; P=0,0578)$. Não foi 
possivel mostrar influências de raça, ordem de parto e estação de ano sobre as relações entre IDC, DC e MO através da análise de regressão com comparação de retas. Houve baixa correlação entre a ultra-sonografia e a análise de progesterona (MOP), para o diagnóstico da ovulação $(r=0,3396 ; P=0.0209)$, sem correlação quando a ocorrência da ovulação foi considerada em intervalos de 24 horas a partir do início do cio $(r=0,2637 ; P=0,0766)$. A porcentagem de fêmeas que, pela ultra-sonografia, ovularam entre 0 e 24, 24 e 48, 48 e 72 e acima de 72 horas após o início do cio foi de, respectivamente, $0 \%, 58,4 \%, 37,5 \%$ e $4,2 \%$ para o IDC de 3 dias, $3,2 \%, 67,7 \%, 29,2 \%$ e $0 \%$ para o IDC de 4 dias, $0 \%, 91,6 \%, 8,3 \%$ e $0 \%$ para o IDC de 5 dias e $10 \%, 90 \%$, $0 \%$ e $0 \%$ para o IDC de 6 e 7 dias. Pela análise de progesterona, para os mesmos intervalos, respectivamente, a porcentagem fêmeas foi de $4,5 \%, 36,3 \%, 50 \%$ e $9,1 \%$ para o IDC de 3 dias, 3,6\%, 32,2\%, 60,7\% e 3,6\% para o IDC de 4 dias, 5,9\%, 35,3\%, $52,9 \%$ e $5,9 \%$ para o IDC de 5 dias e $14,3 \%, 57,1 \%, 28,6 \%$ e $0 \%$ para o IDC de 6 e 7 dias. Nestas condições, O IDC não se mostrou uma referência confiável para ser utilizado como um preditor do momento ideal da inseminação. No entanto, conhecimento das características IDC, DC e MO dentro de cada rebanho ajudam a apontar falhas e elaborar programas eficientes de IA. 


\section{Summary}

The success of artificial insemination (Al) depends on several factors. The ideal moment to realize the $\mathrm{Al}$ is a limiting factor and it is defined as 0 to 24 hours before ovulation. Relationships between weaning-to-estrus interval (WEI), duration of estrus (DE) and moment of ovulation (MO) and the influence of breed, parity and season over these characteristics and the relationships with each other were studied. In a total of 236 sows, of a farm in the west of Santa Catarina, were observed to record the data of WEI and $\mathrm{DE}$, which were tested by back pressure 4 times a day, in presence of a boar. The ovulation was diagnosed in 77 sows, by transcutaneous ultrasonography, 3 times a day at intervals of 8 hours. The blood samples to progesterone analyze were collected of 74 sows, at 24 hours intervals, at 4 occasions to determine basal, 24, 48, 72 hours levels after estrus onset, respectively, and submitted to radioimunoassay. The breed Landrace showed a WEI longer (113,62 hours) than Large White (line 1) $(102,45$ hours) $(P<0,05)$, but there were no differences in relation to Large White (line 2). First parity sows presented a WEI longer (117,44 hours) than second parity sows $(100,47$ hours) and over second parity $(104,78$ hours $)(P<0,05)$. There was no influence of season over all the studied characteristics. There was interaction between season and parity over MO because females over second parity showed an average $\mathrm{MO}$ of 51,76 hours in season 1 and 36,56 hours in season $2(P<0,05)$. There was negative correlation between WEI and $D E(r=-0,4657 ; P=0,0001)$ and between WEI and $M O(r=-0,3955 ; P=0,0004)$, however, there was no correlation between $D E$ and $M O(r=0,2201 ; P=0,0578)$. It was not possible to show influence of breed, parity and season over the relationships between WEI, DE and $\mathrm{MO}$ by analyze of regression with line comparison. There was low correlation between ultrasonography and analyze of progesterone (MOP), to diagnose ovulation $(r=0,3396 ; P=0.0209)$ and no correlation when the occurrence of ovulation was considered at intervals of 24 hours since onset of estrus $(r=0,2637 ; P=0,0766)$. The percentage of females that ovulated (detected by ultrasonography), between 0 to 24,24 to 48,48 to 72 and over 72 hours after the onset of estrus was, respectively, $0 \%, 58,4 \%$, $37,5 \%$ and $4,2 \%$ to WEI of 3 days, $3,2 \%, 67,7 \%, 29,2 \%$ and $0 \%$ to WEI of 4 days, $0 \%$, $91,6 \%, 8,3 \%$ e $0 \%$ to WEI of 5 days and $10 \%, 90 \%, 0 \%$ and $0 \%$ to WEI of 6 and 7 days. 
By progesterone levels, for the same intervals, respectively, the percentage was $4,5 \%$, $36,3 \%, 50 \%$ and $9,1 \%$ to WEI of 3 days, $3,6 \%, 32,2 \%, 60,7 \%$ and $3,6 \%$ to WEI of 4 days, $5,9 \%, 35,3 \%, 52,9 \%$ and $5,9 \%$ to WEI of 5 days and $14,3 \%, 57,1 \%, 28,6 \%$ and $0 \%$ to IDC of 6 and 7 days. In these conditions, the WEI was not a good reference to be utilized as a predictor of ideal moment of insemination. However, the information about the characteristics WEI, DE and MO within each herd help to point the mistakes and to develop Al programs. 
INTRODUÇÃO 
Nas últimas três décadas, as modificações dinâmicas e constantes da produtividade nos sistemas de produção, tem gerado, aumentos significativos na produção de alimentos de maneira direta ou indireta, através de avanços tecnológicos em diversas áreas da exploração animal. A suinocultura, neste contexto, tem se destacado como atividade em pleno desenvolvimento, produtivamente conquistando novos mercados pela qualidade e oferta de carne a um preço acessível.

No campo da reprodução de suínos, a inseminação artificial (IA), vem constituindo-se numa prática indispensável à qualificação da produtividade, possibilitando melhora nos índices e oferecendo novas perspectivas tecnológicas à atividade.

As principais vantagens da IA estão focadas: no melhoramento genético dos sistemas de produção, através da introdução de reprodutores de alto valor zootécnico; na redução do número de reprodutores necessários para atender o plantel, com reflexos no investimento em reprodutores de melhor qualidade; na diminuição dos custos no manejo reprodutivo; na bioseguridade do sistema; no melhor controle da eficiência reprodutiva do plantel e na detecção precoce de falhas reprodutivas devidas ao macho. No entanto, algumas limitações devem ser consideradas para a obtenção de índices satisfatórios como: a qualificação de pessoal, o emprego de um bom manejo reprodutivo adequado a técnica de IA, a necessidade da proximidade à uma central de IA ou sua implantação na própria granja, devido ao curto período de conservação do sêmen (em média 3 dias).

No manejo reprodutivo específico, o momento ideal de inseminar 
tem sido considerado como condição essencial para a obtenção de índices que acompanhem a dinâmica de crescentes aumentos na produtividade, levando os pesquisadores a procura da determinação precisa deste momento, pois guarda relação estreita com a ovulação. O diagnóstico do provável intervalo de ocorrência da ovulação baseou-se em técnicas como dosagens hormonais e indução da ovulação (HELMOND et al.,1986; DZIUK, 1970). Com o advento da ultra-sonografia, o diagnóstico tornou-se mais acurado sem levar o animal a qualquer tipo de stress, não influenciando assim o processo ovulatório (SOEDE et al., 1994a; SOEDE et al., 1995a).

Outro aspecto, dentro desta análise, é que os esquemas atuais de IA consideram o intervalo médio de provável ocorrência da ovulação como base para a realização da mesma. No entanto, há nos suínos grande variabilidade na duração do cio e no momento da ovulação, o que evidencia a pouca acuracidade na determinação do momento ideal, pois algumas fêmeas poderiam estar sendo inseminadas precocemente ou tardiamente em relação a ovulação (KEMP; SOEDE, 1996). Deste modo, os estudos vem sendo conduzidos com o intuito de procurar características que se relacionem diretamente com o momento da ovulação. A correlação positiva entre a duração do cio e o momento da ovulação vem sendo confirmada ocorrendo a ovulação aproximadamente no terço final do período de cio. Com base nestas informações acrescidas da determinação de correlação negativa entre o intervalo desmame-cio (IDC) e a duração do cio (DC) (NISSEN et al., 1997), poderíamos inferir que o IDC seria utilizado como um preditor do provável momento da ovulação, levando assim a um esquema diferenciado de IA. 
Com a determinação do momento ideal para a inseminação, através do diagnóstico da ovulação, seria possível diminuir o número de doses de sêmen por porca, além de evitar falhas no esquema de inseminação que comprometem os índices de produtividade.

Diante do exposto, o presente estudo objetivou:

- estudar a influência de características como raça, ordem de parto e estação do ano sobre o intervalo desmame-cio (IDC), a duração do cio (DC) e o momento da ovulação (MO).

- estudar as inter-relações, intervalo desmame-cio (IDC), duração do cio e momento da ovulação com o auxílio da ultra-sonografia, com a intenção de empregar o IDC como um preditor do momento de ovulação e propor um esquema diferenciado de IA, que alcance melhores índices e diminuição do número de doses utilizadas por fêmea;

- avaliar a utilização da ultra-sonografia, por via trans-cutânea, em comparação aos níveis séricos de progesterona, como técnica para o diagnóstico da ovulação;

- adequar o diagnóstico de cio como parâmetro para a determinação do esquema ideal de IA. 
REVISÃO DE LITERATURA 


\subsection{Aspectos Fisiológicos do Anestro Lactacional}

Tanto o início da puberdade como a retomada da ciclicidade, em porcas desmamadas, são precedidas por um aumento significante nas concentrações séricas de Hormônio Luteinizante (LH), caracterizada por uma alta freqüência (aproximadamente 1 pico/hora) de pulsos de baixa amplitude (KRAELING; BARB, 1990).

A fase lactacional na porca caracteriza-se por um período de inatividade reprodutiva, com baixos níveis de gonadotrofinas, tanto de LH como de hormônio folículo estimulante (FSH) e consequentemente reduzido crescimento folicular e baixos níveis de estrógeno. O principal mecanismo de inibição da atividade reprodutiva está ligado ao estímulo da amamentação (COSTA, 1995).

O efeito inibitório da amamentação parece ser dependente da intensidade de sucção, e conforme a lactação progride a inibição diminui, provavelmente como resultado da freqüência de mamadas e declínio da produção de leite (DE RENSIS et al., 1991).

O provável mecanismo para tal inibição é que, dependendo da intensidade de sucção, existe a liberação de substâncias no sistema nervoso central, denominadas peptídeos opióides endógenos (EOP), os quais fazem parte de um sistema de feed back negativo na liberação de hormônio liberador de gonadotrofinas (GnRH) (KRAELING; BARB, 1990).

Alguns autores consideram ainda que exista uma disfunção no mecanismo de feed back positivo dos estrógenos, durante o início da lactação, a qual é conseqüência da exposição prolongada do eixo hipotálamo-hipófise- 
gônadas aos níveis elevados de progesterona $\left(\mathrm{P}_{4}\right)$ durante a gestação (ELSAESSER; PARVIZI, 1980). No entanto, é bem estabelecido que o LH é um sinal luteotrófico essencial na porca durante a prenhez (ZIECIK et al., 1982), além disso, porcas desmamadas no dia 0 apresentam crescimento folicular. Portanto, estas observações sugerem que os níveis séricos de progesterona na gestação não tem efeito algum sobre a síntese e liberação de gonadotrofinas no período de lactação (VARLEY; FOXCROFT, 1990).

As concentrações de LH, FSH, estrógenos totais e progesterona foram medidas durante e após a lactação em porcas intactas e ovariectomizadas dentro de 4 dias pós-parto. Como as concentrações de FSH aumentaram após a ovariectomia, mas não as de LH e estrógenos, foi proposto que o FSH é controlado em parte por algum fator não esteroidal (provavelmente inibina) secretado pelo ovário (STEVENSON et. al., 1981).

A prolactina também poderia estar envolvida na supressão das gonadotrofinas através da ativação dos terminais dopaminérgicos (VAN DE WIEL et al., 1985). Além da prolactina, outros hormônios tais como ocitocina, relaxina e corticosteróides poderiam estar envolvidos no mecanismo inibitório da reprodução durante a lactação, uma vez que estes também respondem ao estímulo de sucção (VARLEY; FOXCROFT, 1990).

Segundo BRITT (1996), durante o anestro lactacional, o sistema reprodutivo da porca passa por três fases distintas: 1)Fase Hipergonadotrófica, correspondente aos 2 a 3 primeiros dias pós-parto, que é caracterizada por níveis elevados de $\mathrm{LH}$ e $\mathrm{FSH}$, os quais diminuem drasticamente após este período; 2)Fase de Transição, que compreende o período entre o $3^{\circ}$ e $14^{\circ}$ dias pós-parto, 
que é caracterizada pelos mais baixos níveis sangüíneos de $\mathrm{LH}$ e FSH e desaparecimento dos folículos com características ovulatórias e 3)Fase de Normalização, que corresponde ao período a partir do dia 14 até por volta do dia 21 pós-parto, a qual é caracterizada pelo aumento progressivo dos níveis basais de LH e FSH até o desmame.

\subsection{Intervalo Desmame-cio}

Nesta característica os principais fatores a considerar podem ser seqüenciados da seguinte maneira:

\subsubsection{Nutrição}

As influências da nutrição durante a lactação, sobre o IDC tem sido amplamente estudadas. Em estudo realizado com 191 porcas mestiças, onde foram oferecidos três níveis de energia metabolizável ( 8 Mcal/dia, 12 Mcal/dia ou 16 Mcal/dia) durante 28 dias de lactação, não se observou influência na produção de leite em decorrência do ajuste de catabolismo dos tecidos corporais em relação aos requerimentos nutricionais para a lactação. No entanto, as porcas que perderam peso e toucinho excessivamente (alimentadas com baixos níveis de energia) apresentaram um IDC mais prolongado àquelas que conservaram seu peso e toucinho (alimentadas com altos níveis de energia) (REESE et al., 1982).

Outros estudos mostraram que o baixo consumo de energia durante a lactação afetou negativamente a composição corporal, espessura de toucinho e intervalo desmame-cio ( KING; WILLIAMS, 1984; REESE et al., 1984). 
A relação direta entre peso corporal, espessura de toucinho e IDC ainda não foi esclarecida, pois, em fêmeas alimentadas ad libitum, as variações de condição corporal não afetaram o IDC (ARMSTRONG et al., 1986; ESBENSHADE et al., 1986). Aparentemente, o consumo total de energia durante a lactação é mais importante para influenciar o IDC que a condição corporal (TUBBS, 1990).

Normalmente um menor percentual de fêmeas primíparas mostram cio dentro de 7 dias após o desmame, em comparação às pluríparas (REESE et al., 1982; SZAREK et al., 1981). Isso ocorre provavelmente devido aos requerimentos nutricionais das primíparas serem mais altos, devido aos metabolismos diferenciados.

A alimentação ad libitum no período entre o desmame e a cobertura (flushing) é geralmente considerada como um efeito favorável na taxa de ovulação e tamanho de leitegada. No entanto, este efeito não está bem documentado com relação ao IDC, sendo efetivo apenas em porcas primíparas (TUBBS, 1990).

\subsubsection{Período de lactação e tamanho de leitegada}

O período de lactação e o IDC são inversamente correlacionados. Lactações com menos de quatro semanas favorecem um IDC mais longo e lactações com mais de quatro semanas favorecem um IDC mais curto (TUBBS, 1990). No entanto, VESSEUR et al. (1994b) trabalhando com um período de lactação médio de 4 semanas (excepcionalmente 3 ou 5 semanas), não encontraram nenhuma influência do período de lactação sobre o IDC. 
O tamanho de leitegada ao desmame poderia influenciar o IDC. A redução do número de leitões na última semana de lactação, tem sido investigada como método para reduzir o IDC. Estudou-se o ajuste do tamanho de leitegada de modo que cada grupo de porcas amamentasse 3, 8 e 13 leitões por porca, na última semana de lactação. O IDC do grupo que amamentou 3 leitões foi menor (1,1 dia) em comparação aos grupos que amamentaram 8 e 13 leitões (4,1 e 4,0 dias, respectivamente) (STEVENSON; BRITT, 1981).

\subsubsection{Estação do ano e ordem de parto}

Durante o final do verão e início do outono, a porcentagem de fêmeas que retornam ao cio dentro de 7 dias após o desmame diminui (BRITT et al., 1983), com aumento da porcentagem de fêmeas que permanecem em anestro por um período de tempo mais extenso (30 dias), aumentando desta forma o IDC (DIAL, 1984).

Os efeitos da sazonalidade no IDC são mais pronunciados em fêmeas primíparas que em pluríparas. Em estudo com 3119 partos de rebanhos em sistema confinado, demonstrou-se que o IDC foi mais longo nas fêmeas primíparas do que nas pluríparas em todos os meses, sendo ainda mais longo em todas as porcas no final do verão e início do outono do que nas outras estações e que a diferença entre primíparas e pluríparas também foi maior no verão e outono (BRITT et al., 1983).

Fêmeas primíparas evidenciam IDC mais longo que porcas de terceiro ou mais partos, sendo que, as porcas de segundo parto mostram um IDC intermediário (VESSEUR et al., 1994b; LEMAN, 1990). 


\subsubsection{Fatores ambientais}

Dada a variabilidade de fatores envolvidos, TUBBS (1990), num trabalho de revisão, acentua que quando as porcas são alojadas em gaiolas, o percentual de fêmeas que manifestam cio até sete dias é $10 \%$ mais alto em comparação às agrupadas em baias, provavelmente pelo stress advindo de brigas, consumo inadequado de ração e supressão dos sinais físicos de cio nas porcas mais tímidas.

O IDC pode ser influenciado pelo efeito do macho, pois WALTON (1986) observou que porcas alojadas em baias adjacentes às baias dos cachaços apresentaram IDC mais curto que porcas em baias distantes às dos cachaços.

Outro fator ambiental que provavelmente influencia o IDC, independentemente da estação climática, é a temperatura. No entanto, as tentativas de controlar ou manipular a temperatura têm conduzido à resultados variáveis em relação ao IDC. Porcas alojadas em instalações com controle ambiental nos meses de verão, tiveram IDC mais curto do que as alojadas em instalações sem controle de temperatura (DIAL, 1987).

As informações ligadas à influência do fotoperíodo sobre o IDC são conflitantes. Alguns pesquisadores constataram que a exposição de fêmeas em lactação a fotoperíodos artificiais não é efetiva sobre o subsequente IDC (GREENBERG; MAHONE, 1982; PERERA; HACKER, 1984). Outros sugeriram que fotoperíodos longos (16 horas de luz/dia) sincronizam o início do cio pósdesmame e uma proporção mais alta de fêmeas tratadas retornam ao cio dentro de 5 dias em comparação às porcas controle (STEVENSON et al., 1983). 


\subsubsection{Raça}

Não foram encontradas na literatura muitas informações relativas à influência da raça no IDC, possivelmente dada à variabilidade encontrada dentro das raças, tornando difícil comparações válidas. Alguns dados destacam que fêmeas mestiças parecem mostrar menor IDC do que as puras, podendo caracterizar influências da heterose para esta característica, em virtude da baixa herdabilidade expressa para características ligadas à reprodução (TUBBS, 1990).

MAURER et al.(1985), por sua vez, não observaram diferenças significativas entre raças Landrace e Large White com relação às médias IDC, no entanto, as porcas da raça Landrace entraram no cio, em média, 1.1dias antes das Large White.

VESSEUR et al. (1994b) encontraram diferenças significativas entre animais das raças Landrace Holandês, Landrace Holandês x Duroc e o cruzamento rotacional entre as duas raças com IDC médios de 9,67 dias, 7,75 dias e 6,16 dias respectivamente. No entanto, estas diferenças são bastante influenciadas pela heterose originária dos cruzamentos.

\subsubsection{Duração e reflexos na fertilidade.}

A duração média do IDC é de 4 a 5 dias, com médias variando em algumas horas como mostram os autores: WEITZE et al.(1994) $(124,4$ h), KEMP; SOEDE (1996) e NISSEN et al.(1997) (92,0 h), HECK et al. (1997) (103,48 h) e CORRÊA et al.(1997) (113,8 h para fêmeas de $1^{\circ}$ parto, 106,1 h para fêmeas de $2^{\circ}$ parto e 102,4 h para fêmeas acima $2^{\circ}$ parto). 
As porcas tornam-se mais férteis quando o intervalo desmame-cio varia entre 3 e 5 dias, pois nestas, há ocorrência de um maior número de coberturas ou inseminações devido ao período de cio mais longo. Fêmeas com intervalo desmame-cio entre 6 e 15 dias apresentam índices mais baixos de fertilidade, fruto de um período de cio mais curto, onde a oportunidade de múltiplas coberturas é menor (LEMAN, 1990; LEMAN, 1992).

VESSEUR et al.(1994a) também observaram que de acordo com o aumento do IDC, diminui o número de leitões nascidos totais, o número de leitões nascidos vivos e a taxa de parição, e concluíram que o IDC ótimo, em termos de posterior produtividade, é de 4 dias para porcas pluríparas e de 5 dias para porcas primíparas. Baseado nas observações de LEMAN (1992), VESSEUR et al.(1996) utilizaram sêmen de machos de duas linhagens fenotipicamente bastante diferentes, usados alternadamente na primeira ou segunda inseminação. Apenas duas inseminações foram utilizadas com 24 horas de intervalo. Desta maneira, poderia determinar-se qual das inseminações $\left(1^{\mathrm{a}}\right.$ ou $\left.2^{\mathrm{a}}\right)$ seria mais efetiva, pela proporção de descendentes após o parto. Os resultados mostraram que porcas com IDC de 4 dias apresentaram maior proporção de descendentes da $2^{\mathrm{a}}$ inseminação e menor proporção de descendentes da $1^{\mathrm{a}}$ inseminação em comparação às porcas com IDC de 5 dias, provavelmente em decorrência de uma menor DC e, conseqüentemente, um MO mais precoce para as fêmeas com IDC de 5 dias. 


\subsection{ESTRO}

\subsubsection{Ciclo Estral}

Na espécie suína o ciclo estral é de aproximadamente 21 dias, variando entre 17 e 25 dias e pode ser dividido em três fases distintas: diestro (fase luteínica), proestro (fase folicular) e estro (fase folicular com receptividade sexual) (DIAL; BRITT, 1986).

\subsubsection{Desenvolvimento Folicular}

Provavelmente o ovário apresente um contínuo processo de crescimento e atresia de folículos no pool proliferativo. Os folículos aptos à resposta ao recrutamento são classificados na faixa correspondente a 1 a $6 \mathrm{~mm}$ de diâmetro e este recrutamento ocorrendo por volta do $14^{\circ}$ a $16^{\circ}$ dia do ciclo estral. Não havendo recrutamento, estes folículos tornam-se atrésicos sendo substituídos por folículos menores da próxima onda de crescimento (HUNTER; WIESAC, 1990).

O pool proliferativo caracteriza-se por um conjunto de, aproximadamente, 50 folículos entre 2 a $5 \mathrm{~mm}$ de diâmetro, os quais respondem às ondas de secreção de gonadotrofinas (VAN DE WIEL et al., 1981). Na fase de estro, ao redor de 10 a 20 folículos desenvolvem-se até o tamanho pré-ovulatório (8 a 11mm), enquanto que o número de folículos pequenos diminui (ANDERSON, 1993).

Segundo KILLEN et al. (1992), o crescimento folicular em porcas inicia-se já com 6 horas após o desmame, o qual é refletido pelas rápidas alterações nas concentrações de esteróides (principalmente progesterona) no 
fluido folicular.

O início do processo de recrutamento das populações de folículos ovulatórios inicia com o declínio nas concentrações plasmáticas de progesterona, embora o sinal endócrino específico permaneça desconhecido (HUNTER et al., 1992). Provavelmente deve haver o envolvimento de níveis adequados de gonadotrofinas, ou seja, adequados níveis de FSH e aumento basal na secreção de LH na ausência de mecanismos inibitórios locais no ovário (FOXCROFT; HUNTER, 1985).

A heterogeneidade dos folículos após o recrutamento tende a diminuir, pois os folículos pequenos crescem ou entram em atresia, só restando folículos grandes no final da fase folicular (GRANT et al., 1989).

O controle da maturação folicular também está a cargo das gonadotrofinas, uma vez que a supressão das mesmas parece ser a causa primária de interrupção do crescimento folicular (BRITT et al.,1985).

Mais de $70 \%$ dos folículos grandes, por volta de 48 a 72 horas após o desmame, continuam a se desenvolver e ovulam (KILLEN et al., 1992). número de folículos maiores que $4 \mathrm{~mm}$ de diâmetro presentes nos dias 4 e 6 após o desmame excede o número de corpos lúteos que se formam após a ovulação (DYCK, 1983).

A secreção de estradiol pelo folículo em um maior estágio de dominância, dentro da população com características ovulatórias, pode promover a maturação e esteroidogênese nos folículos menos maduros, além de manter a si mesmo num "estado de espera", devido a um efeito inibitório das concentrações muito altas de estradiol intra-folicular. Como o Fator de Crescimento Semelhante 
à Insulina-1(IGF1) poderia incrementar a ação das gonadotrofinas no ovário e, desde que, a concentração de IGF-1 cresce no fluído folicular paralelamente às de estradiol, conforme o folículo aumenta de tamanho, poderia estar havendo uma função inter-folicular do IGF-1 (HUNTER; WEISAK, 1990).

\subsubsection{Perfis hormonais em relação ao estro e à ovulação. \\ Estrógeno:}

As concentrações de estrógeno no plasma periférico começam a aumentar coincidentemente com o declínio repentino dos níveis de progesterona, alcançando o pico 2 dias antes do estro, refletindo o rápido crescimento e maturação dos folículos de Graaf durante o final do próestro. Rapidamente após o próestro, ocorre o declínio dos níveis de estrógeno, os quais permanecem baixos durante a fase luteal (ANDERSON, 1993).

Segundo ROJANASTHIEN (1988), no desmame, os níveis de estradiol tanto na veia útero-ovariana como na jugular foram mais baixos que os limites de detecção da técnica. Após o desmame, os níveis de 17ß-estradiol permaneceram baixos na veia jugular até 60 a 84 horas antes do cio, sendo que na veia úteroovariana o aumento ocorreu entre 24 e 36 horas antes que na jugular. As concentrações de 17ß-estradiol começaram a declinar no início do estro e permaneceram abaixo do limite de detecção do teste.

\section{Progesterona}

No final da gestação da porca, as concentrações de progesterona declinam abruptamente para valores abaixo de $2 \mathrm{ng} / \mathrm{ml}$ por volta do dia 1 pós- 
parto. Esta queda é devido à lise do corpo lúteo (luteólise), causada pela elevação dos níveis de prostaglandina F2 $\alpha(\mathrm{PgF} 2 \alpha)$, secretada pelo útero gestante (FIRST; BAZER, 1982). Durante o período de lactação os níveis de progesterona continuam baixos, ao nível de 2ng/ml (STEVENSON; BRITT, 1980; STEVENSON et al.,1981).

Os níveis de progesterona são baixos no estro (dia 0) e começam a subir abruptamente após o dia 2, alcançando o pico entre os dias 8 e 12, sendo que uma queda repentina ocorre por volta do dia 18 do ciclo estral (ANDERSON, 1993).

As concentrações séricas basais (pré-ovulatórias) de progesterona são muito variáveis. Segundo SOEDE et al. (1994a), de 16 porcas acompanhadas, 2 tiveram concentrações bastante altas em relação à fase $(1,47 \pm 0.36$ e $2,02 \pm 0,44 \mathrm{ng} / \mathrm{ml})$, em uma delas a concentração foi de $0,32 \pm 0,18 \mathrm{ng} / \mathrm{ml}$, sendo que nas 13 restantes, a concentração foi menor que 0,1ng/ml. As concentrações aumentaram de $1 \mathrm{ng} / \mathrm{ml}$ acima dos níveis basais $13 \pm 4$ horas em média após a ovulação, variando entre 6 e 19 horas. Nas duas porcas que apresentaram progesterona aumentada antes da ovulação, o tempo entre a ovulação e o aumento da progesterona (1ng/ml acima dos níveis basais) foi similar aos outros animais.

\section{LH}

Os níveis plasmáticos periféricos de LH mostram um rápido pico no estro e declinam rapidamente, permanecendo baixos durante o restante do ciclo estral (ANDERSON, 1993). Este pico rápido é altamente variável em relação à 
concentração máxima atingida (2,49-11,18ng/ml), à duração (22-40h) e ao perfil (o pico ocorreu após 28-56\% do período liberação) (SOEDE et al., 1994).

\section{FSH}

As concentrações séricas de FSH alcançam níveis de pico dentro de 2 a 3 dias após início dos sintomas de estro, consequentemente, não devendo ter relação com os folículos que vão ovular (ANDERSON, 1993).

\subsubsection{Duração do estro}

Normalmente a duração do estro é de 54 horas, variando entre 24 a 72 horas (ANDERSON, 1982; SOEDE, 1994; SOEDE, 1995a), podendo em alguns casos chegar a 96 horas (WEITZE, 1994). O período de cio puberal normalmente é mais curto, 47 horas, do que em porcas adultas, 56 horas. A duração pode ser afetada também pela raça, estação climática, ocorrendo ainda anormalidades endócrinas (ANDERSON, 1982). CORRÊA et al. (1997) observaram que fêmeas de primeiro e segundo parto apresentam uma DC significativamente menor em comparação às fêmeas com mais de dois partos.

WENTZ et al. (1997) analisaram a influência da raça (Camborough ${ }^{\circledR} 15$ e Camborough ${ }^{\circledR} 22$, linhagens maternas da empresa de genética PIC) sobre a DC e MO não observando diferenças significativas.

Existe uma relação inversa entre o IDC e a duração do cio (ROJKITTIKHUN et al., 1992; WEITZE et al., 1994; KEMP; SOEDE, 1996; NISSEN et al., 1997; CORRÊA et al., 1997), e consequente diminuição no intervalo entre o início do estro e ovulação conforme aumenta o IDC. Porcas que 
entram no cio com até 4 dias de intervalo desmame-cio, normalmente apresentam período de cio, em média, 20 horas mais longo que porcas que entram no cio com um intervalo de 4 a 5 dias após o desmame (WEITZE et al., 1994). Segundo

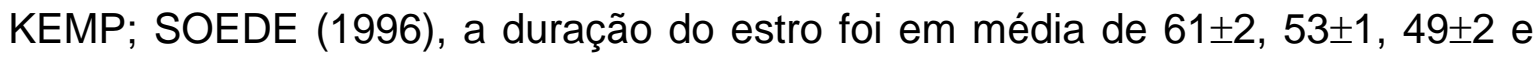
$38 \pm 6$ horas para os IDC de 3, 4, 5 e 6 dias, respectivamente, e o intervalo entre o início do cio e a ovulação foi de $41 \pm 1,37 \pm 1,34 \pm 1$ e $27 \pm 4$ horas para os dias 3,4 , 5 e 6 após o desmame, respectivamente. CORRÊA et al.(1997) verificaram que a redução na duração do IDC está associada com um aumento linear na duração do cio $\left(R^{2}=0,50, P<0,0001\right)$. HECK et al.(1997) encontraram uma alta correlação positiva entre a $\mathrm{DC}$ e o $\mathrm{MO}\left(\mathrm{R}^{2}=0,68, \mathrm{P}=0,0001\right)$, no entanto, nenhuma correlação foi observada entre IDC e DC.

O contato com o macho pode influenciar a duração do estro. Segundo DYCK (1988), em porcas alojadas em baias adjacentes às do macho, separadas por grade ou parede, a duração média do estro foi de 1,6 dias, enquanto que em porcas alojadas longe do macho, a duração média do estro foi de 2,4 dias.

WEITZE et al.(1994) constataram em porcas de 2 a 4 partos duração de cio significativamente mais longa do que porcas com ordem de parto acima de 4. No entanto, estas diferenças só foram verificadas nos meses de verão e não na primavera.

\subsubsection{Sintomas de Cio}

Alterações externas assim como edema, hiperemia e secreção vulvar podem ser observadas dentro de 2 a 8 dias antes da receptividade ao 
cachaço (ANDERSON, 1982). As primeiras alterações comportamentais observadas são o aumento da atividade motora, inquietação, salivação e anorexia, seguidas por tentativas de monta sobre outras fêmeas (ANDERSON, 1993).

A porca em cio permanece firmemente imóvel sobre os membros (posição de cavalete), com a cabeça baixa, orelhas retas, permitindo a monta pelo macho, sendo difícil movê-la desta posição (SIGNORET, 1970; ALEXANDER et al., 1982).

\subsubsection{Diagnóstico de cio (estro)}

O método de eleição para a detecção de cio, junto com utilização do macho, é o teste de tolerância à monta (Back-pressure test). No entanto, sua eficiência está ligada à presença (contato) do macho, pois segundo SIGNORET, (1970), num estudo envolvendo a influência dos estímulos para a manifestação de cio, a porcentagem de marrãs que responderam ao teste na ausência do cachaço foi de 59\% entre 24 a 36 horas após início do cio, aumentando para 90\% em marrãs submetidas aos estímulos auditivo e olfatório, e para 100\% em marrãs com a adição dos estímulos visual e táctil.

O início do cio via de regra ocorre durante o período noturno. Conforme as verificações de ZIMMERMAN; NABER (1971) que diagnosticaram o início do cio em 50\% das fêmeas no horário das 23:00 horas. SMIRNOV; TERESHCHENKO (1980) diagnosticaram o início do cio em 68\% das porcas entre a tarde e a noite. Quando o diagnóstico do cio foi realizado nos horários das 6:00, 12:00 e 18:00 horas, os respectivos percentuais de porcas manifestando reflexo 
de tolerância à monta pelo macho foram de 60\%, 32\% e 8\% (NOGUEIRA, 1982). Estes mesmos horários de observação foram adotados por REIS et al.(1997) com uma distribuição de porcas iniciando o cio de 69,09\%, 14,55\% e 16,36\%, respectivamente.

MUNARI (1985) estudou os horários de início de cio com observações a cada quatro horas. Os horários de observação foram 4:00, 8:00, $12: 00,16: 00,20: 00$ e 24:00 com as respectivas percentagens de porcas iniciando o cio de $10,9 \%, 26,5 \%, 10,3 \%, 10,3 \%, 32,7 \%$ e $9,3 \%$.

\subsection{OVULAÇÃO}

\subsubsection{Mecanismo da ovulação}

Após o pico pré-ovulatório de LH, há a ocorrência de alterações funcionais e estruturais na parede folicular que conduzem à ovulação. Simultaneamente ocorre luteinização das células da granulosa e modificações na parede folicular, resultando no rompimento do folículo com a liberação do oócito maduro e apto à fecundação (LIPNER, 1988). Rapidamente após a ovulação verifica-se a proliferação das células da granulosa e, em menor intensidade, das células da teca revestindo a parede folicular. O corpo lúteo, por sua vez, vai se formando a partir da luteinização destas células (ANDERSON, 1993).

Considerando a seqüência cronobiológica da fase luteínica, inicialmente o corpo lúteo $(C L)$ é classificado como corpo hemorrágico devido ao preenchimento hemorrágico da cavidade central e, dentro de 6 a 8 dias, torna-se uma massa sólida de células luteais com diâmetro variando entre 8 e 11mm, a qual manteria a integridade celular e a atividade secretória até o $16^{\circ}$ dia do ciclo 
estral, quando sofreria uma rápida regressão para corpo albicans (ANDERSON, 1993).

\subsubsection{Momento da ovulação}

Nas espécies suína e eqüina, onde o cio é mais longo, a ovulação sempre ocorre no início de seu terço final (ANDERSON, 1982).

Até recentemente, não era possível diagnosticar o momento da ovulação com precisão, pois os métodos utilizados baseavam-se em níveis hormonais (HELMOND et al.,1986) ou indução da ovulação com hormônios exógenos (DZIUK, 1970). Atualmente, há maior acuracidade no processo de diagnóstico com a utilização da ultra-sonografia, a qual não provoca stress no animal. Alguns autores precisaram o momento da ovulação ocorrendo a um determinado percentual da duração do cio obtendo os seguintes valores: $72 \pm 8 \%$, com variação entre 54\% e $86 \%$, no experimento de SOEDE et al. (1994); $72 \pm 15 \%$, com variação entre $39 \%$ e $133 \%$, no experimento de SOEDE et al. (1995a) e 71,14\% no experimento de NISSEN et al. (1997). Estes resultados confirmam que, independentemente do período de duração do cio, a ovulação ocorre sempre em um momento relativamente constante, ou seja, no início do terço final do cio.

Foi verificada correlação significativa entre a duração do cio e o momento da ovulação, ou seja, porcas com maior período de cio ovulam mais tardiamente que porcas com um período de cio mais curto (HECK et al., 1997). WEITZE et al. (1994) observaram que porcas com um IDC de menos de 93 horas apresentaram um intervalo início do estro-ovulação de 53 horas e porcas com um 
IDC de 107 a 120 horas apresentaram um intervalo de 39 horas.

O diagnóstico preciso do momento da ovulação tem sido importante para determinar o melhor momento para a realização da IA. Quando a inseminação é realizada de 0 a 24 horas antes (SOEDE et al., 1995a; WABERSKI et al., 1994a) ou entre 28 horas antes e 4 horas após a ovulação (NISSEN et al., 1997), a porcentagem de embriões recuperados normais é significantemente mais alta que a realizada antes ou depois destes períodos. Inseminações feitas após a ovulação resultam em baixas taxas de fecundação, provavelmente devido ao limitado tempo de viabilidade dos oócitos, relativo ao período necessário para a capacitação dos espermatozóides e chegada ao local de fecundação (HUNTER, 1994). Em intervalos maiores que 24 horas entre inseminação e ovulação, provavelmente poucos espermatozóides férteis estarão presentes no local da fecundação, característica esta indicada pelo baixo número de espermatozóides acessórios nos embriões (SOEDE et al., 1995a).

O início das alterações degenerativas nos oócitos, ocorre aproximadamente de 8 a 12 horas pós-ovulação, aumentando assim o número de espermatozóides acessórios e a possibilidade de ocorrência de fecundação poliespermática (HUNTER, 1967). A ocorrência deste fenômeno provavelmente é devida ao fato de que, após a ovulação, a regulação do número de espermatozóides que passam do útero para o local de fecundação é menos efetiva (HUNTER, 1977).

O tempo de estocagem do sêmen também pode influenciar a taxa de fecundação, pois em inseminações utilizando sêmen estocado por até 2 dias após a colheita, os níveis de fertilidade não reduziram, com até 24 horas de intervalo 
entre a inseminação e a ovulação. Quando estocou-se o sêmen por um período de 48 a 87 horas, a taxa de fecundação diminuiu mesmo quando a ovulação ocorreu entre 12 a 24 horas após a inseminação. A queda da taxa de fecundação era ainda mais acentuada quando o sêmen foi estocado por um período maior que 87 horas (WABERSKI et al., 1994b).

Baseado nas relações entre IDC, duração do cio e momento da ovulação, WEITZE et al. (1994) tem recomendado que nas porcas que entram no cio de 3 a 4 dias pós-desmame, evidenciando o cio durante 3 dias, as inseminações devem iniciar-se no segundo ou terceiro dia do cio. Nas porcas com intervalo desmame-cio de 5 dias, mostrando cio durante 2 dias, a inseminação deve realizar-se 24 horas após o início do cio e ser repetida 12 horas mais tarde. Por outro lado, as que entram no cio com 6 ou mais dias após o desmame, tendem a apresentar o cio por apenas 1 dia, devendo ser inseminadas dentro de 24 horas após a detecção do cio, não sendo normalmente necessária uma segunda inseminação.

Em um experimento onde todas as fêmeas eram inseminadas e parte delas eram novamente inseminadas logo após a ovulação, com diagnóstico por ultra-sonografia, evidenciou-se significância na diferença em porcentagem de embriões normais quando realizou-se a primeira inseminação entre 24 e 72 horas antes da ovulação, com diferença de apenas $63 \pm 40 \%$ com uma IA para $97 \pm 5 \%$ com duas IA (SOEDE et al., 1995b). Quando a avaliação dos embriões foi efetuada 28 dias após a inseminação, os resultados demonstraram que a inseminação pós-ovulatória, mesmo com o intervalo de 0 a 4 horas, conduz ao aumento das taxas de perda embrionária durante o início da prenhez, quando 
comparados com fêmeas inseminadas no período pré-ovulatório (WABERSKI et al., 1994a).

\subsubsection{Exame ultra-sonográfico do ovário}

Semelhantemente à medicina humana, a ultra-sonografia em medicina veterinária foi primeiramente utilizada como meio diagnóstico das alterações fisiológicas e patológicas dos órgãos da reprodução. O primeiro registro de investigação clínica sonográfica em medicina veterinária ocorreu em 1966, quando Ivan L. Lindahl diagnosticou prenhez em ovelhas (RODRIGUES; RODRIGUES, 1995).

A ultra-sonografia, sonografia ou ecografia é um método de exploração biológica, que utiliza a reflexão de ultra-som de alta freqüência através dos órgãos do paciente (GINTHER, 1986; RODRIGUES; RODRIGUES, 1995). É um procedimento indolor, não invasivo e biologicamente seguro para o operador e para o animal (PIERSON et al., 1988).

A emissão das ondas ultra-sonoras ou ecos ocorre várias vezes por segundo e as imagens modificam-se com os movimentos dos tecidos ou do transdutor, o que possibilita a observação e a análise de funções vitais, como por exemplo o funcionamento cardíaco fetal (TORBECK, 1986) e, como a observação é imediata, reflete o momento do funcionamento orgânico, utilizando-se o termo "tempo real" (real time).

Quatro são as técnicas ultra-sonográficas utilizadas em medicina veterinária e humana: 1-Modo A (Mode A), que apresenta a amplitude e a profundidade das ondas sonográficas propagadas nos tecidos em forma de 
gráfico unidimensional, sendo muito utilizada para a medida de espessura de toucinho em suínos; 2-Modo B (Mode B), com imagem em tempo real, que consiste em um conjunto de ecos ultra-sonográficos dispostos em um plano lado a lado, produzindo uma imagem bidimensional; 3-Modo M (Mode M), uma adaptação do Modo B, utilizada para avaliar os batimentos cardíacos que são representados no monitor em forma unidimensional contínua; 4-Doppler colorido, que permite estudar a dinâmica normal e patológica da circulação sangüínea em coração e vasos, através da determinação da velocidade do sangue. A imagem varia entre as cores vermelha e amarela, a vermelha representando baixa velocidade e a amarela alta velocidade da corrente sangüínea (GINTHER, 1986; MOURA; MERKT, 1994).

Os cristais embutidos nos transdutores são capazes de modificar a energia elétrica em física, convertida em onda ultra-sonora que se propaga através dos tecidos do corpo do animal (RANTANEN, 1986). Os transdutores atuam ao mesmo tempo como transmissores e receptores dos impulsos registrados como pontos luminosos acinzentados de diferentes intensidades no monitor ultra-sonográfico (PIERSON et al.,1988).

Os principais transdutores utilizados atualmente são o linear, o setorial e o setorial convexo (mecânico ou eletrônico) (TORBECK, 1986; RANTANEN, 1986; POWIS, 1986). No setorial (Mechanical or Eletronic Sector Scanner) um a quatro cristais característicos para a freqüência são montados em uma haste, sendo mecânica ou eletronicamente rotacionados. Os cristais giram em círculo ao redor de um eixo do transdutor, transmitindo e recebendo sinais em ângulo de aproximadamente 40 a 50 graus. No transdutor linear (Linear Array), 
vários cristais são montados lado a lado de forma linear por toda a extensão da sonda (probe). Os cristais em forma linear pulsam eletronicamente em uma seqüência que permite a observação da motilidade do órgão explorado. O setorial convexo é semelhante ao linear, entretanto, a disposição dos cristais em forma convexa oferece imagem de maior ângulo (GINTHER, 1986).

A transmissão do sinal ultra-sônico e a recepção das ondas energéticas refletidas são possibilitadas pelas propriedades piezoelétricas (piezo deriva do grego e significa pressão) dos cristais do transdutor (GINTHER, 1986; PIERSON et al., 1988). O cristal mais utilizado é o de quartzo, pois é o que apresenta melhor propriedade piezoelétrica. Esta propriedade é explicada pela influência recíproca dos fenômenos de pressão e corrente elétrica, ou seja, diferença de potencial alternada entre duas faces paralelas e opostas do cristal de quartzo, gerando uma série de contrações e expansões destas faces e esse movimento emite um som. A compressão de uma série de cristais de quartzo entre placas de metal, promove a vibração das mesmas, com a produção de ultrasons, cujas freqüências estão acima de mil ciclos por segundo. Os ultra-sons utilizados em medicina veterinária e humana apresentam freqüência que varia entre 1 e $10 \mathrm{MHz}$ (1MHz = 1.000.000 ciclos por segundo) (SQUIRES, 1988).

As freqüências mais altas apresentam maior resolução e menor penetração tecidual, enquanto que as mais baixas apresentam menor resolução e maior penetração (PIERSON et al.,1988).

As técnicas de ultra-som tem sido utilizadas em suínos desde a década de 70. As primeiras técnicas utilizadas foram o Doppler (FRASER et al., 1971) e Modo A (LINDAHL et al., 1975), para diagnóstico precoce da gestação. 
Mais recentemente, as técnicas de ultra-som por imagem (ultra-sonografia), começaram a ser utilizadas, inicialmente para diagnóstico de gestação (INABA et al., 1983), e posteriormente, no exame dos ovários para o diagnóstico de ovulação (WEITZE et al., 1989).

O exame ultra-sonográfico dos ovários pode ser realizado por várias vias, sendo que as utilizadas em suínos são a trans-cutânea e trans-retal (SOEDE; KEMP, 1993b). Na técnica trans-cutânea, os ovários se localizam na posição dorso-cranial em relação ao joelho (articulação femuro-tíbio-patelar), alguns centímetros abaixo do íleo. O transdutor é colocado logo acima do úbere e direcionado para cima. Na imagem, os ovários aparecem cranialmente ao lado da bexiga, a qual serve de referência para a sua localização. Na técnica trans-retal, o transdutor é guiado pela mão do operador. Os ovários são visualizados 30 a $40 \mathrm{~cm}$ cranialmente ao ânus e ventralmente em relação ao reto. O exame é realizado com a mão protegida por luva lubrificada e o reto deve ser limpo antes da introdução do transdutor, servindo também a bexiga como um ponto de referência (SOEDE et al., 1994b).

A técnica trans-retal é considerada como método de escolha pois a técnica trans-cutânea requer muita prática, com resultados satisfatórios esperados a partir de 2000 exames, enquanto que na técnica trans-retal obtém-se acurácia a partir de 50 a 100 exames (NISSEN et al., 1995).

Segundo SOEDE; KEMP (1993b) a técnica trans-cutânea apresenta como principais desvantagens a posição anatômica do intestino (colo) que freqüentemente bloqueia a visualização do ovário, principalmente do lado esquerdo e a imagem é geralmente confusa e instável devido a movimentação do 
animal, o que torna muito difícil a contagem das estruturas, enquanto a técnica trans-retal parece ser a única técnica em que os ovários podem ser completamente visualizados pois a imagem é muito clara e estável. No entanto, quase todas as marrãs e algumas porcas tem a pelve muito estreita para o uso desta técnica. Neste caso, o uso de um suporte extensor é necessário para possibilitar o exame (KÄHN, 1994), o que é contestado por SOEDE; KEMP (1993b), pois a manipulação ideal do aparelho seria prejudicada. No momento do exame, deve-se tentar evitar que a porca se movimente excessivamente, para isso é importante que esta seja colocada em uma gaiola.

Os folículos caracterizam-se como estruturas que apresentam aparência não ecogênica, devido ao seu preenchimento fluido. Normalmente são numerosos e visíveis a partir do próestro com diâmetro variando entre 5 e $11 \mathrm{~mm}$. Os folículos, no entanto, podem ser confundidos com corpos lúteos hemorrágicos e grandes vasos sangüíneos nas regiões adjacentes aos ovários. Por outro lado as secções transversais dos vasos sangüíneos devem ser diferenciadas sonograficamente de folículos (KÄHN, 1994).

NISSEN et al. (1995) acompanhando o desenvolvimento folicular e ovulação através da ultra-sonografia, detectaram folículos nos exames inicias (início do cio), medindo aproximadamente 4 a 6mm de diâmetro e alcançando um tamanho máximo de 7 a 10mm, no qual permaneciam por aproximadamente 24 horas até a ovulação.

Logo após a ovulação há um reduzido conteúdo de líquido (sangue) que indica a presença de corpos hemorrágicos, os quais não são tão tensos quanto folículos pré-ovulatórios e, consequentemente não são tão claramente 
definidos (WEITZE et al., 1989).

A técnica de ultra-sonografia para examinar os ovários em fêmeas suínas tem sido utilizada para diagnosticar eficientemente o momento da ovulação (SOEDE et al., 1994a; SOEDE et al., 1995a; SOEDE et al., 1995b; WABERSKI et al., 1994a; WABERSKI et al., 1994b; WEITZE et al., 1989; WEITZE et al., 1990; WEITZE et al., 1994), o tempo de duração da ovulação(SOEDE; KEMP, 1993a; SOEDE et al., 1992) e degenerações císticas (KÄHN, 1994).

O exame ultra-sonográfico dos ovários é possível tanto por via transretal como trans-cutânea. Normalmente, folículos, corpos lúteos e cistos ovarianos podem ser diagnosticados, embora a exata identificação e contagem das estruturas exija prática (KÄHN, 1994). 
MATERIAL E MÉTODOS 


\subsection{Local}

O trabalho realizado numa unidade de produção de suínos, no oeste de Santa Catarina, dividiu-se em 2 períodos correspondentes à primavera e outono, nos meses de novembro e dezembro de 1996 e março e abril de 1997, respectivamente. As condições térmicas foram semelhantes para os 2 períodos, com temperatura mínima média do primeiro período de $17,18^{\circ} \mathrm{C}\left( \pm 2,2^{\circ} \mathrm{C}\right)$ e do segundo de $17,68^{\circ} \mathrm{C}\left( \pm 1,7^{\circ} \mathrm{C}\right)$ e máxima do primeiro período de $25,22^{\circ} \mathrm{C}\left( \pm 3,0^{\circ} \mathrm{C}\right)$ e do segundo de $25,75^{\circ} \mathrm{C}\left( \pm 1,8^{\circ} \mathrm{C}\right)$. As fêmeas confinadas em gaiolas individuais durante as fases de lactação, pré-cobertura e até os primeiros 35 dias de gestação, eram transferidas posteriormente em baias coletivas caracterizando um sistema de produção intensivo.

\subsection{Animais}

Foram utilizadas duzentas e trinta e seis (236) fêmeas das raças Landrace, Large White 1 (linhagem com aptidão materna) e Large White 2 (linhagem com aptidão materna voltada para características aprimoradas de carcaça). A ordem de parto variou entre $1^{\circ}$ e $10^{\circ}$ partos, sendo as porcas alojadas, durante a lactação, no setor de maternidade onde receberam ração de lactação e água ad libitum. No período entre o desmame e o início de cio, a ração de lactação era oferecida em duas refeições diárias, num total aproximado de 4kg e a água fornecida ad libitum. Após o desmame as fêmeas eram levadas para as instalações de gestação, sendo confinadas em gaiolas individuais. A condição corporal das fêmeas foi medida ao desmame, classificando-as segundo ROPPA (1991), de 1 a 9. Apenas fêmeas acima da classificação 3, fizeram parte do 
experimento, a fim de evitar influências nutricionais.

\subsection{Determinação do intervalo desmame-cio (IDC).}

O desmame realizado semanalmente, às quintas-feiras e aos sábados, originava dois diferentes grupos. Nas quintas, considerou-se 3, 4, 5, 6 e 7 dias de IDC como domingo, segunda, terça, quarta e quinta, respectivamente. No desmame de sábado, considerou-se os mesmos dias de IDC, ficando respectivamente para a terça, quarta, quinta, sexta e sábado. Para o cálculo do IDC, em horas, o início da mensuração era no momento do desmame, às 07:00 horas da quinta-feira ou do sábado e o final, no momento em que a porca mostrava o reflexo de tolerância positivo na presença do macho.

\subsection{Detecção do cio}

Esta observação foi realizada a partir do terceiro dia após o desmame, considerando intervalos de 6 horas, nos horários de 01:00, 07:00, 13:00 e 19:00 horas. A ocorrência de cio foi definida pelo teste de tolerância positivo na presença do macho, com ou sem apresentação prévia de edema e hiperemia da vulva ou comportamento característico de pré-cio. O macho era conduzido através do corredor entre as fileiras de gaiolas, de modo que permanecesse exatamente em frente à fêmea que estivesse em teste para o reflexo de tolerância (FIG. 1). Para um diagnóstico mais preciso, caso houvesse alguma dúvida com relação ao reflexo de tolerância, a fêmea era levada até a baia do macho. Três cachaços, com idade variando entre 1 e 2 anos, eram utilizados alternadamente para auxiliar na detecção de cio. O início do cio 
definiu-se como o ponto médio de tempo entre a última observação, com teste de tolerância negativo e a primeira, quando o mesmo mostrava-se positivo na presença do macho. Determinou-se como parâmetro o início como teste positivo diminuído de 3 horas. Para a fixação do final de cio, definiu-se o ponto médio de tempo entre a última observação do reflexo de tolerância positivo e a primeira do teste negativo. Também como parâmetro determinou-se o final como igual ao teste negativo diminuído de 3 horas. Foram utilizadas apenas as porcas que entraram em cio entre 3 e 7 dias após o desmame, sendo eliminadas as que já apresentavam reflexo de tolerância positivo na primeira observação do terceiro dia. 


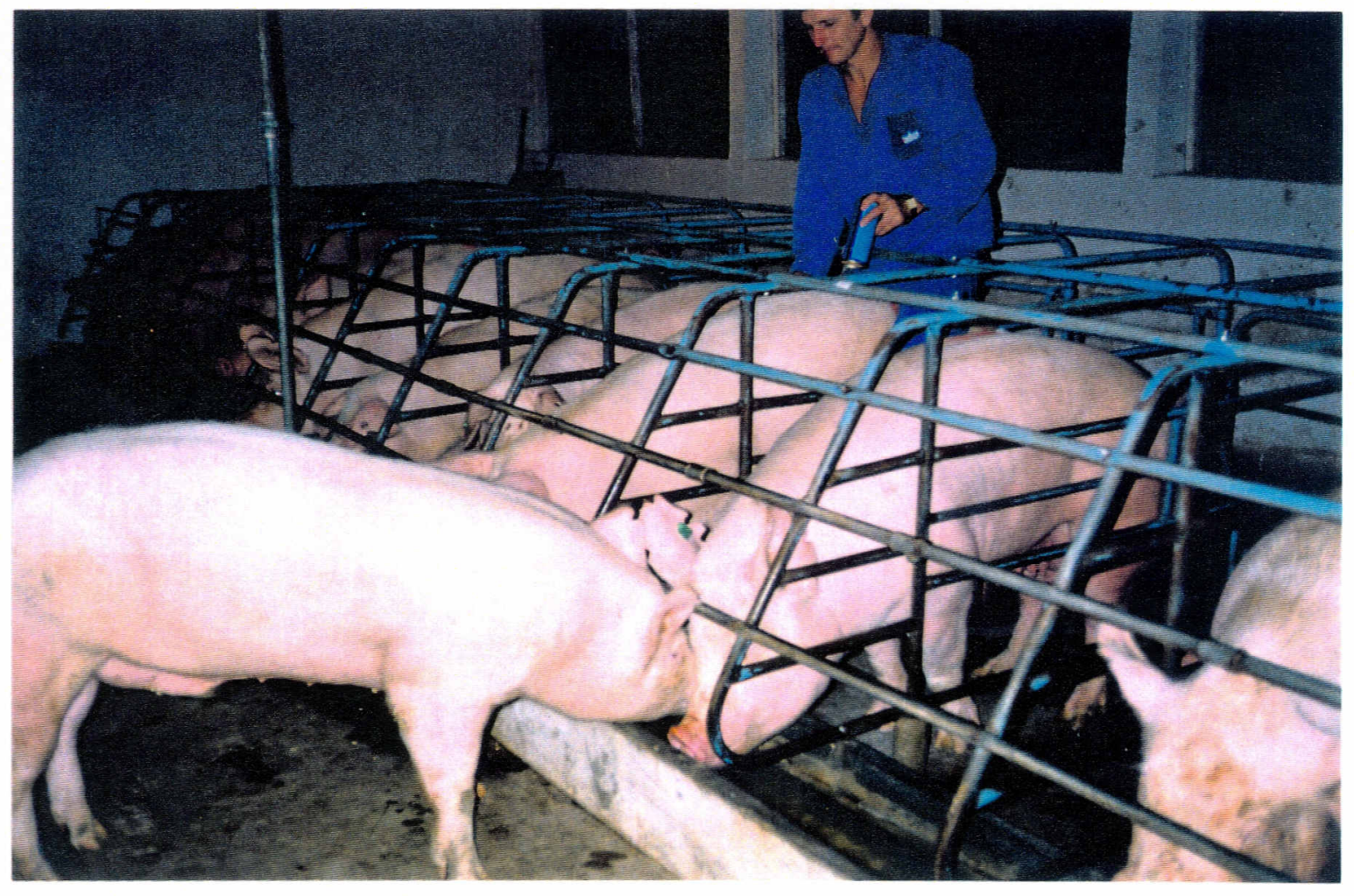

FIGURA 1 - Diagnóstico de cio na presença do macho para a observação do reflexo de tolerância positivo. 


\subsection{Detecção da ovulação}

\subsubsection{Ultra-sonografia}

Através da técnica da ultra-sonografia, 77 das 236 fêmeas foram examinadas por via trans-cutânea, utilizando o aparelho Concept - Dynamic Imaging, com transdutor setorial, na freqüência de $5 \mathrm{MHz}$. Os intervalos entre os exames foram de 7, 7 e 10 horas respectivamente, às 08:30, 15:30 e 22:30 horas. As porcas destinadas à ultra-sonografia foram colocadas em uma fileira de gaiolas e agrupadas de forma a separá-las por uma gaiola vazia (FIG. 2). Esta serviu como espaço necessário para que o operador tivesse acesso ao local de exame nos dois lados do animal. Os animais foram examinados em estação e, caso estivessem muito inquietos, era prontamente oferecido um pouco de ração para evitar movimentos evasivos. No momento do exame a superfície de contato do transdutor era coberta com gel (Carboximetilcelulose), para garantir a propagação do som, e este era posicionado nos flancos direito e esquerdo, aproximadamente no ponto médio entre a articulação femuro-tíbio-patelar e a última costela, $10 \mathrm{~cm}$ acima do úbere (FIG. 3). Considerou-se como pontos de referência para a localização dos ovários, a bexiga, na posição caudal, e as alças intestinais, na posição cranial. Definiu-se o momento da ovulação (MO) como sendo o período de tempo médio entre os exames quando da ocorrência da ovulação. O diagnóstico da ovulação foi determinado quando, ao exame ultrasonográfico, nenhum folículo era encontrado ou quando o número de folículos fosse menor que no exame anterior. 


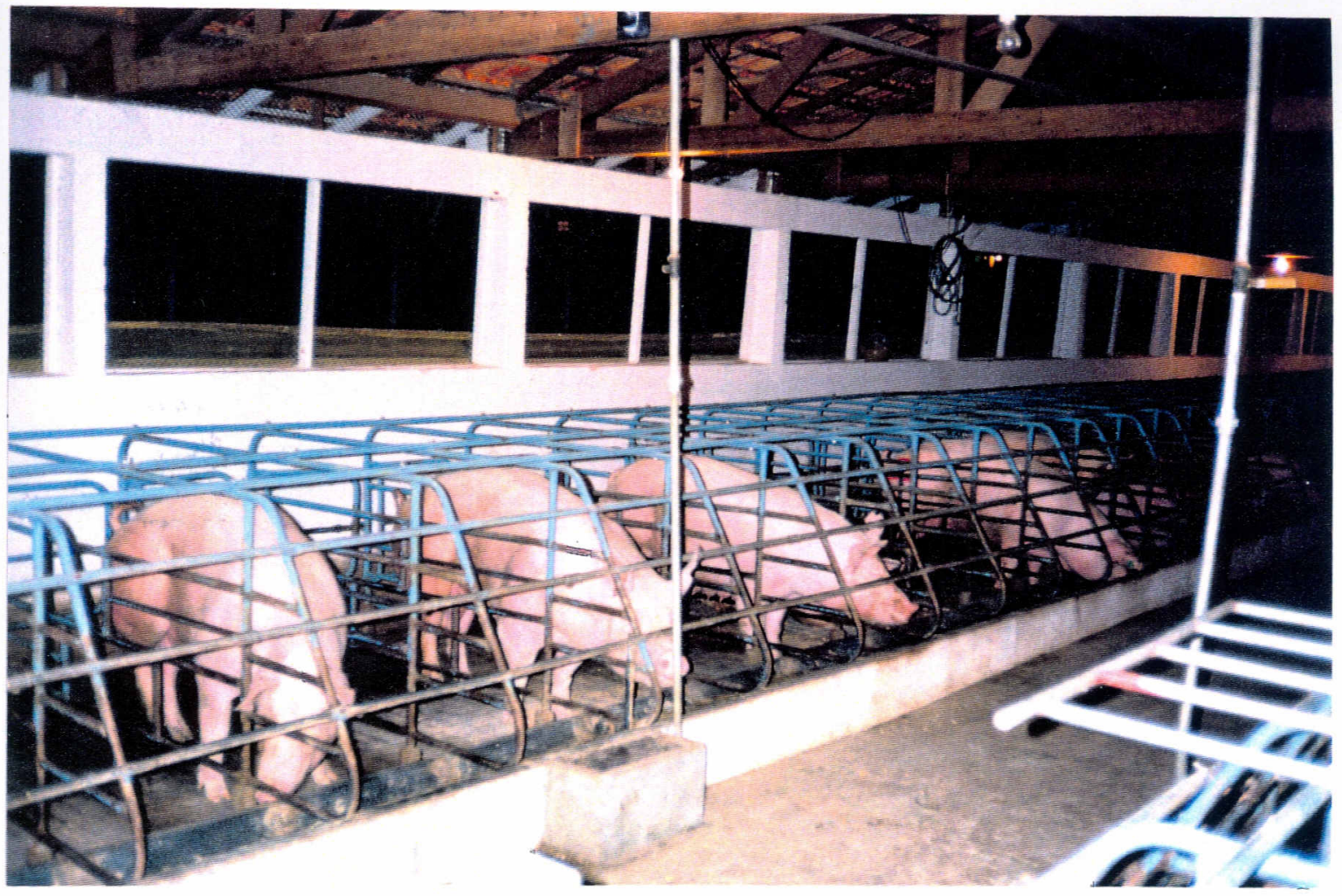

FIGURA 2 - Disposição das fêmeas nas gaiolas para possibilitar o exame ultrasonográfico dos ovários. As fêmeas são alojadas em gaiolas intercaladas. 

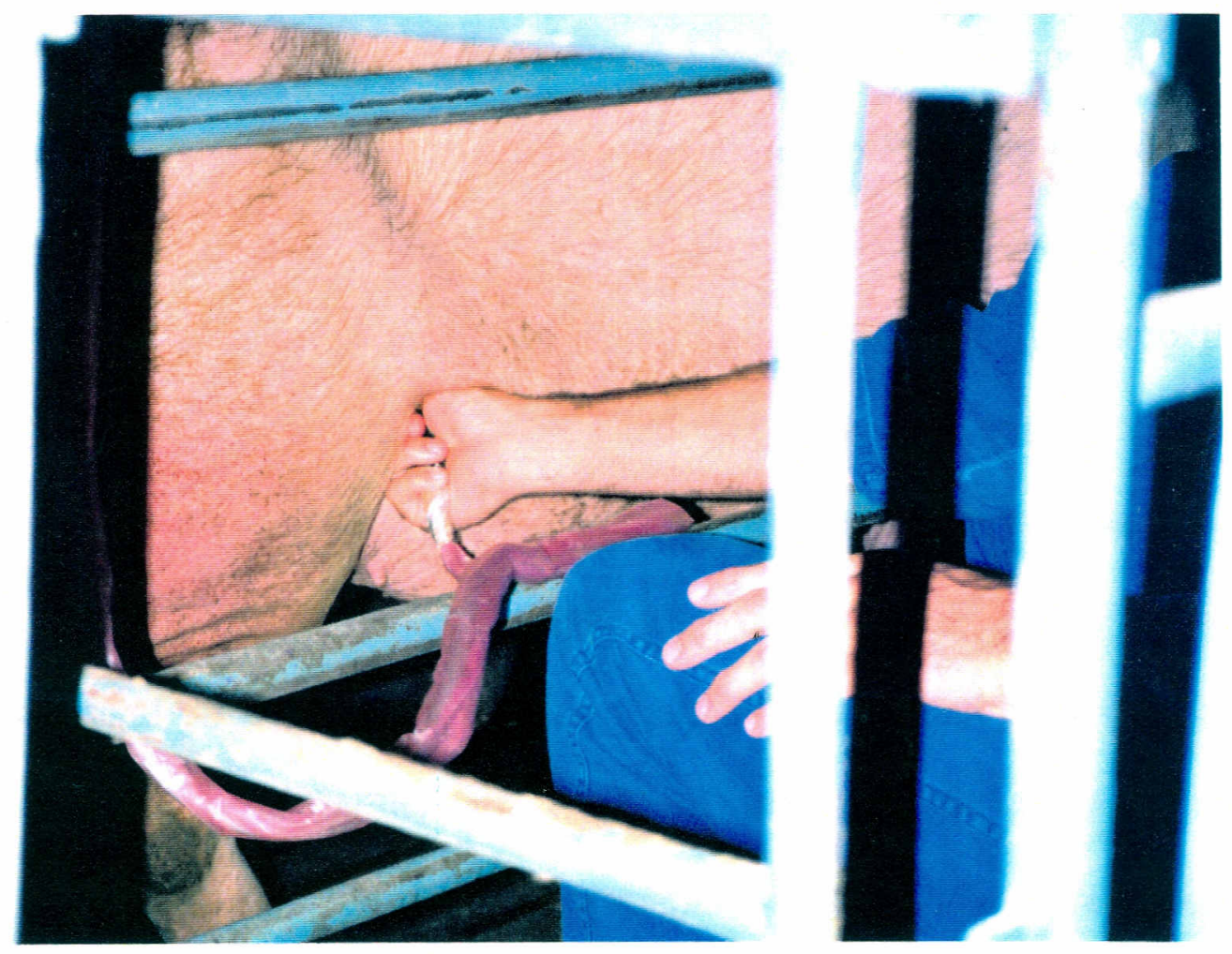

FIGURA 3 - Posição do transdutor em relação ao flanco da fêmea para a realização da ultra-sonografia. 


\subsubsection{Dosagem sérica de progesterona}

Além da ultra-sonografia foi utilizada dosagem sérica de progesterona através da técnica de radioimunoensaio (RIE). Das 236 porcas, 74 foram submetidas à coleta de sangue. As amostras de sangue eram coletadas nas seguintes ocasiões: dois dias após o desmame, para a determinação dos níveis basais e, no $2^{\circ}, 3^{\circ}$ e $4^{\circ}$ dias após o início do cio. A colheita de sangue foi realizada através da punção da veia jugular, com agulha 40/12. 10ml de sangue eram armazenados em tubos de ensaio contendo $0.1 \mathrm{ml}$ de solução de $\operatorname{EDTA}(0.18 \mathrm{~g} / \mathrm{ml})$. Após a colheita centrifugou-se e congelou-se o sangue a $-20^{\circ} \mathrm{C}$ até a ocasião do teste. Os kits foram obtidos da Diagnostic Products Corporation (DPC - Los Angeles), os quais utilizam o método de quantificação em fase sólida com os padrões de progesterona diluídos em plasma humano, validado por GEISERT et al.(1995). Baseou-se a precisão do teste nos coeficientes de variação intra e inter ensaio e a sensibilidade foi de $0.02 \mathrm{ng} / \mathrm{ml}$, apresentando reação cruzada com $5 \alpha$-Pregnan-3,20-dione ao nível de 9,0\% e $5 \beta$ - Pregnan3,20-dione ao nível de 3,2\%. Para a determinação da contagem total (T) e de ligações não específicas (NSB) em duplicata utilizaram-se 4 tubos não revestidos. $\mathrm{Na}$ determinação da curva empregaram-se 14 tubos com receptores de progesterona aderidos, com calibradores denominados de A a G em duplicata, conforme TAB.1. 
TABELA 1 - Concentração de progesterona dos calibradores.

Calibradores

A (máximo de ligação)

B

C

D

E

F

G $\mathrm{ng} / \mathrm{ml}$

0

0,1

0,5

2

10

20

40

Pipetou-se $100 \mu$ l de calibrador A dentro dos tubos NSB e A, $100 \mu l$ de cada calibrador de B a G nos tubos correspondentes e $100 \mu l$ para as amostras de soro e controles. Adicionou-se a estes tubos 1,0ml de solução de progesterona marcada com $\mathrm{I}^{125}$. Em seguida, o material foi incubado por três horas, decantado e levado para a contagem no contador gama por 1 minuto para cada tubo. Para o controle de qualidade, realizado no início, meio e fim do teste, em duplicata, utilizou-se controles alto (calibrador C) e baixo (calibrador F). Os coeficientes de variação intra e inter-ensaio foram 7,02\% e 7,95\%, respectivamente.

Padronizou-se o momento da ovulação, através da análise de progesterona (MOP), correspondendo a 12 horas antes do aumento maior que 1ng/ml de progesterona, em relação aos níveis basais (SOEDE et al., 1994a).

Com os dados obtidos a partir da ultra-sonografia e da análise de progesterona, duas comparações foram realizadas, uma entre MO e MOP e outra dividindo o período de cio em intervalos de 0 a 24, 24 a 48, 48 a 72 e 72 a 96 
horas, classificando assim os animais, de acordo com a ovulação pela progesterona e ultra-sonografia, dentro destes intervalos.

\subsection{Análise Estatística}

As análises de Variância processadas pelo método dos quadrados mínimos em modelos lineares (Proc GLM do SAS*), incluiu as variáveis dependentes - IDC, duração do cio (DC) e momento da ovulação (MO), e as independentes - ordem de parto, estação do ano e raça, segundo o modelo matemático específico. Foram consideradas como covariáveis as características: número de leitões desmamados, duração da lactação e condição corporal. 


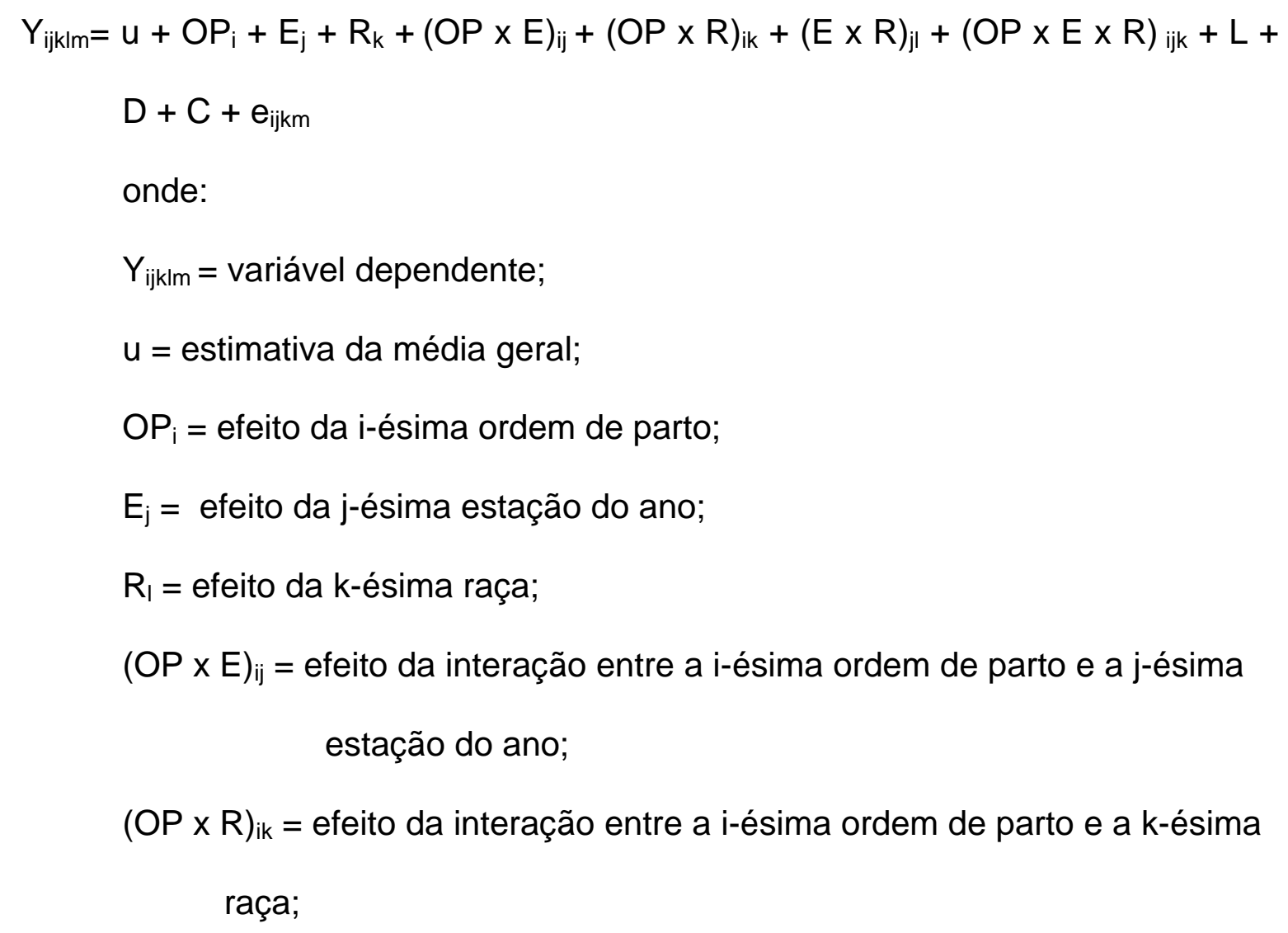

$(E \times R)_{j k}=$ efeito da interação entre a j-ésima estação do ano e a k-ésima raça;

$(\mathrm{OP} \times E \times R)_{\mathrm{ijk}}=$ efeito da interação entre a i-ésima ordem de parto, j-ésima estação do ano e a k-ésima raça;

$\mathrm{L}$ = efeito da covariável número de leitões desmamados;

D = efeito da covariável duração da lactação;

C = efeito da covariável condição corporal;

$\mathrm{e}_{\mathrm{ijkm}}=$ erro inerente a cada observação.

Empregou-se nível de significância dos efeitos e das médias de $\mathrm{P}<0,05$

Dividiu-se a classe raça em três categorias: Landrace (L), Large 
White1 (LW1) e Large White2 (LW2), sendo que as categorias LW1 e LW2 de duas linhagens diferentes, a classe ordem de parto em três categorias: fêmeas de primeiro parto, segundo parto e acima de segundo e a classe estação do ano em dois períodos: 1 - novembro a dezembro de 1996 e 2 - março a abril de 1997.

Foram realizadas análises de correlação e regressão entre IDC, DC e MO, entre MO e MOP e entre os prováveis intervalos em que a ovulação ocorreu pelo MO e MOP.

Para a análise das freqüências de distribuição da provável ovulação dentro das divisões (intervalos de 24 horas) da duração do cio foi utilizado o teste de QUI-quadrado.

Utilizou-se também a análise de regressão com comparação de retas como uma outra alternativa de análise para detectar algum efeito dos fatores raça, OP e estação do ano sobre as relações entre IDC, DC e MO.

Para testar a diferença entre os níveis médios de progesterona de acordo com os grupos de IDC, utilizou-se o teste t de Student. 
RESULTADOS 


\section{1- Distribuição das porcas de acordo com o IDC, DC e MO.}

Os valores médios e desvios padrão para as características intervalo desmame-cio (IDC), duração do cio (DC) e momento da ovulação (MO) das 236 porcas foram respectivamente 106,73 $\pm 19,6$ horas (78 a 180 horas), $67,4 \pm 12.2$ horas (42 a 108 horas) e 44,23 $\pm 9,65$ horas ( 23 a 75 horas). Das 236 porcas acompanhadas, a porcentagem de fêmeas que entraram no cio com 3, 4, 5, 6 e 7 dias de IDC, foi de 30,5\%, 45,6\%, 16,8\%, 6,2\% e 0,8\%, respectivamente. A tabela 2 e figura 4 mostram a distribuição das porcas de acordo com o IDC, discriminando em dias e horas após o desmame. 
TABELA 2 - Distribuição das porcas de acordo com o intervalo desmame-cio (IDC), discriminado em dias e horas após o início do cio.

\begin{tabular}{|c|c|c|c|c|}
\hline \multicolumn{2}{|c|}{ IDC } & \multirow[b]{2}{*}{$n$} & \multirow[b]{2}{*}{$\%$} & \multirow[b]{2}{*}{$\% /$ dia } \\
\hline dia & horas & & & \\
\hline \multirow[t]{4}{*}{3} & 72 & ----- & ---- & \\
\hline & 78 & 8 & 3,4 & \\
\hline & 84 & 16 & 6,8 & \\
\hline & 90 & 48 & 20,3 & 30,5 \\
\hline \multirow[t]{4}{*}{4} & 96 & 29 & 12,3 & \\
\hline & 102 & 23 & 9,7 & \\
\hline & 108 & 27 & 11,3 & \\
\hline & 114 & 29 & 12,3 & 45,6 \\
\hline \multirow[t]{4}{*}{5} & 120 & 14 & 5,9 & \\
\hline & 126 & 10 & 4,2 & \\
\hline & 132 & 10 & 4,2 & \\
\hline & 138 & 6 & 2,5 & 16,8 \\
\hline \multirow[t]{4}{*}{6} & 144 & 5 & 2,1 & \\
\hline & 150 & 6 & 2,5 & \\
\hline & 156 & 2 & 0,8 & \\
\hline & 162 & 2 & 0,8 & 6,2 \\
\hline \multirow[t]{4}{*}{7} & 168 & 1 & 0,4 & \\
\hline & 174 & --- & --- & \\
\hline & 180 & 1 & 0,4 & \\
\hline & 186 & --- & --- & 0,8 \\
\hline
\end{tabular}

A tabela 3 e a figura 5 mostram porcentagem de porcas de acordo com DC. 
TABELA 3 - Distribuição das porcas de acordo com a duração do cio (DC) em horas.

\begin{tabular}{ccc}
\hline $\mathrm{DC}$ & $\mathrm{n}^{\mathrm{o}}$ & $\%$ \\
\hline 42 & 3 & 1,3 \\
48 & 18 & 7,6 \\
54 & 38 & 16 \\
60 & 25 & 10,5 \\
66 & 43 & 18,1 \\
72 & 48 & 20,3 \\
78 & 38 & 16,0 \\
84 & 11 & 4,6 \\
90 & 6 & 2,5 \\
96 & 4 & 1,7 \\
102 & 2 & 0,8 \\
108 & 1 & 0,4 \\
\hline
\end{tabular}

A distribuição das porcas de acordo com o MO foi de 2 (2,6\%), 3 (3,9\%), 28 (36,4\%), 24 (31,2\%), $11(14,3 \%), 7(9,1 \%), 1(1,3 \%)$ e $1(1,3 \%)$ nos respectivos intervalos: 0 a 24, 24 a 32, 32 a 40, 40 a 48, 48 a 56, 56 a 64, 64 a 72 e acima de 72 horas (FIG. 6).

\subsection{Distribuição das porcas de acordo com horário de início do cio.}

A distribuição das porcas de acordo com o horário de observação em que estas iniciaram o cio foi de $24 \%$ a $1: 00$ hora, $38 \%$ as $7: 00$ horas, $24,9 \%$ as 13:00 horas e $13,1 \%$ as 19:00 horas (FIG. 7).

\subsection{Raça}

Detectou-se efeito significativo de raça apenas sobre o IDC, identificando-se fêmeas da raça Landrace com IDC médio estimado de 113,62 horas, o qual foi significativamente mais alto $(P<0,05)$ do que em fêmeas da raça 
Large White 1 , as quais tiveram IDC médio estimado de 102,45 horas. O IDC médio estimado para as fêmeas da raça Large White 2 foi de 106,51 horas, não mostrando significância em comparação às raças Large White 1 e Landrace $(P>0,05)$. Na análise não foi destacada influência de raça sobre a DC e o MO (TAB. 4).

TABELA 4 - Médias estimadas (LS means) do intervalo desmame-cio (IDC), da duração do cio (DC) e do momento da ovulação (MO) em horas, de acordo com as categorias da classe raça.

\begin{tabular}{ccccccc}
\hline & \multicolumn{7}{c}{ Raça } & & & \\
Variáveis & L & LW1 & LW2 & Média & CV & Probab. \\
\cline { 2 - 6 } & $113,62^{\mathrm{a}}$ & $102,45^{\mathrm{b}}$ & $106,51^{\text {ab }}$ & 106,73 & 18,24 & 0,0279 \\
\hline IDC & 67,59 & 64,58 & 64,43 & 67,40 & 18,24 & 0,3328 \\
DC & 40,49 & 44,78 & 45,78 & 44,22 & 21,98 & 0,2347 \\
MO & & & & & \\
\hline
\end{tabular}

\subsection{Ordem de Parto}

A ordem de parto influenciou significativamente o IDC e a DC. Fêmeas de $1^{\circ}$ parto apresentaram IDC médio estimado de 117,44 horas, sendo significantemente mais alto $(\mathrm{P}<0,05)$ que os apresentados pelas fêmeas de $2^{\circ}$ parto e acima deste, cujos IDCs médios estimados foram de 100,47 e 104,78 horas respectivamente. As médias de IDC das fêmeas de $2^{\circ}$ e acima de $2^{\circ}$ parto não diferiram significativamente $(P>0,05)(T A B .5)$.

As médias estimadas de DC das porcas de 1 e 2 partos foram 61,24 
e 65,23 horas respectivamente, não diferindo significativamente. Nas porcas com mais de 2 partos a DC média estimada foi de 70,12 horas, diferindo significativamente das porcas com 1 e 2 partos. Na análise não foi destacada influência de ordem de parto sobre o MO (TAB. 5).

TABELA 5 - Médias estimadas (LS means) do intervalo desmame-cio (IDC), da duração do cio (DC) e do momento da ovulação (MO) em horas, de acordo com as categorias da classe ordem de parto.

\begin{tabular}{cccccccc}
\hline & \multicolumn{9}{c}{ OP } & & & \\
Variáveis & $1^{0}$ parto & $2^{\circ}$ parto & $>2$ partos & Média & CV & Probab. \\
\cline { 2 - 6 } & $117,44^{\mathrm{a}}$ & $100,47^{\mathrm{b}}$ & $104,68^{\mathrm{b}}$ & 106,73 & 18,24 & 0,0007 \\
IDC & $61,24^{\mathrm{b}}$ & $65,23^{\mathrm{b}}$ & $70,12^{\mathrm{a}}$ & 67,40 & 18,24 & 0,0004 \\
MO & 41,99 & 44,89 & 44,16 & 44,22 & 21,98 & 0,7565 \\
\hline
\end{tabular}

Médias seguidas por letras sobrescritas iguais, dentro do mesmo item e mesma linha não diferem estatisticamente entre si $(P<0,05)$.

\subsection{Estação do Ano}

A tabela.6 mostra as médias estimadas das características IDC, DC e MO para os efeitos de estação do ano, não identificando-se significância. 
TABELA 6 - Médias estimadas (LS means) do intervalo desmame-cio (IDC), da duração do cio (DC) e do momento da ovulação (MO) em horas, de acordo com as categorias da classe estação do ano.

\begin{tabular}{cccccc}
\hline & \multicolumn{3}{c}{ Estação } & & \\
Variáveis & 1 & 2 & Médias & CV & Probab. \\
\cline { 2 - 6 } & 107,87 & 107,18 & 106,73 & 18,24 & 0,8521 \\
\hline IDC & 67,38 & 63,69 & 67,40 & 18,24 & 0,1079 \\
DC & 46,01 & 41,36 & 44,22 & 21,98 & 0,3533 \\
\hline
\end{tabular}

\subsection{Interação de ordem de parto x estação}

$\mathrm{Na}$ interação entre ordem de parto e estação do ano, destacou-se a característica MO, conforme demonstração da TAB. 7, pelos valores médios estimados onde fêmeas com OP acima de 2 partos mostraram o MO influenciado pela estação. 
TABELA 7 - Médias estimadas (LS means) do momento da ovulação (MO) em horas, de acordo com a interação entre ordem de parto e estação do ano.

\begin{tabular}{ccc}
\hline Estação & OP & Média \\
\hline 1 & 1 & 42,66 \\
1 & 2 & 43,60 \\
1 & 3 & $51,76^{\mathrm{a}}$ \\
2 & 1 & 41,33 \\
2 & 2 & 46,18 \\
2 & 3 & $36,56^{\mathrm{b}}$
\end{tabular}

Médias seguidas por letras sobrescritas iguais, dentro do mesmo item e mesma coluna não diferem estatisticamente entre si $(P>0,05)$.

\subsection{Correlação e Regressão}

As análises revelaram correlações negativas significativas entre o intervalo desmame-cio e a duração do cio, com um co'eficiente de correlação de $r=-0,4657(P=0,0001)$ e entre o intervalo desmame-cio e o intervalo início do cioovulação com um coeficiente de correlação de $r=-0,3955(P=0,0004)$. Não foi verificado correlação significativa entre duração do cio e intervalo início do cioJvulação ( $r=0,2201 ; P=0,0578)$. As figuras 8,9 e 10, identificam as relações entre as características IDC, DC e MO.

As análises de regressão com comparação entre retas não ossibilitaram a constatação de influência significativa de estação sobre as :lações entre IDC e DC ( $P=0,4922$; FIG. 11), IDC e MO ( $P=0,8900$; FIG. 12) e C e MO ( $P=0,1096 ; F I G .13)$. Também não foi possível mostrar influências da 
estação sobre as relações entre IDC e DC (P=0,4922; FIG. 11), IDC e MO ( $P=0,8900 ;$ FIG. 12) e DC e MO (P=0,1096; FIG. 13). Também não foi possível mostrar influências da raça sobre as relações entre IDC e DC ( $P=0,4277$; FIG.

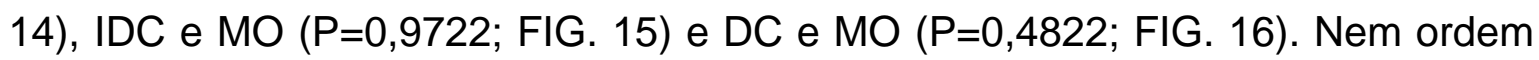
de parto mostrou influências sobre as relações entre IDC e DC ( $P=0,5300$; FIG. 17), IDC e MO (P=0,4765; FIG. 18) e DC e MO (P=0,3947; FIG. 19).

As comparações entre as técnicas de ultra-sonografia e análise da progesterona para o diagnóstico do momento da ovulação, apresentaram baixa correlação positiva e significativa entre MO e MOP ( $r=0,3396 ; P=0,0209)$. Quando levou-se em consideração os possíveis intervalos (quartis) em que a ovulação ocorreu pelo MO e MOP, não caracterizou-se significância e observou-se ainda um menor coeficiente de correlação ( $r=0,2637 ; P=0,0766)$.

Os valores médios DC e MO foram respectivamente de 73,9 $\pm 10,4$ e $48,3 \pm 11,0$ horas, para porcas com IDC de 3 dias, de $66,7 \pm 11,4$ e 44,5 $\pm 8,4$ horas, para porcas com IDC de 4 dias, de $61,8 \pm 11,4$ e $41,25 \pm 8,6$ horas, para porcas com IDC de 5 dias e de 56,5 $\pm 12,6$ e 37,0 $\pm 6,0$ horas, para porcas com IDC de 6 a 7 dias (FIG. 20). A ovulação ocorreu, em média, aos 69,4£16,41\% (25,5 a 109,3\%) do período de duração do cio independente do IDC.

\subsection{Dosagem de Progesterona}

Os níveis médios de progesterona obtidos através da técnica de radioimunoensaio foram de $0,2 \mathrm{ng} / \mathrm{ml}, 0,27 \mathrm{ng} / \mathrm{ml}, 0,97 \mathrm{ng} / \mathrm{ml}$ e $2,57 \mathrm{ng} / \mathrm{ml}$ para as amostras de nível basal, 24, 48 e 72 horas após o início do cio, respectivamente. Os níveis médios de progesterona no grupo de porcas com IDC de 6 e 7 dias aumentaram antecipadamente em relação aos grupos com IDC de 3 e 4 dias $(P=0,003$ e $P=0,005$, respectivamente). Estas diferenças foram observadas 
apenas nas amostras coletadas 48 horas após o início do cio. No entanto, existe uma tendência $(P=0,068)$ dos níveis do grupo com IDC de 6 e 7 dias estarem elevados, em relação ao grupo de 3 dias, já 24 horas após o início do cio. Não foi possível mostrar diferenças estatísticas entre o grupo com IDC de 5 dias em relação aos outros grupos (FIG. 21). A TAB. 8 apresenta os níveis médios de progesterona de acordo com os grupos de IDC.

TABELA 8 - Níveis médios de progesterona, em ng/ml, de porcas com intervalo desmame-cio (IDC) de 3, 4, 5 e 6 a 7 dias.

\begin{tabular}{ccccc}
\hline IDC & \multicolumn{4}{c}{ Níveis médios de progesterona $(\mathrm{ng} / \mathrm{ml})$} \\
\cline { 2 - 5 } & basal $^{*}$ & $24 \mathrm{~h}^{\mathrm{a}}$ & $48 \mathrm{~h}^{\mathrm{a}}$ & $72 \mathrm{~h}^{\mathrm{a}}$ \\
\hline 3dias & 0,20 & 0,22 & $0,72^{\mathrm{b}}$ & 2,84 \\
4dias & 0,23 & 0,27 & $0,75^{\mathrm{b}}$ & 2,63 \\
5dias & 0,16 & 0,26 & $1,05^{\mathrm{ab}}$ & 2,01 \\
6 a 7dias & 0,13 & 0,46 & $1,81^{\mathrm{a}}$ & 2,60
\end{tabular}

* - Amostra coletada 2 dias após o desmame para a determinação dos níveis basais.

a - Horário aproximado em que as amostras foram coletadas.

Níveis médios seguidos por letras sobrescritas iguais, dentro do mesmo item e mesma coluna não diferem estatisticamente entre si, pelo teste $t$ de Student $(P<0,05)$

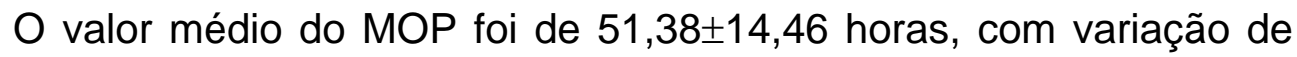
24 a 84 horas, o que representou 77,68\% (25,0\% a 133,3\%) da DC. Os valores médios de MOP para as fêmeas com IDC de 3, 4, 5 e 6 a 7 dias foram de $57,81 \pm 14,64$ horas, $51,48 \pm 11,67$ horas, $48,71 \pm 14,98$ horas e $39,0 \pm 15,38$ respectivamente (FIG. 20). 


\subsection{Distribuição do momento da ovulação pela ultra-sonografia (MO) e progesterona (MOP) em intervalos de 24 horas}

Considerando MO, a distribuição das fêmeas nos diferentes intervalos desmame-cio, mostrou que 58,4\% ovularam entre 24 e 48 horas, 37,5\% ovularam entre 48 e 72 horas e 4,2\% ovularam entre 72 e 96 horas para fêmeas de IDC de 3 dias. Fêmeas de IDC de 4 dias, 3,2\% ovularam entre 0 e 24 horas, $67,7 \%$ ovularam entre 24 e 48 horas e $29,2 \%$ ovularam entre 48 a 72 horas. Aquelas com IDC de 5 dias, 91,6\% ovularam entre 24 e 48 horas e 8,3\% ovularam entre 48 e 72 horas. Finalmente, as de IDC de 6 e 7 dias, 10\% ovularam entre 0 e 24 horas e $90 \%$ ovularam entre 24 e 48 horas, de acordo com a tabela 9 e a figura 22.

Com relação ao MOP, a distribuição das fêmeas foi a seguinte: aquelas com IDC de 3 dias, 4,5\% ovularam entre 0 e 24 horas, 36,3\% ovularam entre 24 e 48 horas, 50,0\% ovularam entre 48 e 72 horas e 9,1\% ovularam entre 72 e 96 horas. As com IDC de 4 dias, 3,6\% ovularam entre 0 e 24 horas, 32,2\% ovularam entre 24 e 48 horas, 60,7\% ovularam entre 48 a 72 horas e 3,6\% ovularam acima de 72 horas. Para as com IDC de 5 dias, 5,9\% ovularam entre 0 e 24 horas, $35,3 \%$ ovularam entre 24 e 48 horas, 52,9\% ovularam entre 48 e 72 horas e 5,9\% ovularam acima de 72 horas. Finalmente, as de IDC de 6 e 7 dias, 14,3\% ovularam entre 0 e 24 horas, 57,1\% ovularam entre 24 e 48 horas e 28,6\% ovularam entre 48 e 72 horas, de acordo com a tabela 10 e a figura 23. 
TABELA 9 - Número e percentual de porcas nos diferentes grupos de intervalo desmame-cio (IDC), distribuídas em intervalos de 24 horas, onde estas provavelmente ovularam, de acordo com o momento da ovulação diagnosticada pela ultra-sonografia (MO).

\begin{tabular}{|c|c|c|c|c|c|c|c|c|}
\hline \multirow[b]{3}{*}{ Ovulação } & \multicolumn{5}{|c|}{ IDC } & \multirow[b]{2}{*}{ Total/8h } & \multirow[b]{3}{*}{$\mathrm{QUI}^{2}$} & \multirow[b]{3}{*}{ Prob. } \\
\hline & 3 dias & 4 dias & 5 dias & \multicolumn{2}{|c|}{6 e 7 dias } & & & \\
\hline & $\mathrm{N} \quad(\%)$ & (\%) & (\%) & $\mathrm{N}$ & $(\%)$ & (\%) & & \\
\hline $0-24 \mathrm{~h}$ & (0) & $1 \quad(3.2)$ & (0) & 1 & $(10)$ & $2 \quad(2,6)$ & 3,174 & 0,366 \\
\hline 24-32 h & $1 \quad(4,2)$ & $1 \quad(3.2)$ & $1 \quad(8,3)$ & 0 & $(0)$ & $3 \quad(3,9)$ & - & - \\
\hline $32-40 \mathrm{~h}$ & 7 (29.2) & 8 (25.8) & $6 \quad(50,0)$ & 7 & (70) & $28(36,4)$ & - & - \\
\hline $40-48 \mathrm{~h}$ & $6 \quad(25.0)$ & $12(38,7)$ & $4 \quad(33.3)$ & 2 & (20) & $24(31,2)$ & - & - \\
\hline $24-48 \mathrm{~h}$ & $14(58,4)$ & $21(67,7)$ & $11(91,6)$ & 9 & (90) & $55(71,4)$ & 6,321 & 0,097 \\
\hline $48-56 \mathrm{~h}$ & 5 (20.8) & $\begin{array}{ll}6 & (19.4)\end{array}$ & (0) & 0 & (0) & $11(14,3)$ & - & - \\
\hline $56-64$ h & 3 (12.5) & $3 \quad(9,8)$ & $(8,3)$ & 0 & $(0)$ & $7 \quad(9,1)$ & - & - \\
\hline $64-72 \mathrm{~h}$ & $1 \quad(4,2)$ & (0) & (0) & 0 & (0) & $1 \quad(1,3)$ & - & - \\
\hline 48-72 h & $10(37,5)$ & $9 \quad(29,2)$ & $(8,3)$ & 0 & (0) & $20(26,0)$ & 8,676 & $0,034^{*}$ \\
\hline$>72 \mathrm{~h}$ & $1 \quad(4,2)$ & (0) & (0) & 0 & (0) & $1 \quad(1,3)$ & 2,237 & 0,525 \\
\hline Total & $24(31,2)$ & $31(40,3)$ & $12(15,6)$ & 10 & $13,0)$ & 77 & - & - \\
\hline
\end{tabular}

* Porcentagens dentro da mesma linha são estatisticamente diferentes pelo teste de QUI-quadrado. 
TABELA 10 - Número e percentual de porcas nos diferentes grupos de intervalo desmame-cio (IDC), distribuídas em intervalos de 24 horas, onde estas provavelmente ovularam, de acordo com o momento da ovulação estimado pelos níveis séricos de progesterona (MOP).

\begin{tabular}{|c|c|c|c|c|c|c|c|}
\hline \multirow[b]{3}{*}{ Ovulação } & \multicolumn{4}{|c|}{$\overline{\text { IDC }}$} & \multirow[b]{2}{*}{ Total/8h } & \multirow[b]{3}{*}{$\mathrm{QUI}^{2}$} & \multirow[b]{3}{*}{ Prob. } \\
\hline & 3 dias & 4 dias & 5 dias & 6 e 7 dias & & & \\
\hline & $\mathrm{N} \quad(\%)$ & $\mathrm{N} \quad(\%)$ & $\mathrm{N} \quad(\%)$ & $\begin{array}{ll}\mathrm{N} & (\%)\end{array}$ & $\mathrm{N} \quad(\%)$ & & \\
\hline $0-24 \mathrm{~h}$ & $1 \quad(4,5)$ & $1 \quad(3,6)$ & $1 \quad(5,9)$ & $1(14,3)$ & $4 \quad(5,4)$ & 1,303 & 0,728 \\
\hline $24-32 \mathrm{~h}$ & $0 \quad(0)$ & $\begin{array}{ll}0 & (0)\end{array}$ & $2(11,8)$ & $3(42,9)$ & $5 \quad(6,8)$ & - & - \\
\hline $32-40$ h & $5(22,7)$ & $5(17,9)$ & $3(17,6)$ & $1(14,3)$ & $14(18,9)$ & - & - \\
\hline $40-48 \mathrm{~h}$ & $3(13,6)$ & $4(14,3)$ & $1 \quad(5,9)$ & $0 \quad(0)$ & $8(10,8)$ & - & - \\
\hline $24-48 \mathrm{~h}$ & $8(36,3)$ & $9(32,2)$ & $6(35,3)$ & $4(57,1)$ & $27(36,5)$ & 1,527 & 0,676 \\
\hline $48-56 \mathrm{~h}$ & $3(13,6)$ & $12(42,9)$ & $6(35,3)$ & $2(28,6)$ & $23(31,1)$ & - & - \\
\hline $56-64 \mathrm{~h}$ & $7(31,8)$ & $3(10,7)$ & $2(11,8)$ & $(0)$ & $12(16,2)$ & - & - \\
\hline $64-72 \mathrm{~h}$ & $1 \quad(4,5)$ & $2 \quad(7,1)$ & $1 \quad(5,9)$ & $(0)$ & $4 \quad(5,4)$ & - & - \\
\hline $48-72 \mathrm{~h}$ & $11(50,0)$ & $17(60,7)$ & $9(52,9)$ & $2(28,6)$ & $39(52,7)$ & 2,421 & 0,490 \\
\hline$>72 \mathrm{~h}$ & $2 \quad(9,1)$ & $1 \quad(3,6)$ & $1 \quad(5,9)$ & $(0)$ & $4 \quad(5,4)$ & 1,176 & 0,759 \\
\hline Total & $22(29,7)$ & $28(37,8)$ & $17(23,0)$ & $7 \quad(9,5)$ & 74 & & \\
\hline
\end{tabular}




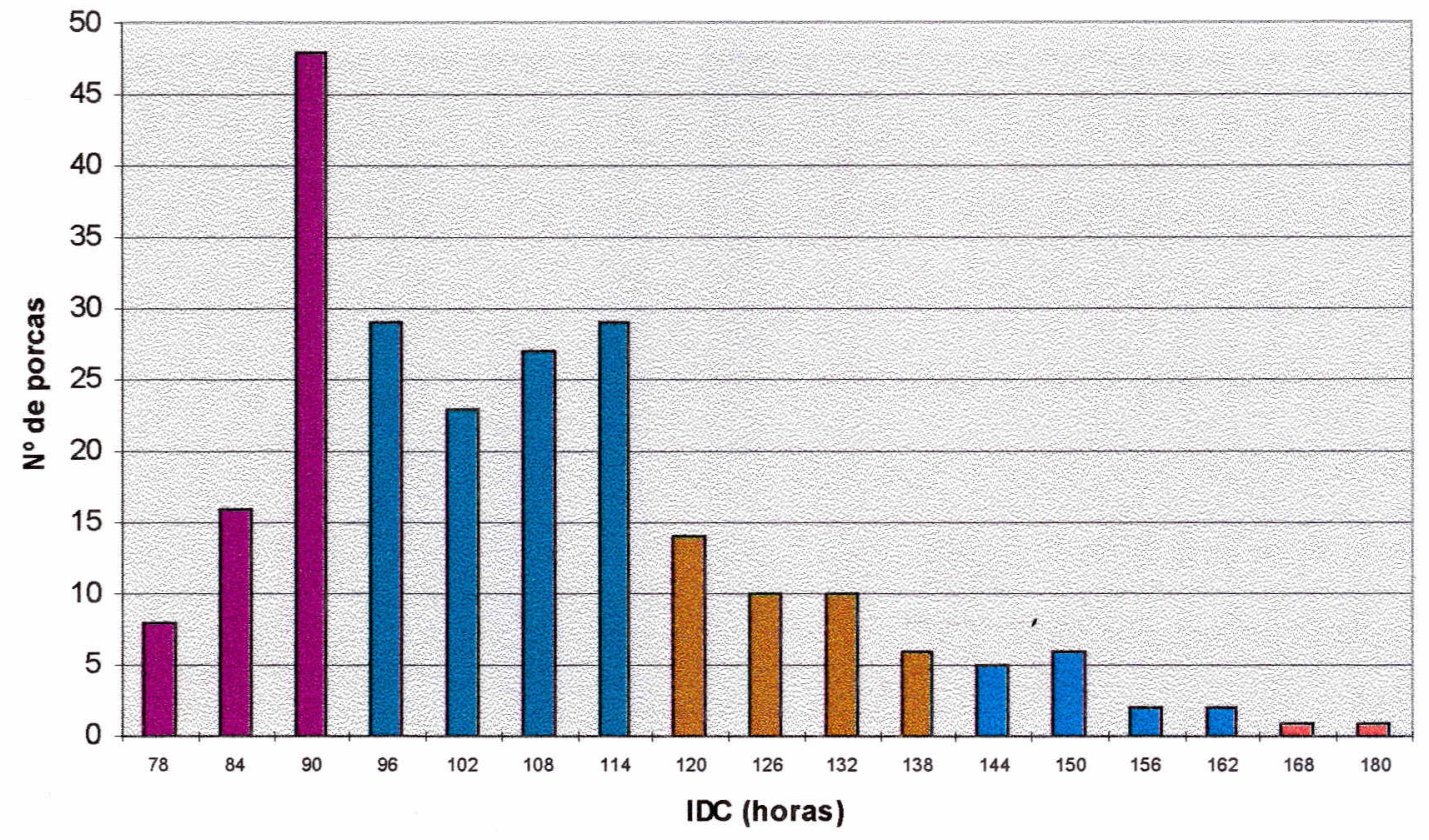

FIGURA 4 - Distribuição das porcas $(n=236)$ de acordo com o intervalo desmame-cio (IDC) em horas. As cores diferentes das colunas indicam IDC de 3, 4, 5, 6 e 7 dias. 


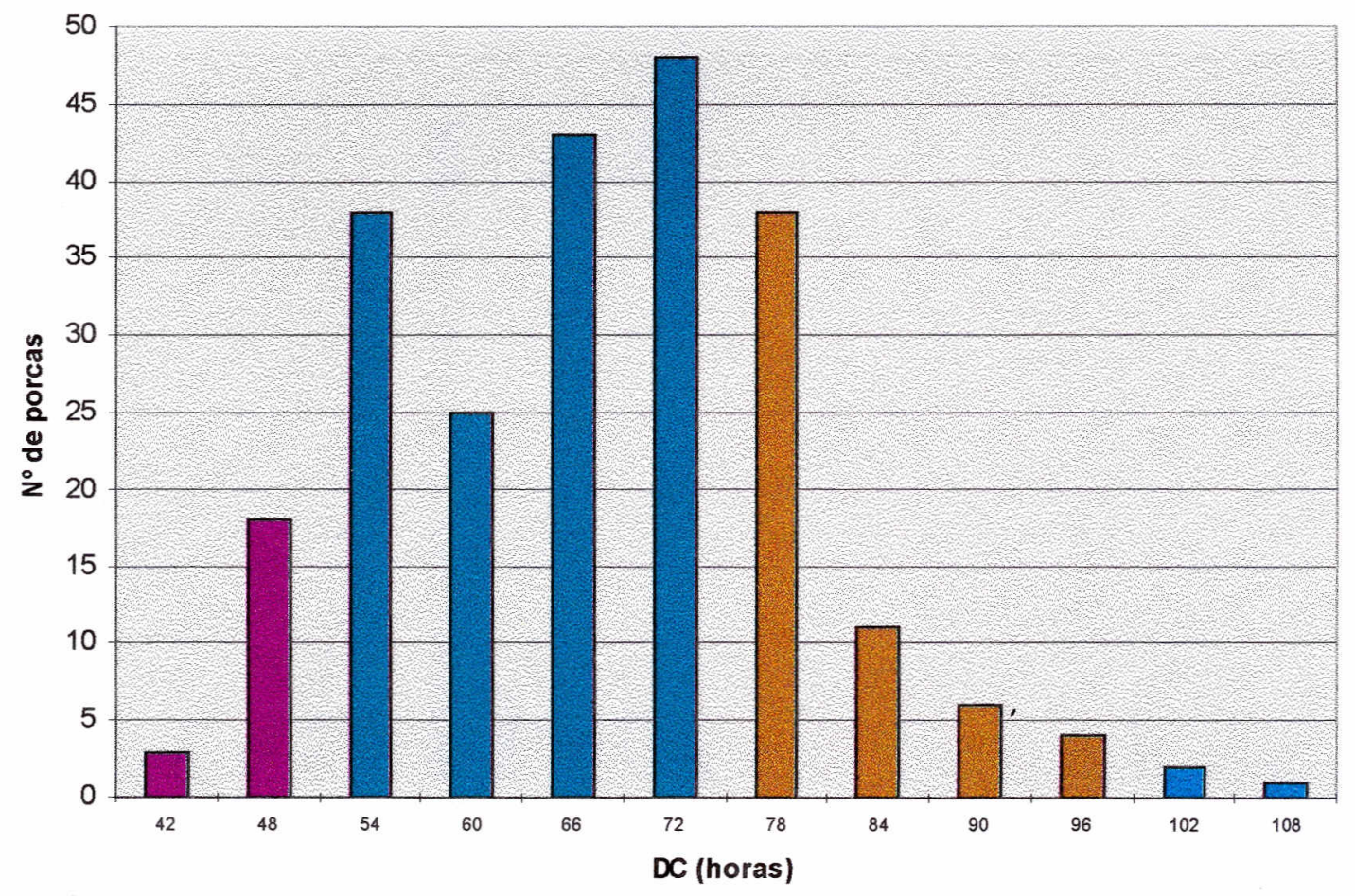

FIGURA 5 - Distribuição das porcas $(n=236)$ de acordo com a duração do cio (DC) em horas. As cores diferentes das colunas indicam DC de 2, 3, 4 e acima de 4 dias. 


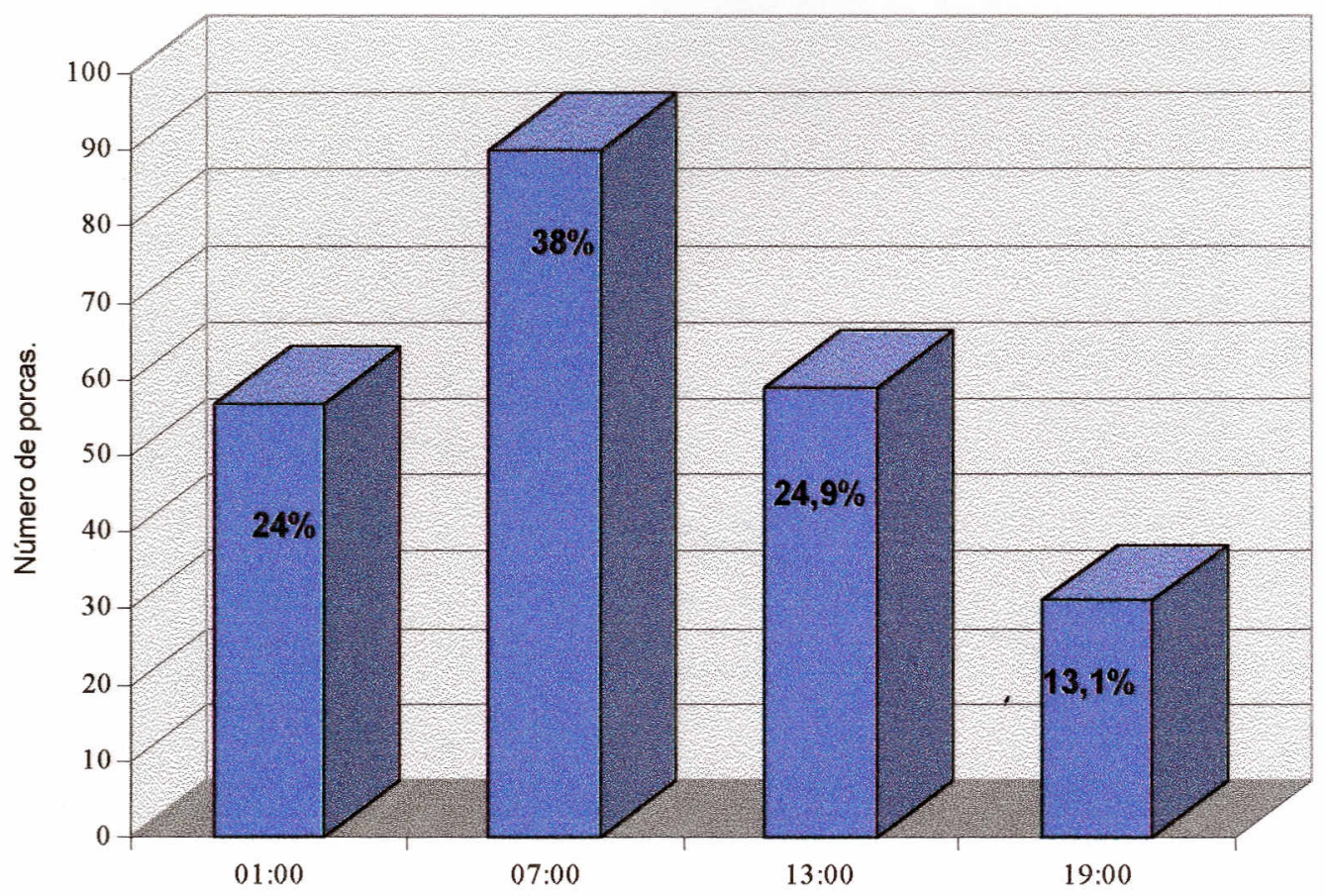

Horários de diagnóstico.

FIGURA 7 - Distribuição das porcas de acordo com o horário em que estas foram diagnosticadas em cio. 


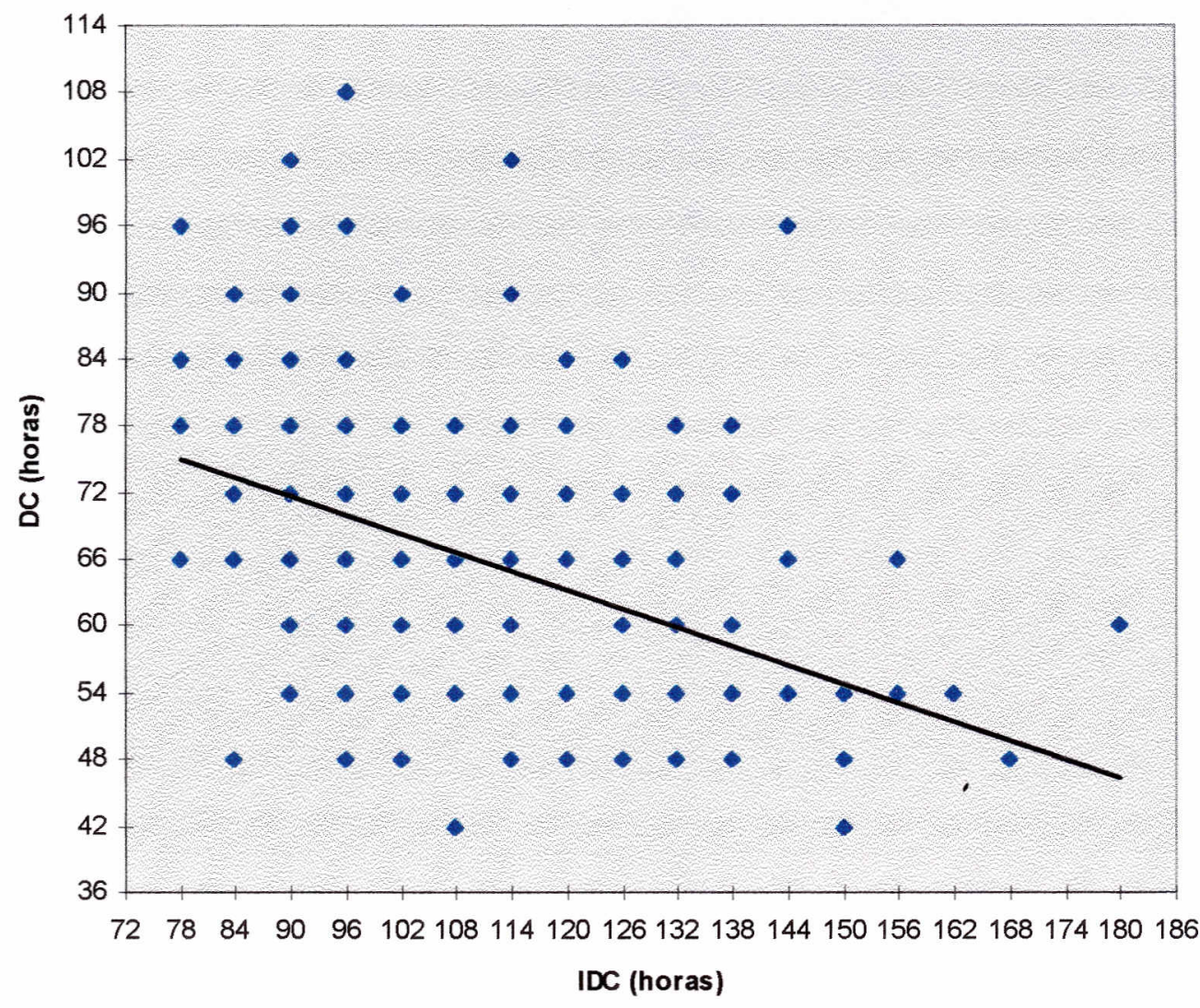

FIGURA 8 - Relações entre o intervalo desmame-cio (IDC) e a duração do cio (DC) $\left(\mathrm{DE}=96,878-0,2808 \mathrm{IDC}, \mathrm{R}^{2}=0,2169\right.$ e $\left.\mathrm{P}=0,0001\right)$. 


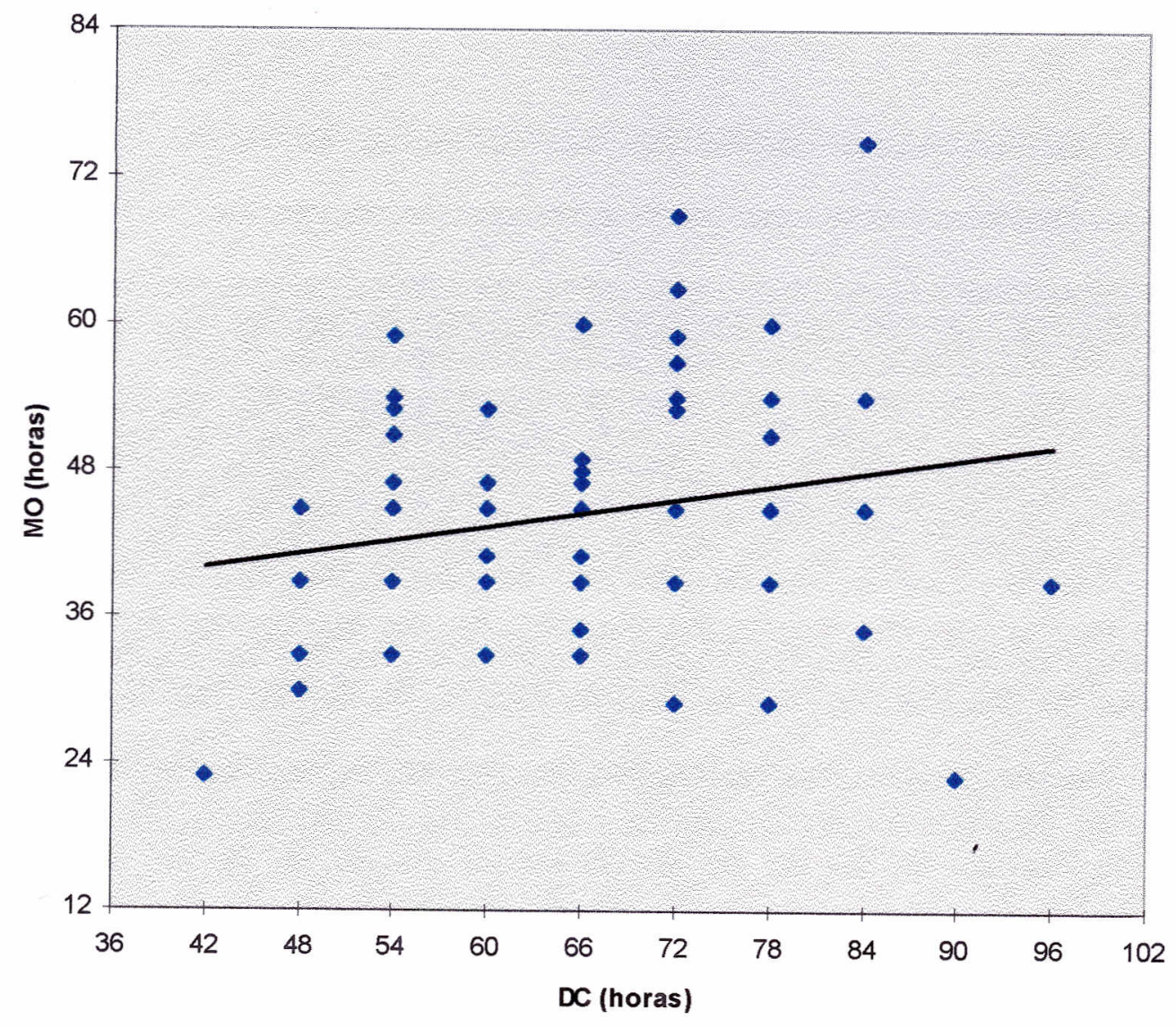

FIGURA 9 - Relações entre a duração do cio (DC) e o momento da ovulação (MO) $\left(\mathrm{MO}=32,360+0,1835 \mathrm{DC}, \mathrm{R}^{2}=0,0484\right.$ e $\left.\mathrm{P}=0,0578\right)$. 


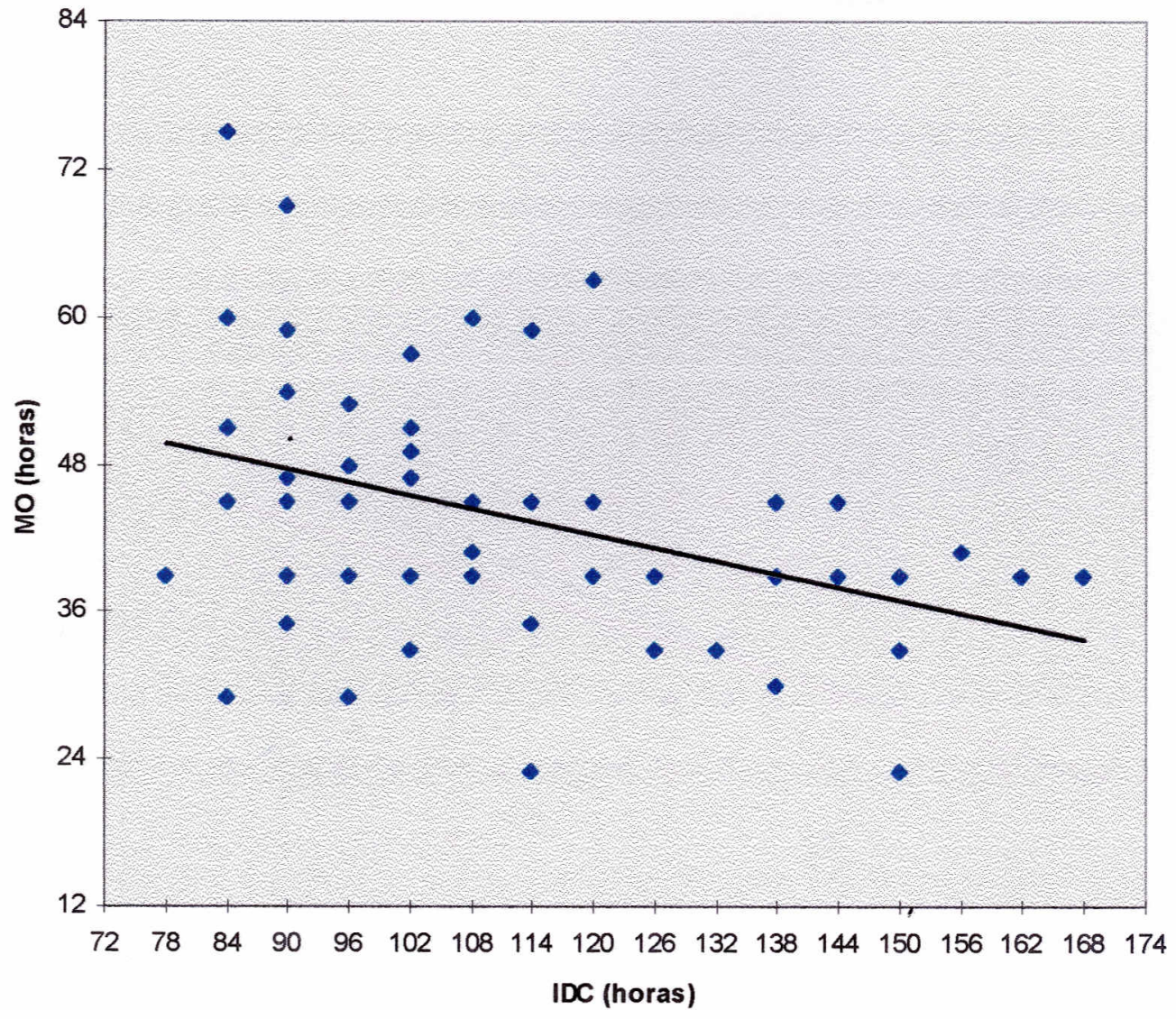

FIGURA 10 - Relações entre o intervalo desmame-cio (IDC) e o momento da ovulação (MO) (MO=63,377-0,1762IDC, $R^{2}=0,1564$ e $\left.P=0,0004\right)$. 


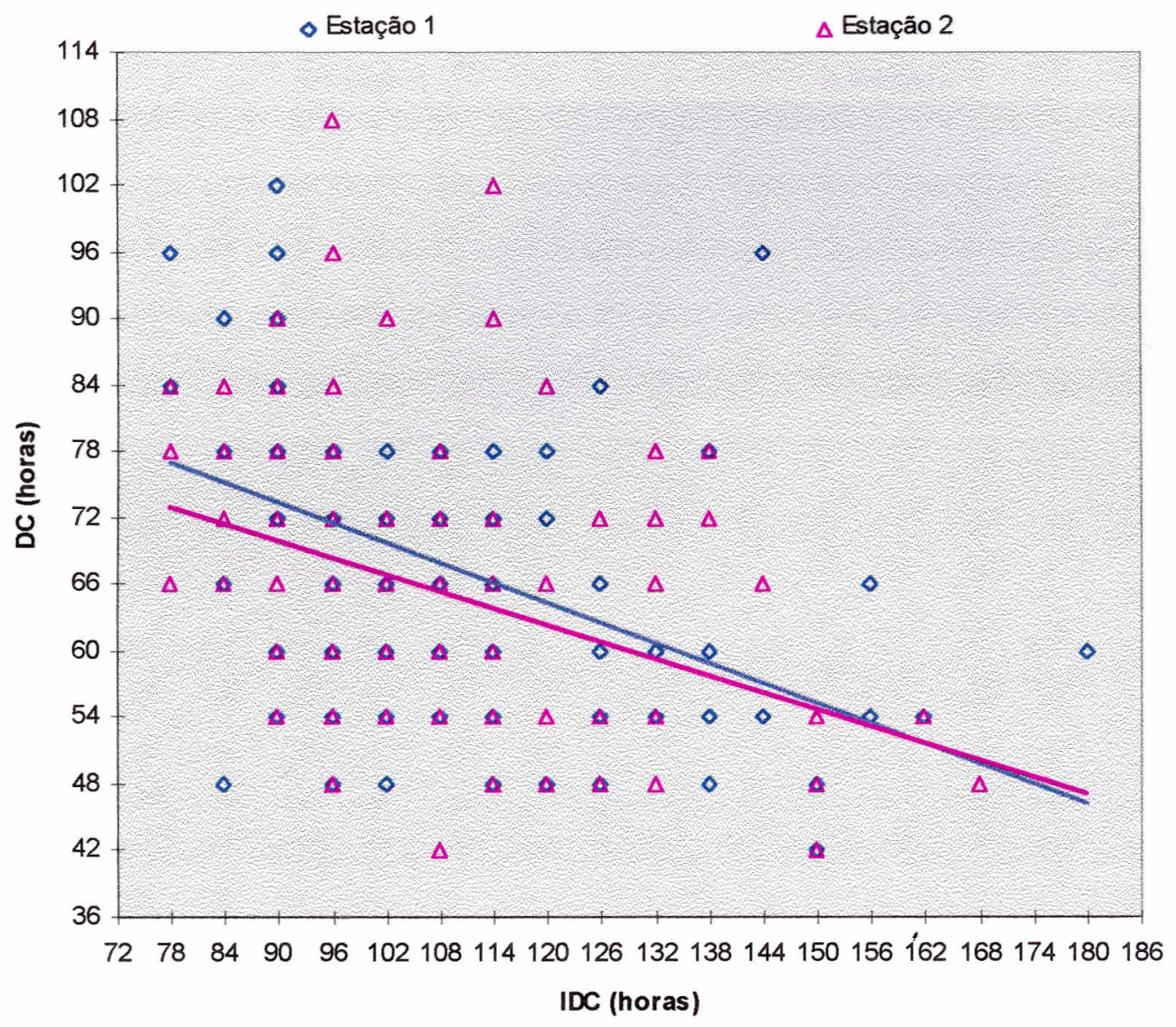

FIGURA 11 - Análise de regressão entre intervalo desmame-cio (IDC) e duração do cio (DC) com comparação de retas de acordo com a classe estação do ano: estação 1 ( $D C=100,585-0,3018 \mathrm{IDC}, R^{2}=0,2947$ e $P=0,0001)$ e estação 2 (DC=92,838-0,2536IDC, $R^{2}=0,1598$ e $P=0,0001)$. $A$ interação IDC $x$ estação não foi significativa $(P=0,4922)$. 


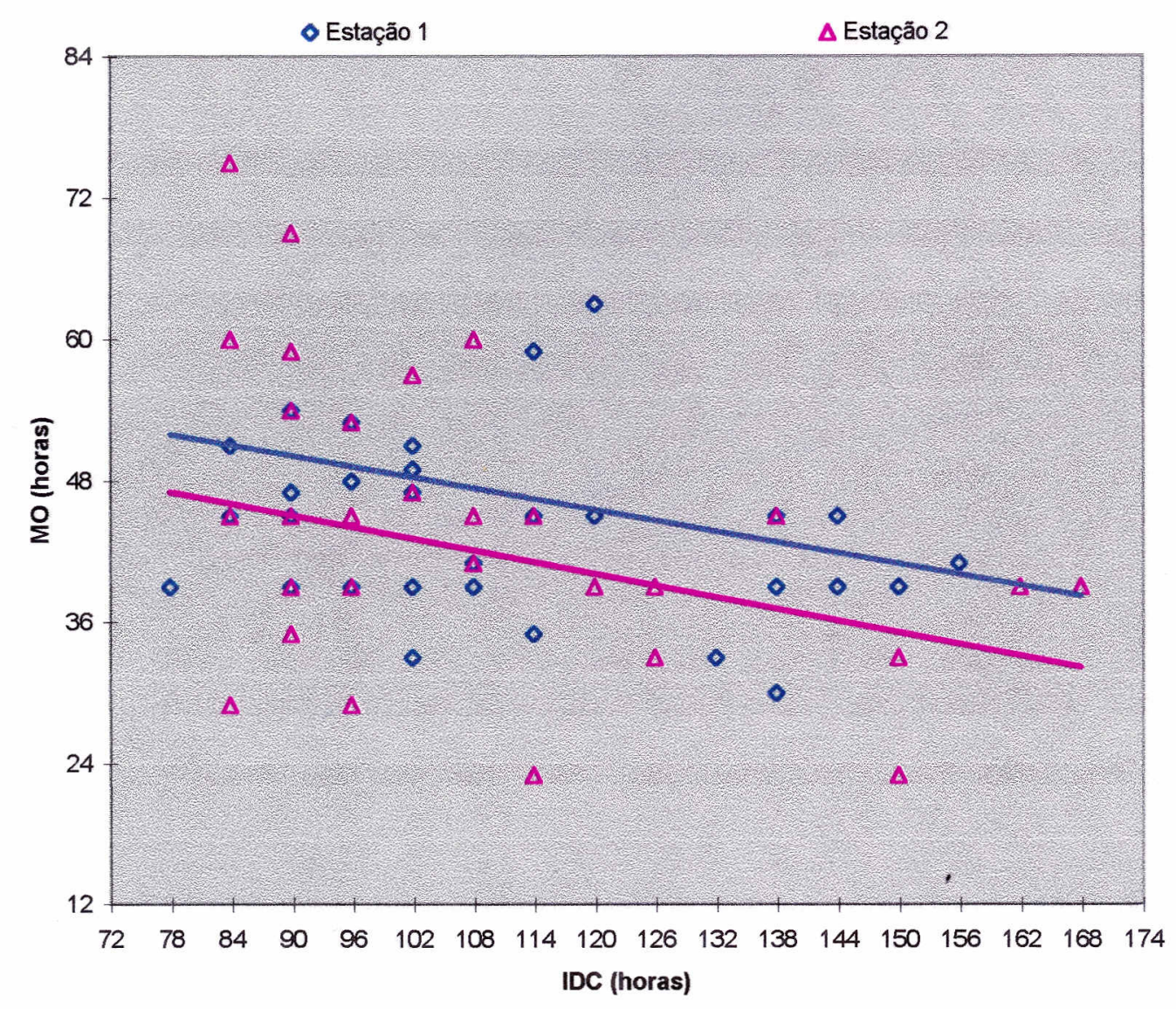

FIGURA 12 - Análise de regressão entre intervalo desmame-cio (IDC) e momento da ovulação (MO) com comparação de retas de acordo com a classe estação do ano: estação 1 (MO=63,8490,1524IDC, $R^{2}=0,1349$ e $P=0,0387$ ) e estação 2 ( $M O=59,979$ 0,1654 IDC, $R^{2}=0,1423$ e $\left.P=0,0127\right)$. $A$ interação IDC $\times$ estação não foi significativa $(P=0,8900)$. 


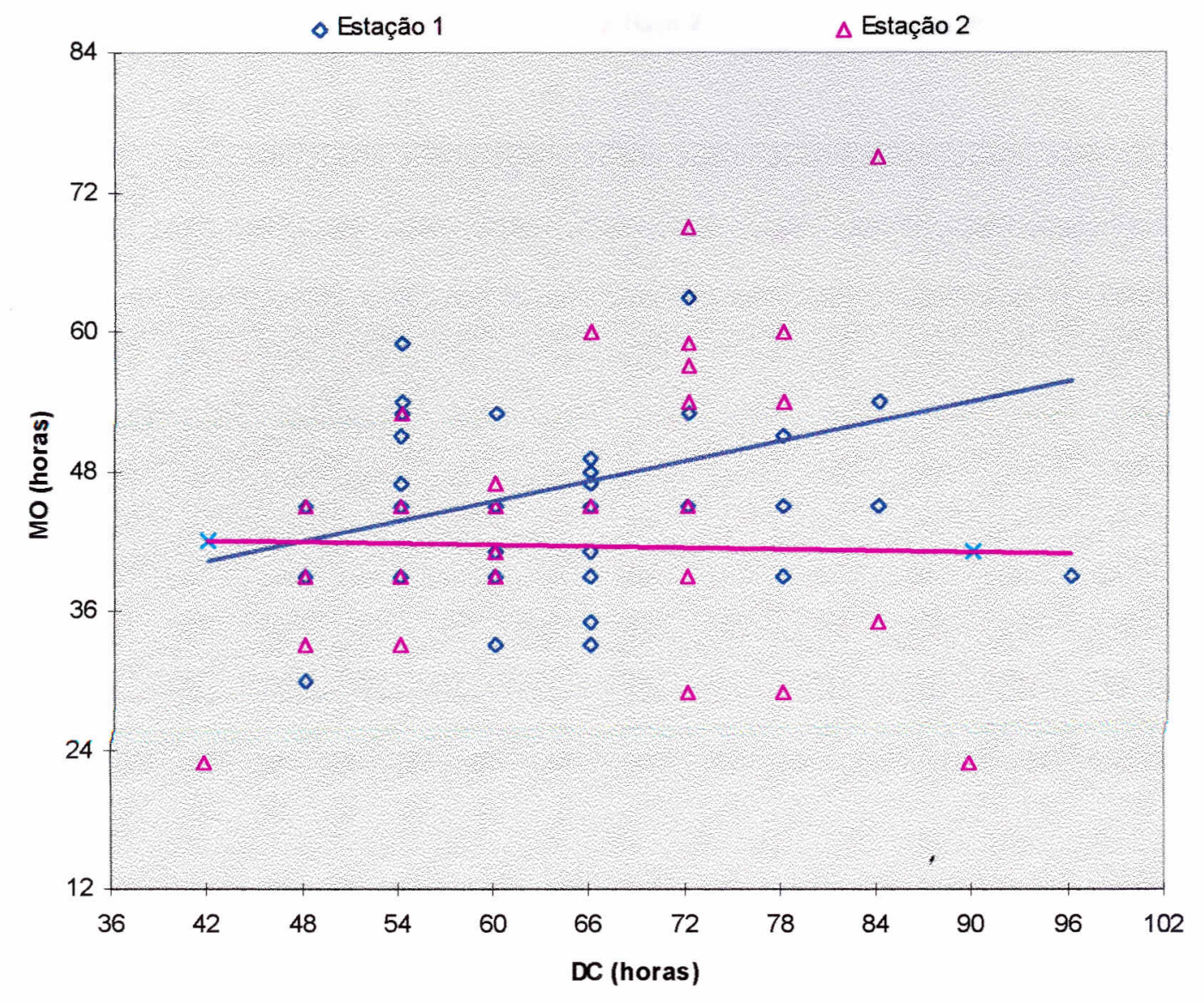

FIGURA 13 - Análise de regressão entre duração do cio (DC) e momento da ovulação (MO) com comparação de retas de acordo com a classe estação do ano: estação $1\left(M O=28,357+0,2849 D C, R^{2}=0,1140\right.$ e $\mathrm{P}=0,0587)$ e estação $2\left(\mathrm{MO}=42,959-0,0217 \mathrm{DC}, \mathrm{R}^{2}=0,0007\right.$ e $P=0,8622)$. $A$ interação IDC $x$ estação não foi significativa $(P=0,1096)$. 


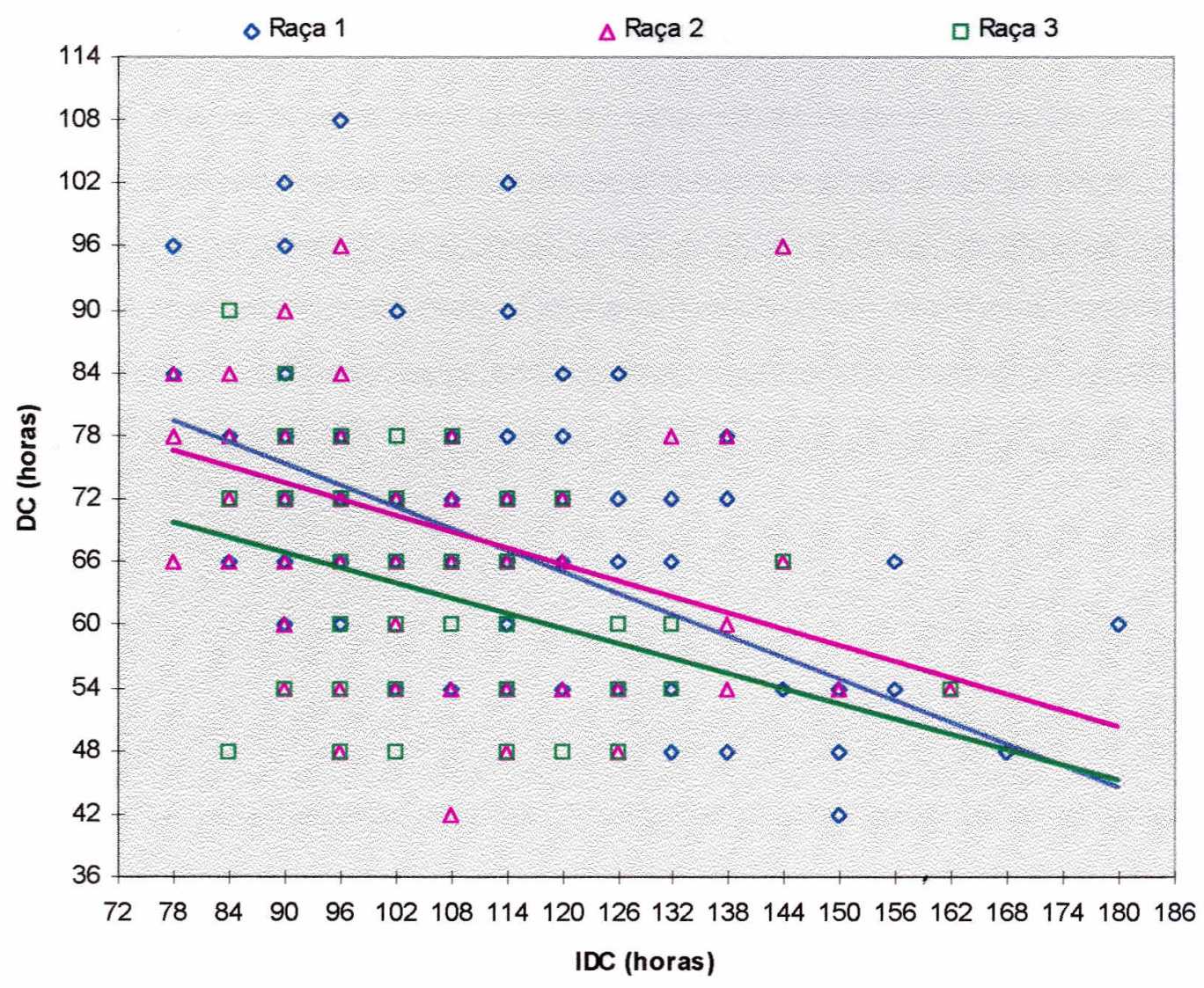

FIGURA 14 - Análise de regressão entre intervalo desmame-cio (IDC) e duração do cio (DC) com comparação de retas de acordo com a classe raça: raça 1 ( $D C=106,149-0,3423 I D C, R^{2}=0,3375$ e $\left.P=0,0001\right)$, raça $2\left(D C=96,543-0,2560 I D C, R^{2}=0,1739\right.$ e $\left.P=0,0001\right)$ e raça 3 ( $D C=88,423-0,2400$ IDC, $R^{2}=0,1274$ e $\left.P=0,0064\right)$. A interação IDC $x$ raça não foi significativa $(P=0,4277)$. 


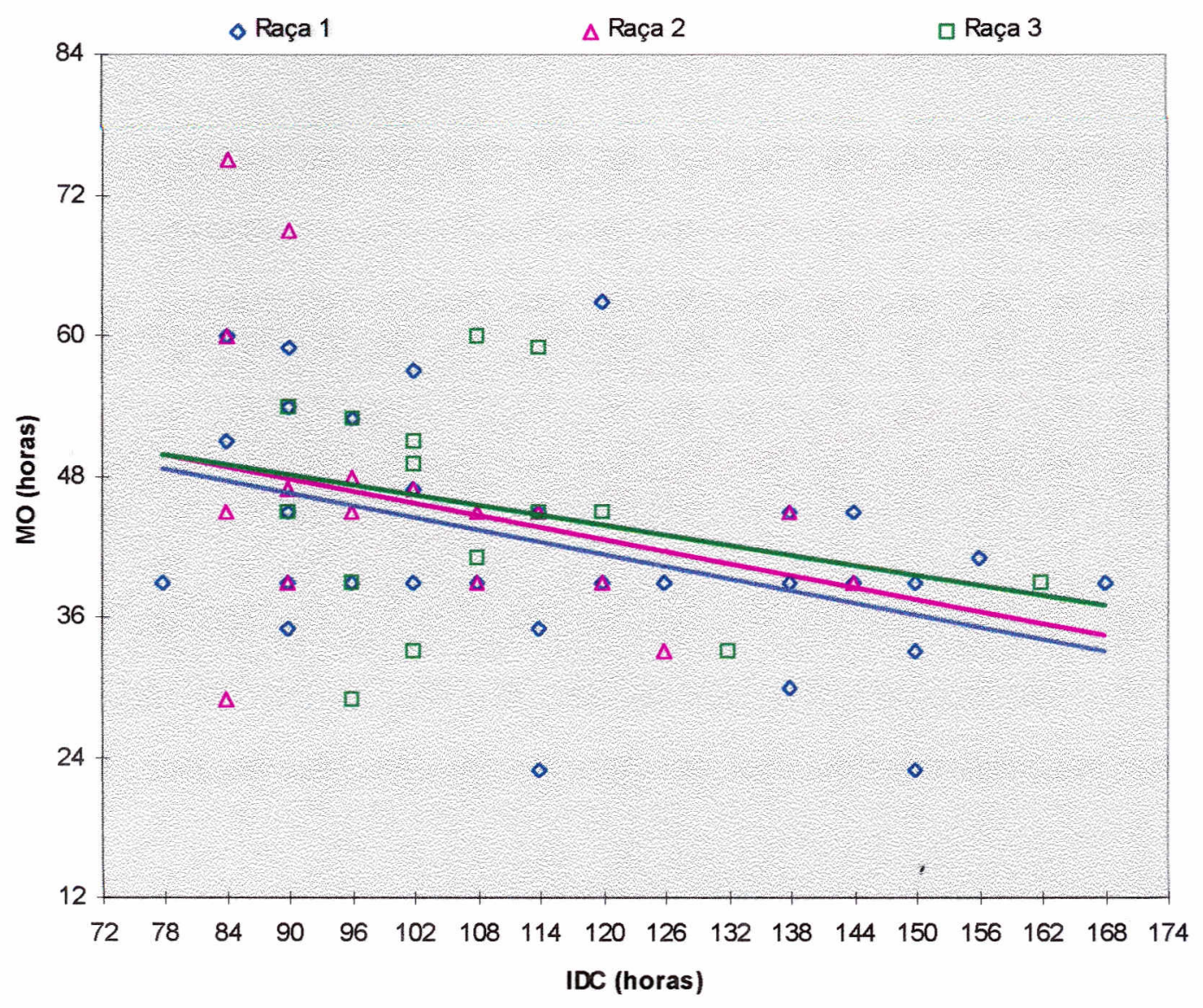

FIGURA 15- Análise de regressão entre intervalo desmame-cio (IDC) e momento da ovulação $(\mathrm{MO})$ com comparação de retas de acordo com a classe raça: raça $1\left(\mathrm{MO}=62,276-0,1744 \mathrm{IDC}, \mathrm{R}^{2}=0,2130 \mathrm{e}\right.$ $P=0,0069)$, raça $2\left(M O=63,216-0,1718 I D C, R^{2}=0,0788\right.$ e $\left.P=0,2306\right)$ e raça $3\left(M O=60,864-0,1423 I D C, R^{2}=0,0781\right.$ e $\left.P=0,2079\right)$. $A$ interação IDC $x$ raça não foi significativa $(P=0,9722)$. 


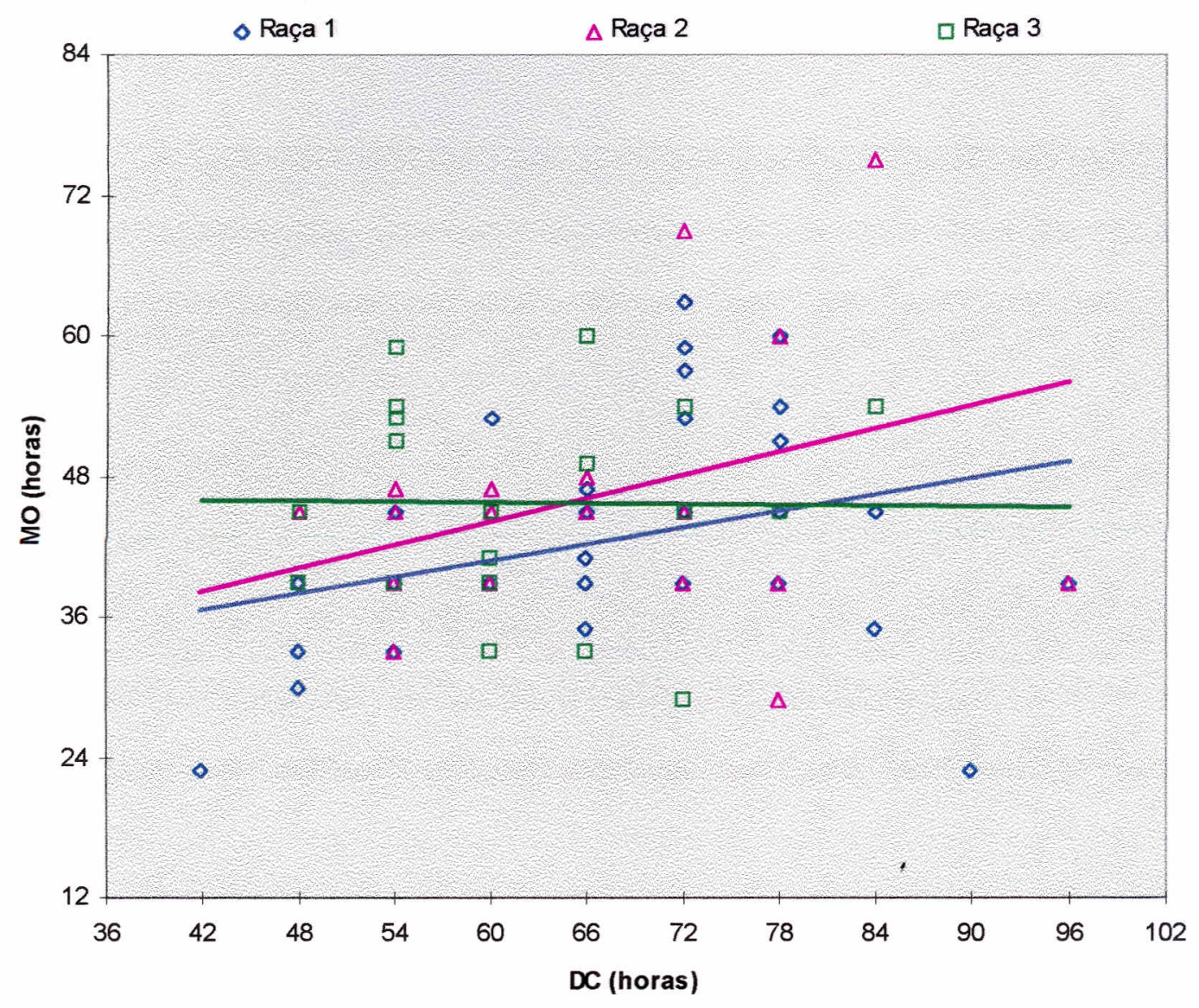

FIGURA 16- Análise de regressão entre duração do cio (DC) e momento da ovulação (MO) com comparação de retas de acordo com a classe raça: raça $1\left(\mathrm{MO}=26,639+0,2357 \mathrm{DC}, \mathrm{R}^{2}=0,1050\right.$ e $\left.\mathrm{P}=0,0658\right)$, raça $2\left(\mathrm{MO}=24,064+0,3339 \mathrm{DC}, \mathrm{R}^{2}=0,1052\right.$ e $\mathrm{P}=0,1630$ ) e raça 3 ( $M O=46,446-0,0116 D C, R^{2}=0,0002$ e $\left.P=0,9535\right)$. A interação IDC $x$ raça não foi significativa $(P=0,4822)$. 


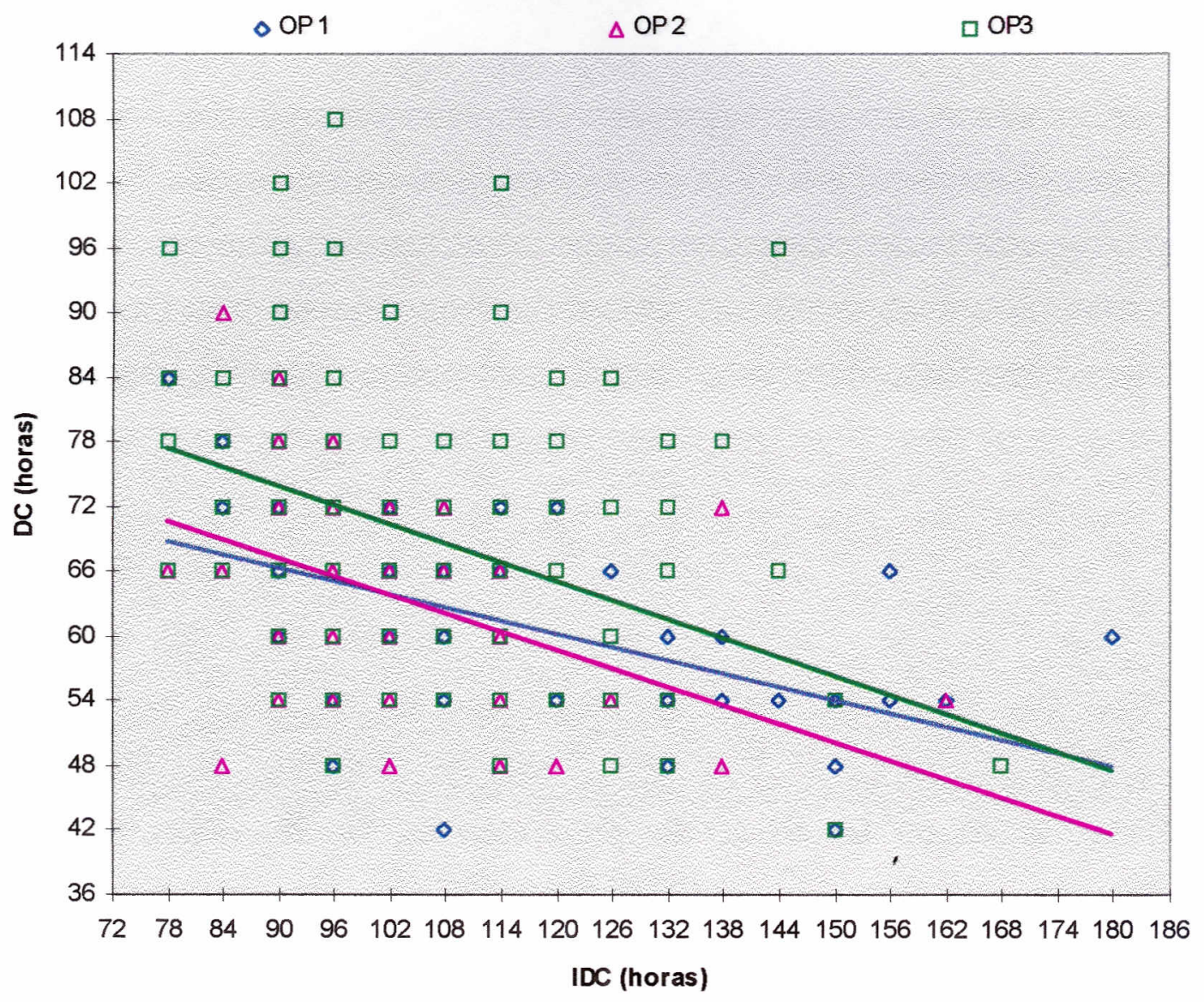

FIGURA 17 - Análise de regressão entre intervalo desmame-cio (IDC) e duração do cio (DC) com comparação de retas de acordo com a classe ordem de parto: OP 1 ( $D C=84,618-0,2039 I D C, \quad R^{2}=0,2822$ e $P=0,0005)$, OP $2\left(D C=92,867-0,2842 I D C, R^{2}=0,1686\right.$ e $\left.P=0,0046\right)$ e OP 3 ( $D C=100,308-0,2930$ IDC, $R^{2}=0,1911$ e $P=0,0001$ ). A interação IDC x OP não foi significativa $(P=0,5300)$. 


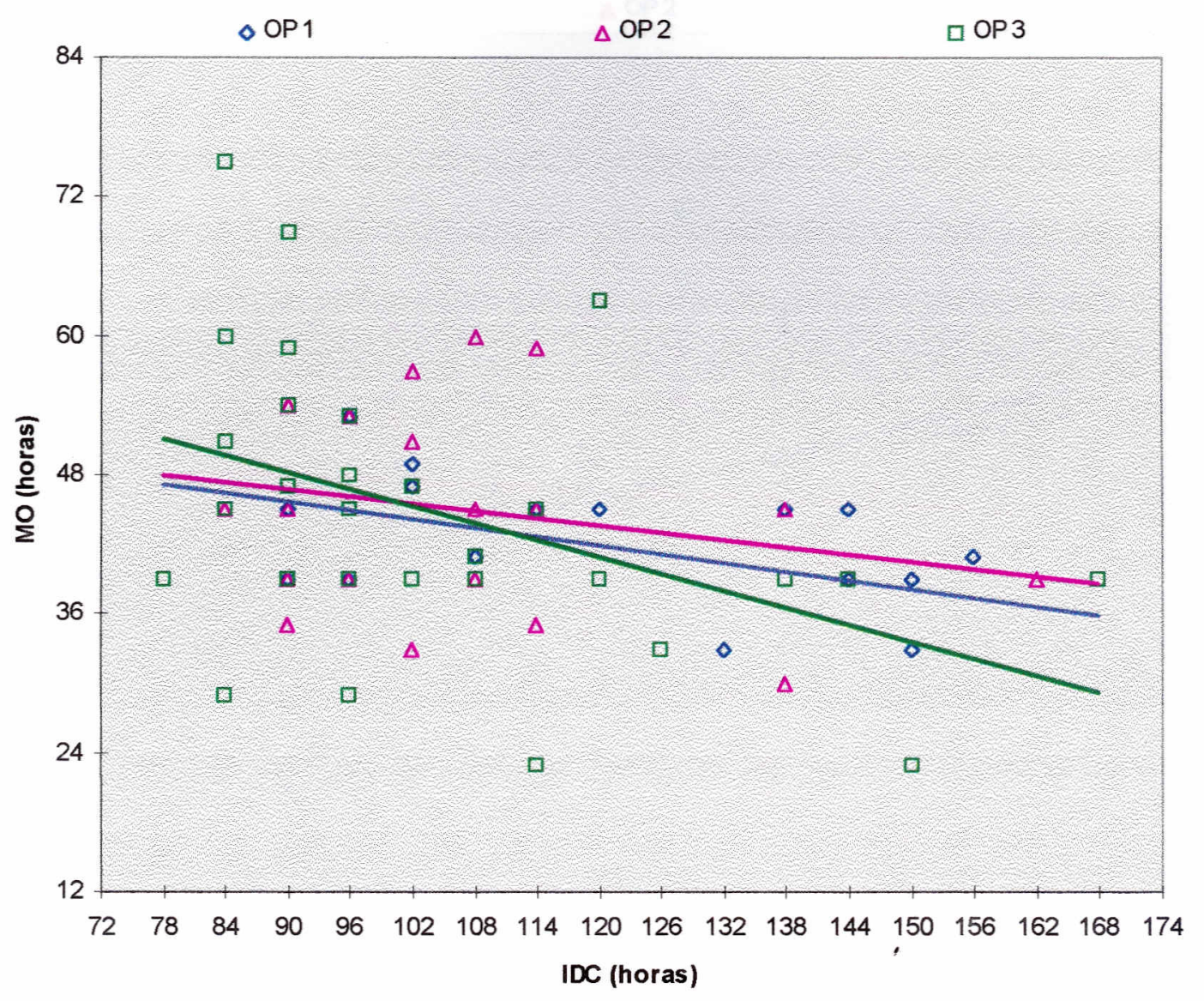

FIGURA 18 - Análise de regressão entre intervalo desmame-cio (IDC) e momento da ovulação (MO) com comparação de retas de acordo com a classe ordem de parto: OP 1 (MO=57,238-0,1273IDC, $\mathrm{R}^{2}=0,2787$ e $\left.\mathrm{P}=0,0243\right)$, OP 2 (MO=56,080-0,1038IDC, $\mathrm{R}^{2}=0,0530$ e $\left.\mathrm{P}=0,3152\right)$ e OP 3 (MO=70,199-0,2442IDC, $R^{2}=0,1742$ e $\left.P=0,0113\right)$. A interação IDC $x$ OP não foi significativa $(P=0,4765)$. 


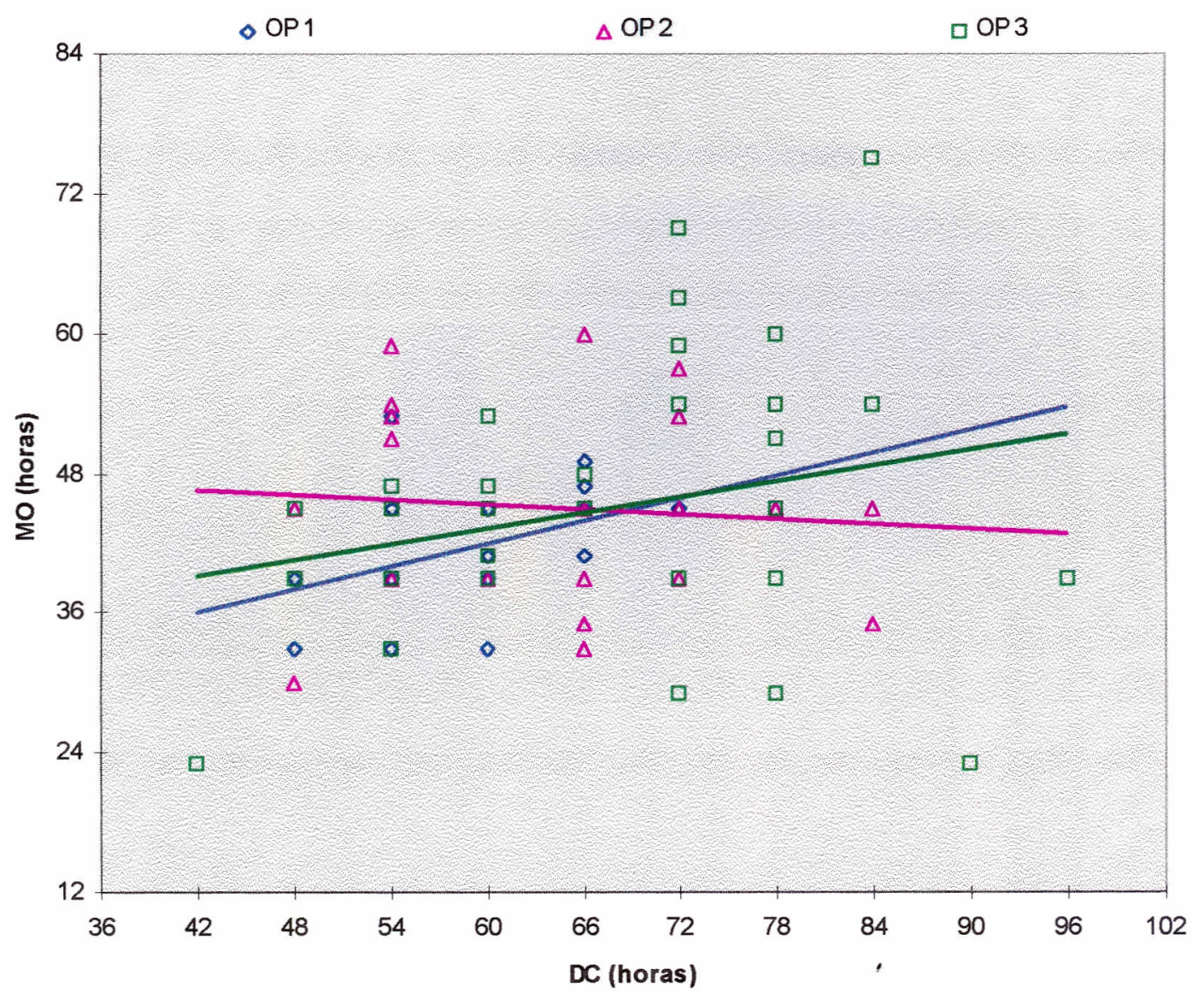

FIGURA 19 - Análise de regressão entre duração do cio (DC) e momento da ovulação (MO) com comparação de retas de acordo com a classe ordem de parto: OP 1 (MO=22,345+0,3275DC, $R^{2}=0,2084$ e $\mathrm{P}=0,0569)$, OP $2\left(\mathrm{MO}=49,490-0,0685 \mathrm{DC}, \mathrm{R}^{2}=0,0072\right.$ e $\left.\mathrm{P}=0,7139\right)$ e OP 3 (MO=29,728+0,2265DC, $R^{2}=0,0611$ e $\left.P=0,1459\right)$. A interação IDC x OP não foi significativa $(P=0,3947)$. 


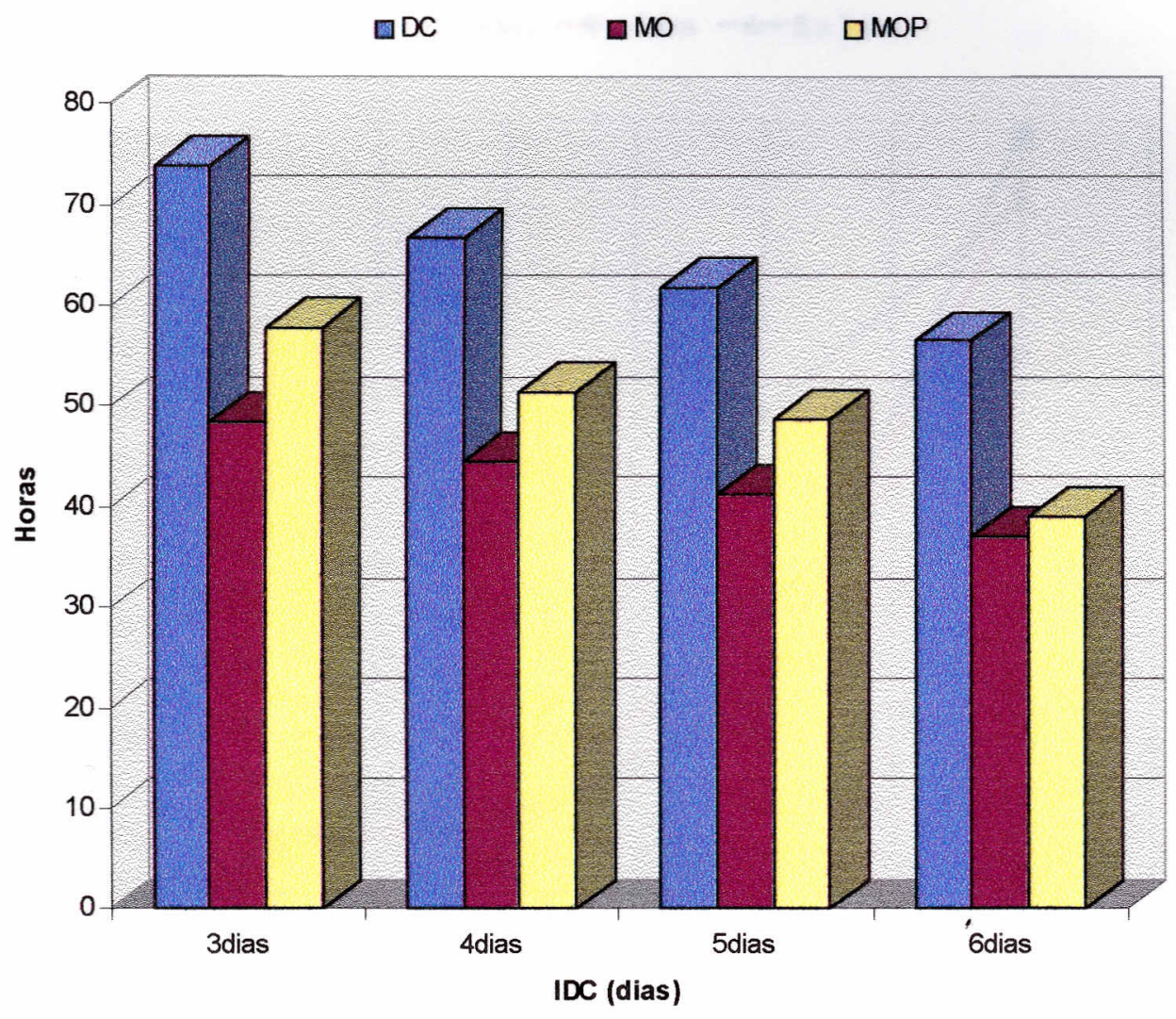

FIGURA 20 - Valores médios, em horas, referentes à duração do cio (DC), momento da ovulação pela ultra-sonografia (MO) e momento da ovulação pela progesterona (MOP), de acordo com o intervalo desmame-cio (IDC) em dias. 
$-\not-3$ dias $-\square-4$ dias $\multimap 5$ dias $\triangle 6$ a 7 dias

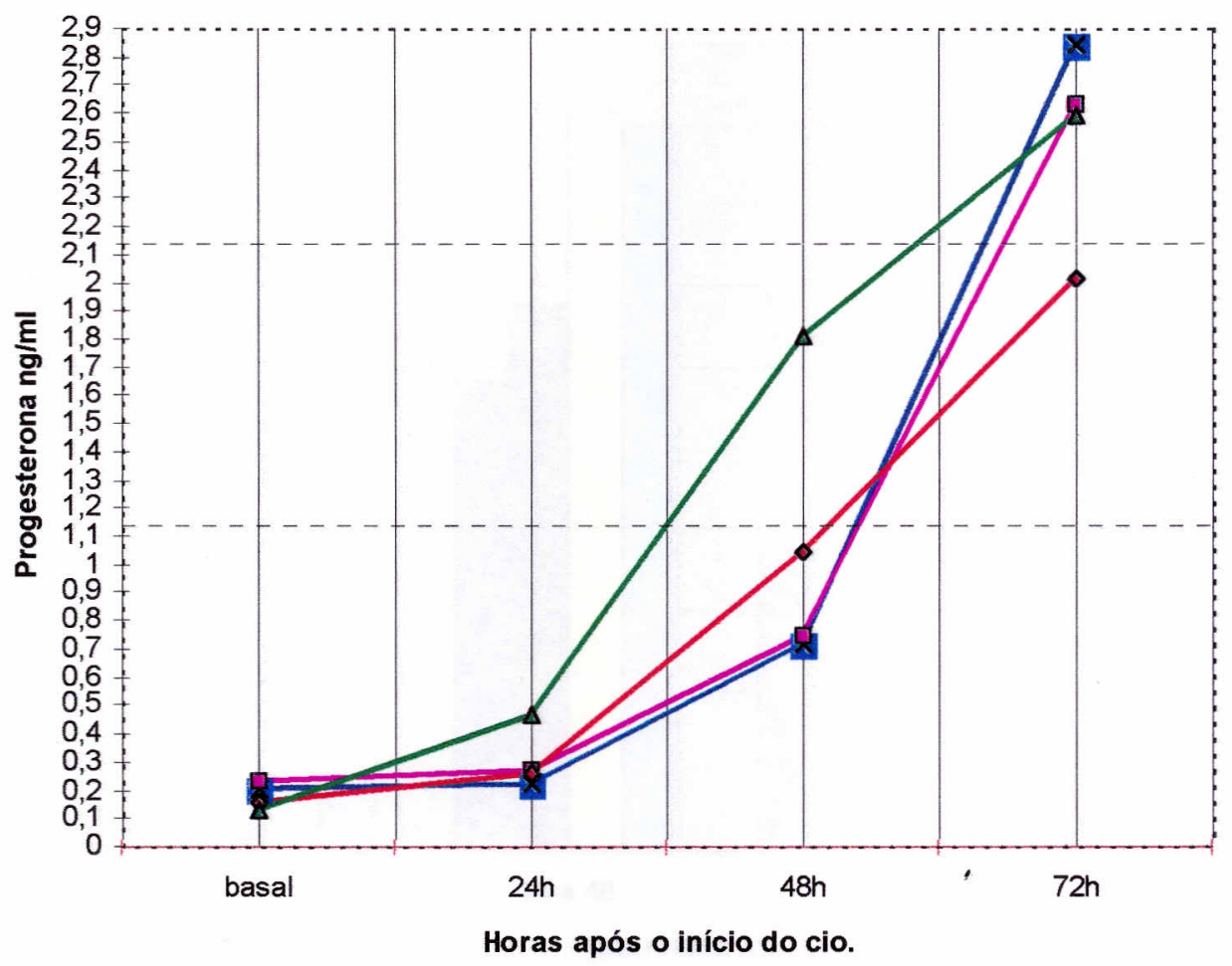

FIGURA 21 - Níveis médios de progesterona de acordo com os grupos de intervalo desmame-cio (IDC) em dias. 


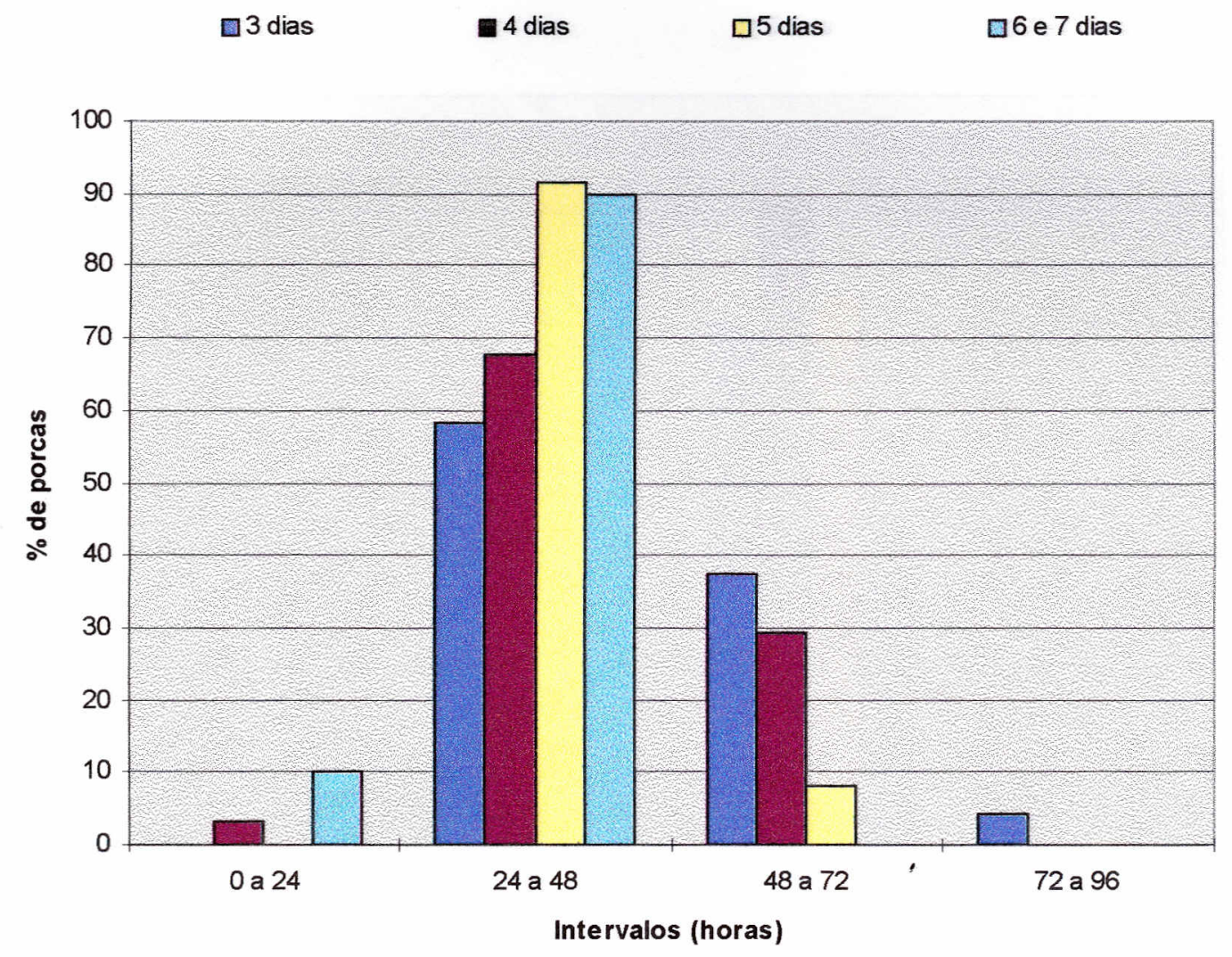

FIGURA 22 - Percentual de porcas nos diferentes grupos de intervalo desmame-cio (IDC)(3, 4, 5 e 6 e 7 dias), distribuídas em intervalos de 24 horas, onde estas provavelmente ovularam, de acordo com o momento da ovulação diagnosticada pela ultrasonografia (MO). 


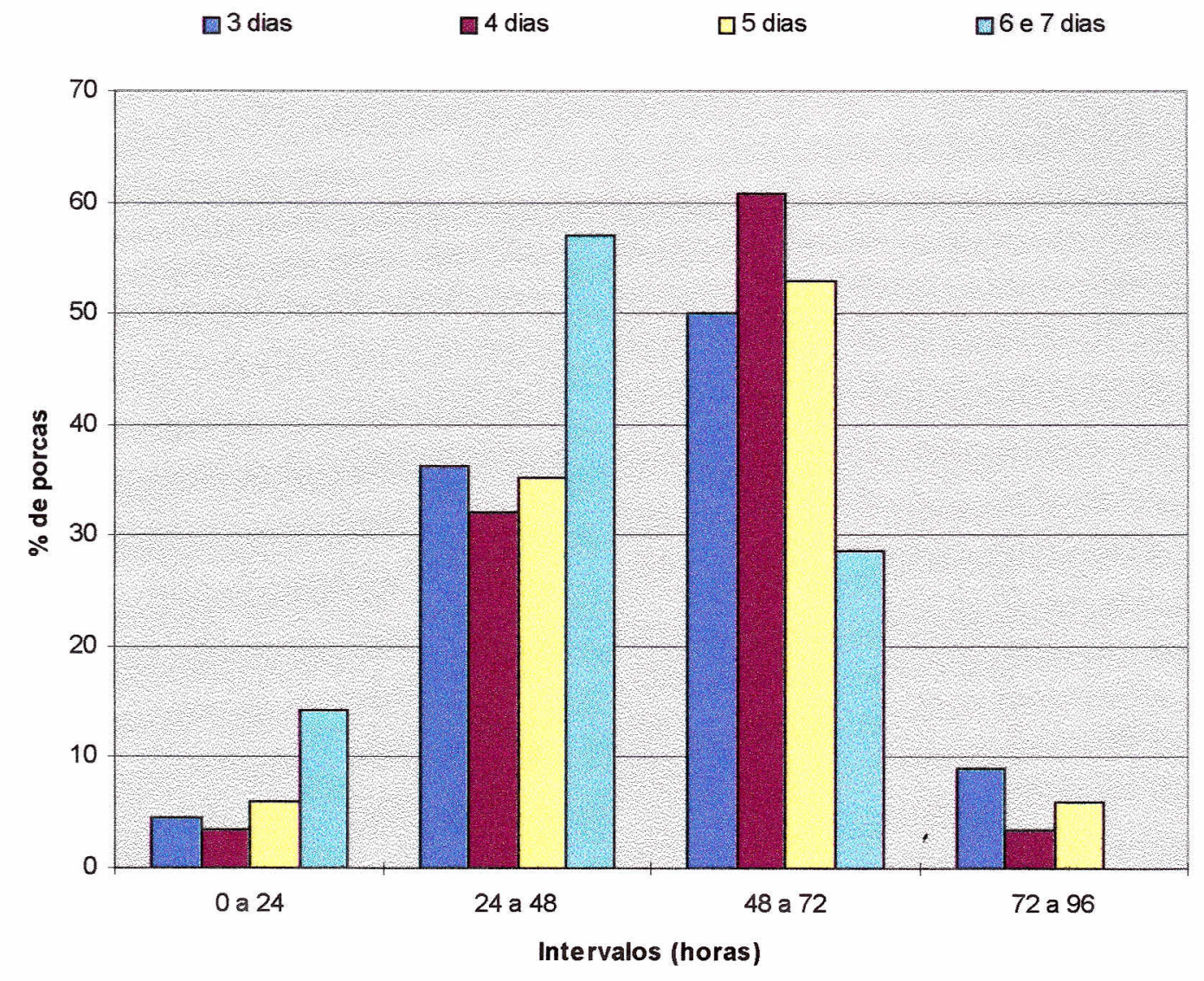

FIGURA 23 - Percentual de porcas nos diferentes grupos de intervalo desmame-cio (IDC), distribuídas em intervalos de 24 horas, onde estas provavelmente ovularam, de acordo com o momento da ovulação estimado pelos níveis de progesterona (MOP). 
DISCUSSÃO 
Dados encontrados na literatura tem mostrado que o consumo durante a lactação exerce maior influência sobre o IDC do que a condição corporal dos animais (ARMSTRONG et al., 1986; ESBENSHADE et al., 1986; TUBBS, 1990). Provavelmente a perda de condição corporal seja mais importante que a condição corporal ao desmame, pois refletiria um baixo consumo energético durante a lactação e, deste modo, mostraria relação indireta com o IDC, fundamentando os resultados encontrados por REESE et al.(1982), KING; WILLIAMS(1984) e REESE et al.(1984). No presente experimento, não foi possível medir a perda de condição corporal e nem consumo durante a lactação, no entanto, foi mensurada a condição corporal ao desmame, considerando-a como covariável e, deste modo, retirando qualquer possível efeito nutricional da análise estatística. Além disso, só foram considerados animais acima da condição corporal 3 (ROPPA, 1991) para melhorar a homogeneidade das unidades experimentais.

TUBBS (1990) relata que o período de lactação e o IDC apresentam geralmente relação inversa. No entanto, VESSEUR et al.(1994b) não encontraram nenhuma influência do período de lactação sobre o IDC, esclarecendo que o efeito apresenta-se mais evidente quando o período de lactação é tão curto quanto 1 ou 2 semanas e que essa ausência de efeito, constatada em seus dados, é explicada devido ao período de lactação médio ter sido de 4 semanas (excepcionalmente 3 ou 5 semanas). Considerando que o período de lactação médio do presente experimento foi bastante próximo ao do experimento de VESSEUR et 
al.(1994b), esta característica foi considerada como covariável para retirar algum possível efeito dos resultados obtidos na análise.

Da mesma forma como a condição corporal e o período de lactação, o tamanho da leitegada ao desmame foi considerado como uma covariável, isolando qualquer possível efeito desta característica nos resultados da análise estatística, pois os resultados de STEVENSON; BRITT (1981) mostraram efeito da diminuição do número de leitões amamentados, na última semana de lactação, sobre o IDC.

No presente experimento os valores médios de IDC foram superiores nas fêmeas primíparas em comparação às de 2 ou mais partos, em concordância com os resultados de BRITT et al. (1983). No entanto, VESSEUR et al. (1994b) constataram nas primíparas um IDC médio significativamente mais elevado que nas pluríparas e que fêmeas de segundo parto também apresentavam IDC mais longo em relação às pluríparas acima de segundo parto. A OP também influenciou significativamente a DC, de modo que porcas de primeiro e segundo partos mostraram um cio mais curto em relação às de OP superior, resultado este também demonstrado por CORRÊA et al. (1997). Os valores médios das DCs em fêmeas de $1^{\circ}, 2^{\circ}$ e acima de $2^{\circ}$ parto $(61,24,65,23$ e 70,12 horas, respectivamente), foram semelhantes aos encontrados por CORRÊA et al. (1997) $(56,9,64,7,71,5$ horas, respectivamente) e sugerem que, mesmo não ocorrendo diferenças significativas entre fêmeas de $1^{\circ}$ e $2^{\circ} \mathrm{OP}$ em ambos experimentos, existe uma tendência das porcas primíparas em manifestar a DC mais curta em comparação às de segundo parto. 
Apesar da OP não haver influenciado significativamente o MO, as médias encontradas no presente trabalho (TAB. 2) foram próximas às encontradas por WEITZE et al. (1994), onde porcas de primeiro parto ovularam precocemente em relação às demais $O P(P \leq 0,05)$. A provável explicação para esta diferença entre experimentos é no tocante à amostragem mais reduzida e a variabilidade da característica.

O efeito da interação entre estação do ano e OP no presente experimento, mostrou que as porcas acima de segundo parto ovularam, em média, mais tardiamente (51,76 horas) no período de novembro a dezembro em comparação ao de março a abril (36,56horas). Apesar das diferenças serem significativas, não foram encontradas na literatura informações que pudessem explicar estes achados.

Quanto à estação climática, não foram encontradas diferenças nas médias de IDC, apesar de que em outros trabalhos observou-se diminuição no percentual de fêmeas que retornam ao cio dentro de 7 dias e um aumento no percentual de fêmeas que permanecem em anestro após o desmame (BRITT et al., 1983; DIAL, 1984), tal circunstância pode ser embasada nos achados de DIAL (1987), uma vez que verificou-se pouca variação de temperatura nos 2 períodos estudados.

Apesar das diferenças significativas detectadas entre as raças Landrace e Large White-1, a variação foi de apenas 11,17 horas. No entanto, apesar de não haver demonstrado diferenças significativas, MAURER et al. (1985) observaram em fêmeas da raça Landrace, cio 1,1dias mais cedo que as da raça Large White. Deste modo, acredita-se que as diferenças de IDC 
entre raças, quando significativas, apresentam baixa magnitude. A influência da heterose, apesar de variável e pouco conhecida (TUBBS, 1990), parece ser de maior influência considerando os achados de VESSEUR et al. (1994b), onde fêmeas mestiças mostraram IDC 3,51dias mais curto do que as puras. Não houve influência significativa da raça na DC, à semelhança dos resultados obtidos por WENTZ et al. (1997).

O IDC médio de 106,73 horas encontra-se bastante próximo dos valores encontrados na literatura mais recente, tanto nos experimentos realizados na Alemanha (WEITZE et al., 1994), Holanda (KEMP; SOEDE, 1996) e Dinamarca (NISSEN et al.,1997) e principalmente aqueles realizados no Brasil (HECK et al., 1997; CORRÊA et al., 1997). O valor médio da DC (67,4 horas) também se mostrou próximo aos encontrados na literatura consultada, muito embora, a maior parte dos trabalhos mostraram uma DC substancialmente menor (ANDERSON, 1982, 56 horas; WEITZE et al., 1994, 59,6 horas; KEMP; SOEDE, 1996, 53,0 horas; NISSEN et al.,1997, 60,0 horas; HECK et al., 1997, 56,5 horas). Estas diferenças na DC, ocorreram provavelmente pelas variações do manejo no diagnóstico de cio, adotado neste estudo, onde as fêmeas duvidosas em relação ao final de cio eram levadas à baia do macho para diagnóstico mais preciso, com associação dos estímulos olfatório, auditivo, visual e tátil em maior intensidade, embasados nos achados referenciais de SIGNORET (1970). Tal prática não foi citada em nenhum dos trabalhos. Portanto fêmeas duvidosas que não fossem positivas na gaiola poderiam ser consideradas como negativas, originando as diferenças encontradas neste experimento e na literatura consultada. 
CORRÊA et al. (1997), por sua vez, não utilizaram o macho para a determinação do final do cio e observaram uma DC média (65,0 horas) bastante próxima à encontrada neste experimento, sugerindo que, talvez não haja apenas uma diferença de manejo, mas também variabilidade individual, inerente à própria granja. A influência do contato com o macho sobre a DC, relatada por DICK (1988) em porcas alojadas em baias adjacentes às do macho, não ocorreu no presente experimento devido ao tipo de manejo adotado.

A distribuição das porcas de acordo com o horário de início do cio foi semelhante à maioria dos resultados encontrados na literatura consultada (SMIRNOV; TERESHCHENKO, 1980; NOGUEIRA, 1982; REIS et al.,1997), evidenciando que na maior parte das porcas (acima de 60\%) observadas, o início do cio ocorreu durante a noite, ou seja, foram diagnosticadas em cio pela manhã. Neste experimento $24 \%$ das porcas foram diagnosticadas em cio a 1:00 e outros autores encontraram resultados ainda superiores, assim como 50\% as 23:00 (ZIMMERMAN; NABER; 1971) e $32,7 \%$ as $20: 00$ e $9,3 \%$ as $24: 00$ (MUNARI, 1985). Os resultados alertam para o fato de que, quando programas de IA são embasados em duas observações de cio por dia com intervalos irregulares (as 8:00 e as 16:00, por exemplo), uma parte representativa das fêmeas que são diagnosticadas em cio pela manhã, iniciaram o cio há aproximadamente 9 horas atrás. Este intervalo entre o início e o diagnóstico do cio constituiria numa observação particularmente importante para fêmeas com IDC longo e, conseqüentemente, manifestação de cio curto. 
A relação inversa entre IDC e $D C\left(R^{2}=0.22, P=0,0001\right)$ observada no presente trabalho também foi verificada em outros estudos (ROJKITTIKHUN et al., 1992; WEITZE et al., 1994; KEMP; SOEDE, 1996; NISSEN et al., 1997; CORRÊA et al., 1997). No entanto, a magnitude das correlações foram diferentes entre os experimentos, como por exemplo KEMP; SOEDE (1996) $\left(R^{2}=0.25, P<0,001\right)$, NISSEN et al. $(1997)\left(R^{2}=0.45\right.$, $P<0,0001)$ e CORRÊA et al. (1997) $\left(R^{2}=0.50, P<0,0001\right)$. Houve relação inversa também entre IDC e $M O\left(R^{2}=0.16, P=0,0004\right)$, que também foi observada no experimento de NISSEN et al. (1997) $\left(R^{2}=0.29, P<0,0001\right)$. Considerando estas informações, podemos afirmar que o IDC influencia negativamente a DC e o MO. No entanto, a diferença de magnitude destas influências, encontrada nos experimentos acima, sugere que elas variam de rebanho para rebanho. Estas diferenças de magnitude também foram constatadas comparando-se as DC médias para os grupos de IDC de 3 e 6 a 7 dias do presente experimento, as quais mostraram diferença de 17,4 horas comparadas às de WEITZE et al. (1994), que conseguiram diferença ainda maior (aproximadamente 20 horas) comparando grupos de porcas com IDC abaixo de 93 horas e de 107 a 120 horas. As mesmas comparações foram feitas para as médias de MO, as quais destacaram diferença de 11,3 horas no presente trabalho e de 14,5 horas no experimento de WEITZE et al. (1994). Deste modo, o IDC poderia ser utilizado como um preditor do MO em programas de IA considerando sua influência local. De acordo com informações já referidas e discutidas, de que a DC e o MO também podem variar de rebanho para rebanho, as informações detalhadas sobre estas 
características, ao nível de avaliação de sistema de produção, deveriam ser analisadas e conhecidas para o sucesso da técnica, através do emprego de programas diferenciados de IA.

O significado dessa relação inversa entre o IDC e a DC não é conhecido, no entanto, ROJKITTIKHUN et al. (1992) observaram intervalo mais longo entre a elevação de estrógeno e o início do estro em porcas com IDC prolongado, sugerindo que estas seriam menos sensíveis ao estrógeno como sinal para a apresentação dos sintomas de estro, como descrito por SIGNORET (1970) e ALEXANDER et al. (1982).

Apesar de não ter havido correlação entre DC e $M O\left(R^{2}=0.05\right.$, $P=0,0578)$ no presente experimento, outros autores encontraram correlação positiva entre DC e MO $\left(R^{2}=0.45, P<0,0001\right.$, NISSEN et al., $1997 ; R^{2}=0.68$, $P=0,0001$, HECK et al., 1997). Talvez a baixa correlação encontrada no presente experimento esteja relacionada a um menor número de animais $(n=77)$ utilizados no diagnóstico da ovulação em comparação aos experimentos de NISSEN et al. (1997) $(n=118)$ e HECK et al. (1997) $(n=398)$, justificando o que já foi anteriormente exposto a respeito da variabilidade particular da característica.

$\mathrm{Na}$ elaboração de um programa de IA, seria importante conhecer as influências de características que são relacionadas ao IDC, assim como estação, raça e OP, sobre as relações entre IDC, DC e MO. Na dependência da existência e magnitude destas influências, ajustes no programa deveriam ser estudados, para eficiente utilização do IDC como preditor do MO. Neste particular, não foi possível mostrar a influência destas 
características sobre as relações (FIG. 11 a 19) e, conseqüentemente, considerações a respeito das mesmas seriam inadequadas. No entanto, devido à grande variabilidade observada nos dados, estudos adicionais seriam interessantes para a constatação destas possíveis influências.

A comparação entre o MO e o MOP mostrou baixa correlação positiva significativa $(r=0,3396 ; P=0,0209)$, provavelmente em razão do intervalo de 24 horas entre as colheitas de sangue pois, o MOP foi baseado nas determinações de SOEDE et al. (1994) onde os intervalos de colheita eram de 8 horas, o que poderia diminuir em até 16 horas a precisão da estimativa do MOP no presente trabalho. Este fato também explica a baixa correlação entre MO e MOP $(r=0,2637 ; P=0,0766)$ considerados em intervalos de 24 horas.

Apesar da baixa correlação entre o MO e o MOP, os níveis médios de progesterona confirmaram que fêmeas com IDC mais curto ovulam mais tardiamente que fêmeas com IDC mais longo. Tal confirmação foi verificada pela elevação média da progesterona (FIG. 21) e pela diferença de distribuição das fêmeas, de acordo com o intervalo onde a ovulação ocorreu, nos grupos de IDC de 3, 4, 5 e 6 a 7 dias, conforme apresentado na tabela 10 e figura 23.

Os níveis médios de progesterona se elevaram gradativamente, dentro dos limites encontrados na literatura (FIRST et al., 1982; STEVENSON \& BRITT, 1980; STEVENSON et al.,1981; ANDERSON, 1993; SOEDE et al., 1994). No experimento de SOEDE et al. (1994) 2 animais mostraram níveis basais acima de $1 \mathrm{ng} / \mathrm{ml}(1,47 \pm 0.36$ e $2,02 \pm 0,44 \mathrm{ng} / \mathrm{ml})$, enquanto que no 
presente experimento apenas 1 animal apresentou nível basal acima de $1 \mathrm{ng} / \mathrm{ml}(1,29 \mathrm{ng} / \mathrm{ml}), 35$ animais entre 0,1 e $1 \mathrm{ng} / \mathrm{ml}$ e 32 animais abaixo de 0,1ng/ml, confirmando a importância da dosagem dos níveis basais como parâmetro individual para a determinação da curva após o início do estro.

Considerando as informações de que os melhores resultados são obtidos quando a IA é realizada entre 0 e 24 horas antes da ovulação (HUNTER, 1967; HUNTER, 1977; HUNTER, 1994; WABERSKI et al., 1994a; WABERSKI et al., 1994b; SOEDE et al., 1995a; SOEDE et al., 1995b; NISSEN et al.,1997), KEMP; SOEDE (1996) estimaram a porcentagem de fêmeas que seriam inseminadas precocemente, tardiamente e dentro do intervalo ideal para cada grupo de $\operatorname{IDC}(3,4,5$ e 6 dias), na suposição de que fosse realizada uma IA 24 horas após o início do cio. Os resultados obtidos por estes autores foram que, $70 \%$ seriam inseminadas dentro do intervalo ideal, $22 \%$ precocemente e $8 \%$ tardiamente para fêmeas com IDC de 3 dias e que $45 \%$ seriam inseminadas dentro do intervalo ideal, $9 \%$ precocemente e $45 \%$ tardiamente para fêmeas com IDC de 6 dias, admitindo ainda que o grupo de IDC que apresentaria maior porcentagem de fêmeas dentro do intervalo ideal seria o de 4 dias com 86\%. No presente experimento, assumindo as mesmas condições de KEMP; SOEDE (1996), $58,4 \%$ das fêmeas seriam inseminadas dentro do intervalo ideal e $41,7 \%$ precocemente para fêmeas com IDC de 3 dias e 90\% dentro intervalo ideal e 10\% tardiamente para fêmeas com IDC de 6 e 7 dias, sendo que o grupo de IDC que apresentaria maior porcentagem de fêmeas dentro do intervalo ideal seria o de 5 dias com 91,6\%. Estas estimativas reforçam a afirmação de que 
o programa ideal de inseminação é bastante flexível e dependente das características do rebanho. Deste modo, o esquema de IA proposto por WEITZE et al. (1994) talvez não seja válido para a generalização em rebanhos distintos.

As observações de que fêmeas com IDC variando entre 3 e 5 dias são mais férteis que as que apresentam IDC entre 6 e 15 dias (LEMAN, 1992; VESSEUR et al., 1994a), tem algumas possíveis justificativas. LEMAN (1990) considera que esta baixa fertilidade poderia ser confundida com um efeito de utilização excessiva do macho, já que estas fêmeas são as últimas a serem cobertas do grupo de desmame. No entanto, VESSEUR et al. (1994a) observaram esta baixa fertilidade, mesmo quando as porcas foram inseminadas. LEMAN (1992) já sugere uma DC mais curta para porcas de IDC entre 6 e 15 dias, levando a uma menor oportunidade de múltiplas coberturas. Provavelmente a baixa fertilidade parece estar ligada a uma menor DC nestas porcas, não pela menor oportunidade de coberturas múltiplas, mas devido a uma maior dificuldade de se cobrir ou inseminar dentro do intervalo ideal (KEMP; SOEDE, 1996), principalmente em granjas que apresentam deficiências quanto ao diagnóstico de cio. Os resultados de VESSEUR et al. (1996) mostraram a importância da duração do cio, pois porcas com IDC de 5 dias apresentaram proporção maior de descendentes da primeira inseminação que porcas com IDC de 4 dias, as quais apresentaram uma proporção maior de descendentes da segunda inseminação. 
A ocorrência da ovulação aos $69,4 \pm 16,41 \%(25,5$ a 109,3\%) do período de cio mostrou-se muito próxima às obtidas nos experimentos de SOEDE et al. (1994) (72 $\pm 8 \%$; 54-86\%), SOEDE et al. (1995a) (72 $\pm 15 \%$; 39133\%) e NISSEN et al. (1997) (71,14\%). Estes dados suportam as informações de ANDERSON (1982), de que a ovulação ocorre sempre no início do terço final do estro.

A técnica de ultra-sonografia por via trans-cutânea foi de grande valia no presente estudo. NISSEN et al. (1995) consideram a técnica trans-retal como método de escolha, pois a via trans-cutânea requer muita prática (resultados satisfatórios a partir de 2000 exames). A experiência adquirida no presente experimento e num período de treinamento prévio, mostrou que bastariam ao redor de 50 exames para adquirir resultados satisfatórios se o examinador estivesse familiarizado com a técnica de ultrasonografia e conhecesse a anatomia da região a ser examinada. As desvantagens da técnica trans-cutânea citadas por SOEDE; KEMP (1993b), da posição anatômica do colo que freqüentemente bloqueia a visualização do ovário, principalmente do lado esquerdo e a imagem geralmente confusa e instável devido a movimentação do animal, também foram observadas no presente trabalho, impossibilitando a contagem das estruturas (folículos e corpos lúteos) e, conseqüentemente, o tempo de duração da ovulação (SOEDE; KEMP, 1993a; SOEDE et al., 1992). No entanto, em dois dos animais examinados, os ovários foram mais facilmente visualizados pelo flanco esquerdo.

Os resultados obtidos no presente experimento mostraram que 
a técnica trans-cutânea é efetiva para o diagnóstico do momento da ovulação em concordância com a literatura consultada (SOEDE et al., 1994; SOEDE et al., 1995a; SOEDE et al., 1995b; WABERSKI et al., 1994a; WABERSKI et al., 1994b; WEITZE et al., 1989; WEITZE et al., 1990; WEITZE et al., 1994).

A informação citada por KÄHN (1994) de que folículos poderiam ser confundidos com corpos hemorrágicos e vasos sangüíneos das regiões adjacentes foram consideradas nos exames realizados no presente experimento. A principal diferenciação entre folículos e corpos hemorrágicos era o formato circular apresentado pelo folículo, que após a ovulação apresentava certa deformação, parecendo menos tenso, o que dificulta sua visualização (WEITZE et al., 1989), já que o interior se apresentava não ecogênico devido ao conteúdo hemorrágico (ANDERSON, 1993). Já a diferenciação de folículos e vasos sangüíneos era obtida através de movimentação circular do transdutor em seu próprio eixo, à procura de "cortes" longitudinais destes vasos.

Apesar dos dados referentes ao tamanho das estruturas não serem considerados neste experimento, o tamanho das estruturas está de acordo com os achados de NISSEN et al.(1995), de que nos exames iniciais os folículos mediam aproximadamente 4 a $6 \mathrm{~mm}$ de diâmetro e alcançavam um tamanho máximo de 7 a 10mm. 
CONCLUSÕES 
Os resultados do presente experimento permitem as seguintes conclusões:

1 Houve relação inversa entre intervalo desmame-cio e duração do cio e entre intervalo desmame-cio e momento da ovulação, no entanto, devido a grande variabilidade destas relações, a proposta de utilizar o intervalo desmame-cio como um preditor do momento de realização da IA não seria segura. Por outro lado, o conhecimento destas relações nos rebanhos individualmente seria muito útil para apontar falhas no programa de IA.

2 A ultra-sonografia por via trans-cutânea mostrou-se uma técnica efetiva no diagnóstico da ovulação. No entanto, houve uma baixa correlação entre o diagnóstico da ovulação pela ultra-sonografia e pela dosagem de progesterona, provavelmente devido ao intervalo entre as colheitas de sangue (24 horas). Este intervalo fornece apenas a informação de que a porca ovulou ou não, mas para a determinação do provável momento da ovulação, intervalos menores entre as colheitas são necessários. Segundo os dados discutidos o intervalo ideal seria de 8 horas entre as colheitas.

30 intervalo desmame-cio foi influenciado pela raça e ordem de parto bem como, a duração do cio foi influenciada apenas pela ordem de parto, havendo também uma influência da interação ordem de parto x estação do ano sobre o momento da ovulação. 
4 A observação de cio quatro vezes ao dia mostrou que nos atuais programas de IA, baseados em duas observações diárias, pode haver um lapso entre o momento real de início de cio e o observado. Este lapso deve ser considerado na determinação do esquema de $\mathrm{IA}$, já que a maioria das granjas não tem condições práticas de realizar mais que duas observações diárias. 
REFERÊNCIAS BIBLIOGRÁFICAS 
ALEXANDER, D.; SIGNORET, J.P.; HAFEZ, E.S.E. Conduta sexual materna e neonatal. In: HAFEZ, E.S.E. Reprodução animal. 4. ed. Detroit: Manole, 1982. p. 346-83.

ANDERSON, L.L. Ciclos reprodutivos: suinos. In: HAFEZ, E.S.E. Reprodução animal. 4. ed. Detroit: Manole, 1982. p. 412-46.

ANDERSON, L.L. Reproductive cycles: pigs. In: HAFEZ, E.S.E. Reproduction in farm animals. 6. ed. Philadelphia: Lea \& Febiger, 1993. p.343-60.

ARMSTRONG, J.D.; BRITT, J.H.; KRAELING, P.R. Effect of restriction of energy during lactation on body condition, energy metabolism, endocrine changes and reproductive performance in primiparous sows. Journal of Animal Science, v. 63, n. 6, p. 1915-25, 1986.

BRITT, J.H.; SZAREK, V.E.; LEVIS, D.G. Characterization of summer infertility of sows in large-confinement units. Theriogenology, v. 20, n. 1, p. 133-40, 1983.

BRITT, J.H.; ARMSTRONG, J.D.; COX, N.M.; ESBENSHADE, K.L. Control of follicular development during and after lactation in sows. Journal of Reproduction and Fertility, Supl. 33, p. 37-54, 1985.

BRITT, J.H. Biology and management of the early weaned sow. American Association of Swine Practitioners, Proceedings, p. 417-26, 1996.

CORREAA, M.N.; DESCHAMPS, J.C.; GUIMARÃES, P.N.M.B.; MACEDO, M.C.Jr.; LUCIA, T.Jr.; SECHIN, A.; BASTOS, R.G.; CARDELLINO, R.A. Relação entre o intervalo desmame-cio e a duração de cio em porcas. In: CONGRESSO BRASILEIRO DE VETERINÁRIOS ESPECIALISTAS EM SUÍNOS, 8. Foz do Iguaçu, 1997. Anais. Foz do Iguaçu: Associação Brasileira de Veterinários Especialistas em Suínos, 1997. p.327-8.

COSTA, A.N. Aspectos fisiológicos do anestro lactacional da fêmea suína. Revista Brasileira de Reprodução Animal, v. 19, n.1-2, p. 89-99, 1995. 
DE RENSIS, F.; HUNTER, M.G.; GRANT, S.A.; LANCASTER, R.T.; FOXCROFT, G.R. Effect of estrogen administration on endogenous and luteinizing hormonereleasing-hormone-induced luteinizing hormone secretion and follicular development in the lactating sow. Biology of Reproduction, v. 44, n. 6, p. 975-82, 1991.

DIAL, G.D. Environmental and seasonal influences on swine reproduction. Compendium of Continuing Education Practice Veterinary, v. 6, n. 9, p. 528-34, 1984.

DIAL, G.D. 1987 apud TUBBS, R.C. Factors that influence the weaning-to-estrus interval in sows. Compendium of Continuing Education Practice Veterinary, v. 12, n. 1, p. 105-15, 1990.

DIAL, G.D.; BRITT, J.H. The clinical endocrinology of reproduction in the pig. In: MORROW, D.A. Current therapy in theriogenology. Philadelphia, Saunders, 1986. p. $908-9$.

DYCK, G.W. Postweaning changes in the reproductive tract of the sow. Canadian Journal of Animal Science, v. 63, n. 3, p. 571, 1983.

DYCK, G.W. The effect of housing facilities and boar exposure after weaning on the incidence of post lactational anoestrus in primiparous sows. Canadian Journal of Animal Science, v. 68, n. 4, p. 983-5, 1988.

DZIUK, P. Estimation of optimun time for insemination of gilts and ewes by double mating at certain times relative to ovulation. Journal of Reproduction and Fertility, v. 22, n. 2, p. 277-82, 1970.

ELSAESSER, F.; PARVIZI, N. Partial recovery of the stimulatory oestrogen feedback action on LH release during late lactation in the pig. Journal of Reproduction and Fertility, n. 59, n. 1, p. 63-7, 1980.

ESBENSHADE, K.L.; BRITT, J.H.; ARMSTRONG, J.D. Body condition of sows across parities and relationship to reproductive performance. Journal of Animal Science, v. 62, n. 5, p. 1187-93, 1986. 
FIRST, N.L.; BAZER, F.W. Pregnancy and parturition. Journal Animal Science, v. 57(Supl. 2), p. 425-60, 1982.

FOXCROFT, G.R.; HUNTER, M.G. Baisc physiology of follicular maturation in the pig. Journal of Reproduction and Fertility, Supl. 33, p. 1-19, 1985.

FRASER, A.F.; NAGARATNAN, V.; CALLICOTT, R.B. The comprehensive use of doppler ultrasound in farm animal reproduction. Veterinary Record, v. 88, n. 8, p. 202-5, 1971.

GEISERT, R.D.; DIXON, M.J.; PRATT, T.; SCHMITT, R.A.M.; LESSLEY, B.A.; MCCANN, J.P. Isolation and characterization of a $30-\mathrm{kDa}$ endometrial glycoprotein synthesized during the estrous cycle and early pregnancy of the pig. Biology of Reproduction, v. 53, n. 5, p. 1038-50, 1995.

GINTHER, O.J. Ultrasonic imaging and reproductive events in the mare. Madison, Equiservices, 1986. 378p.

GRANT, S.A.; HUNTER, M.G.; FOXCROFT, G.R Morphological and biochemical characteristics during ovarian follicular development in the pig. Journal of Reproduction and Fertility, v. 86, n. 1, p. 171, 1989.

GREENBERG, L.G.; MAHONE, J.P. Failure of a 16-hour light:8-hour dark on an 8-hour light:16 hour dark photoperiod to influence lactation on reproductive efficiency in sows. Canadian Journal Animal Science, v. 62, n. 1, p. 141-45, 1982.

HECK, A.; BORTOLOZZO, F.P.; WENTZ, I.; MARTINI, R.L.; STAHLBERG, R.; GUIDONI, A.L.; NAGAE, R. Determinação do momento da ovulação em porcas de granjas comerciais via diagnóstico ultra-sonográfico transcutâneo. In: CONGRESSO BRASILEIRO DE VETERINÁRIOS ESPECIALISTAS EM SUÍNOS, 8. Foz do Iguaçu, 1997. Anais. Foz do Iguaçu: Associação Brasileira de Veterinários Especialistas em Suínos, 1997. p.333-4.

HELMOND, F.; AARNINK, A; OUDENAARDEN, C. Periovulatory hormone profiles in relation to embryonic development and mortality in pigs. In: SREENAN, J.N.; DISKIN, M.G. Embryonic mortality in farm animals. Dordrecht: Martinus Nijhoff , 1986. p. 119-25. 
HUNTER, R.H.F. Porcine ovulation after injection of human chorionic gonadotropin. Veterinary Record, v.81, n. 1, p. 21-3, 1967.

HUNTER, R.H.F. Physiological factors influencing ovulation, fertilization, early embryonic development and stablishment of pregnancy in pigs. British Veterinary Journal, v.133, n. 5, p. 461-70, 1977.

HUNTER, R.H.F.,1994. apud SOEDE, M.N.; WETZELS, C.C.H.; ZONDAG, W.; HAZELEGER, W.; KEMP, B. Effects of a second insemination after ovulation on fertilization rate and accessory sperm count in sows. Journal of Reproduction and Fertility, v. 105, n. 1, p. 135-40, $1995 \mathrm{~b}$.

HUNTER, M.G.; BIGGS, C.; FAILLACE, L.S.; PICTON, H.M. Current concepts of folliculogenesis in monovular and polyovular farm species. Journal of Reproduction and Fertility, Supl. 45, p. 21-38, 1992.

HUNTER, M.G.; WIESAK, T. Evidence for and implications of folicular heterogeneity in pigs. Journal of Reproduction and Fertility, Supl. 40, p. 16377, 1990.

INABA, T.; NAKAZIMA, Y.; MATSUI, N. \& IMORI, T. Early pregnancy diagnosis in sows by ultrasonic linear electronic scanning. Theriogenology, v. 20, n. 1, p. 97-101, 1983.

KÄHN, W. Veterinary reproductive ultrasonography. Hannover: Mosby-Wolfe, 1994. 256 p.

KEMP, B.; SOEDE, N.M. Relationship of weaning-to-estrus interval to timinng of ovulation and fertilization in sows. Journal of Animal Science, v. 74, n. 5, p. 944-9, 1996.

KILLEN, J.H.; CHRISTENSON, R.K.; FORD, J.J. Ovarian follicular changes after weaning in sows. Journal Animal Science, v. 70, n. 9, p. 2801-8, 1992.

KING, R.H.; WILLIANS, I.H. The effect of nutrition on the reproductive peformance of first-litter sows. 2. Protein and energy intakes during lactation. Animal Production, v. 38, n. 2, p. 249-56, 1984. 
KRAELING, R.R.; BARB, C.R. Hypothalamic control of gonadotrophin and prolactin secretion in pigs. Journal of Reproduction and Fertility, Supl. 40, p. 3-17, 1990.

LEMAN, A.D. Mate sows once 3 - 5 days after weaning. International Pig Letter, v.10, n. 8, p. 29, 1990.

LEMAN, A.D. Optimizing farrowing rate and litter size and minimizing nonproductive sow days. Veterinary Clinics of North America, v. 8, n. 3, p. 609-21, 1992.

LINDAHL, I.L.; TOTSCH, J.P.; MARTIN, P.A.; DZIUK, P.J. Early diagnosis of pregnancy in sows by ultrasonic amplitude-depth analysis. Journal of Animal Science, v. 40, n. , p. 220-2, 1975.

LIPNER, H. Mechanism of mammalian ovulation. In: KNOBIL, E.; NEIL, J.D. The phisiology of reproduction. New York: Raven, 1988. p. 447-88.

MAURER, R.R.; FORD,J.J.; CHRISTENSON, R.K. Interval to first postweaning estrus and causes for leaving the breeding herd in Large White, Landrace, Yorkshire and Chester White females after three parities. Journal of Animal Science, v. 61, n. 6, p. 1327-34, 1985.

MOURA, J.C.A.; MERKET, H. A ultra-sonografia na reprodução eqüina. Salvador, Editora Universitária, 1994. 116p.

MUNARI, J.L.P. Determinação dos horários de início e duração do cio e influência de diferentes momentos de inseminação sobre o desempenho reprodutivo de porcas e leitoas nos meses de verão. Dissertação (Mestre em Medicina Veterinária). Universidade Federal de Santa Maria, Santa Maria, 1985.

NISSEN, A.K.; LEHN-JENSEN, H.; HYTTEL, P.; GREVE, T. Follicular development and ovulation in sows: effect of hCG and GnRH treatment. Acta Veterinaria Scadinavica, v. 36, n. 1, p. 123-43, 1995. 
NISSEN, A.K.; SOEDE, N.M.; HYTTEL, P.; SCHMIDT, M.; D'HOORE, L. The influence of time of insemination relative to time of ovulation on farrowing frequency and litter size in sows, as investigated by ultrasonography. Theriogenology, v. 47, n. 8, p. 1571-1582, 1997.

NOGUEIRA, L.A.G. Efeitos do momento e do número de inseminações artificiais em certos aspectos da eficiência reprodutiva de fêmeas da raça Landrace. Belo Horizonte. 52p. Tese (Mestre em Medicina Veterinária). Universidade Federal de Minas Gerais, Belo Horizonte, 1982.

PERERA, A.N.M.; HACKER, R.R. Effects of different photoperiods on reproduction in sow. Journal of Animal Science, v. 58, n. 6, p. 1418-22, 1984.

PIERSON, R.A.; KASTELIC, J.P.; GINTHER, O.J. Basic principles and techniques for transrectal ultrasonography in cattle and horses. Theriogenology, v. 29, n. 1, p. 3-20, 1988.

POWIS, R.L. Ultrasound science for the veterinarian. The Veterinary Clinics of North America: Equine Practice, v. 2, n. 1, p. 3-27, 1986.

RANTANEN, N.W. General considerations for ultrasound examinations. The Veterinary Clinics of North America: Equine Practice, v. 2, n. 1, p. 29-32, 1986.

REESE, D.E.; MOSER, B.D.; PEO, E.R. Influence of energy intake during lactation on the interval from weaning to first estrus in sows. Journal of Animal Science, v. 55, n. 3, p. 590-8, 1982.

REESE, D.E.; PEO, E.R.; LEWIS, A.J. Relationship of lactation energy intake and occurrence of postweaning estrus to body and back-fat composition in sows. Journal of Animal Science, v. 58, n. 5, p. 1236-44, 1984.

REIS, F.T.;SILVA FILHO, J.M.; REIS,R.; MOURÃO,G.B.; MALM, C.; FERREIRA, H.I. Efeitos de diferentes estímulos sexuais sobre algumas características do cio de porcas. In: CONGRESSO BRASILEIRO DE VETERINÁRIOS ESPECIALISTAS EM SUÍNOS, 8. Foz do Iguaçu, 1997. Anais. Foz do Iguaçu: Associação Brasileira de Veterinários Especialistas em Suínos, 1997. p.323-4. 
RODRIGUES, B.A.; RODRIGUES, J.L. Ultra-sonografia na clínica de pequenos animais. Hora Veterinária, v. 15, n. 86, p. 51-8, 1995.

ROJANASTHIEN, S. LH-Patters in jugular plasma and oestradiol-17 $\beta$ and progesterone in utero-ovarian and jugular plasma of primiparous sows around weaning. Journal of Veterinary Medicine A, v. 35, n. 7, p. 498-505, 1988.

ROJKITTIKHUN, T.; STERNING, M.; RYDMER, L.; EINARSSON, S. Oestrous symptoms and plasma levels of oestradiol- $17 \beta$ in relation to the interval from weaning to oestrus in primiparous sows. CONGRESS OF THE INTERNATIONAL PIG VETERINARY SOCIETY, 12. The Hague,1992. Anais. p. 485.

ROPPA, L. A nutrição e a alimentação das fêmeas reprodutrizes. In: CONGRESSO BRASILEIRO DE REPRODUÇÃO ANIMAL, 9. Belo Horizonte, 1991. Anais. Belo Horizonte: Colégio Brasileiro de Reprodução Animal, 1991. v.2, p.217-47.

SIGNORET, J.P. Reproductive behaviour of pigs. Journal of Reproduction and Fertility, Supl. 11, p. 105-17, 1970.

SMIRNOV, I.; TERESHCHENKO, I. Insemination of pigs on large farms. Animal Breeding Abstracts, v. 48, n. 12, p. 890, 1980. (Abst. 7405).

SOEDE, M.N.; HELMOND, F.A.; KEMP, B. Periovulatory profiles oestradiol, LH and progesterone in relation to oestrus and embryo mortality in multiparous sows using transrectal ultrasonography to detect ovulation. Journal of Reproduction and Fertility, v. 101, n. 3, p. 633-41, 1994a.

SOEDE, M.N.; KEMP, B. In synchronized pigs, the duration of ovulation is not affected by insemination and is not a determinant for early embryonic diversity. Theriogenology, v. 39, n. 5, p. 1043-53, 1993a.

SOEDE, M.N.; KEMP, B. Transrectal ultrasonography of pig ovaries: can it be applied in the case of fertility problems? Veterinary Vision, v. 1, n. 1, p.1-6, 1993b. 
SOEDE, M.N.; NOORDHUIZEN, J.P.T.M.; KEMP, B. The duration of ovulation in pigs, studied by transrectal ultrasonography, is not related to early embryonic diversity. Theriogenology, v. 38, n. 4, p. 653-66, 1992.

SOEDE, N.M.; WETZELS, C.C.H.; ZONDAG, W; DE KONING, M.A.I.; KEMP, B. Effects of time of insemination relative to ovulation, as determined by ultrasonography, on fertilization rate and accessory sperm count in sows. Journal of Reproduction and Fertility, v. 104, n. 1, p. 99-106, 1995 a.

SOEDE, M.N.; WETZELS, C.C.H.; ZONDAG, W.; HAZELEGER, W.; KEMP, B. Effects of a second insemination after ovulation on fertilization rate and accessory sperm count in sows. Journal of Reproduction and Fertility, v. 105, n. 1, p. 135-40, 1995b.

SOEDE, M.N.; WETZELS, C.C.H.; KEMP, B. Ultrasonography of pig ovaries: benefits in research and on farms. Reproduction in Domestic Animals, v. 29, n. 5, p. 366-70, 1994b.

SQUIRES, E.L.; McKINNON, A.O.; SHIDELER, R.K. Use of ultrasonography in reproductive management of mares. Theriogenology, v. 29, n. 1, p. 55-70, 1988.

STEVENSON, J.S.; BRITT, J.H. Luteinizing hormone, total estrogens and progesterone secretion during lactation and after weaning in sows. Theriogenology, v. 14, n. 6, p. 453-62, 1980.

STEVENSON, J.S.; BRITT, J.H. Interval to estrus in sows and porformance of pigs after alteration of litter size during late lactation. Journal of Animal Science, v. 53, n. 1, p. 177-81, 1981.

STEVENSON, J.S.; COX, N.M.; BRITT, J.H. Role of the ovary in controlling luteinising hormone, folicle stimulating hormone and prolactin secretion during and after lactation in pigs. Biology of Reproduction, v. 24, n. 2, p. 341-53, 1981.

STEVENSON, J.S.; POLLMAN, D.S.; DAVIS, D.L. Influence of supplemental light on sow performance during and after lactation. Journal of Animal Science, $v$. 56, n. 6, p. 1281-6, 1983. 
SZAREK, V.E.; LEVIS, D.G., BRITT, J.H. Characteristics of summer infertility in sows. Journal of Animal Science, v. 53, supl. 1, p. 3, 1981.

TORBECK, R.L. Diagnostic ultrasound in equine reproduction. Veterinary Clinics of North America: Equine Practice, v. 2, n. 1, p. 227- 52, 1986.

TUBBS, R.C. Factors that influence the weaning-to-estrus interval in sows. Compendium of Continuing Education Practice Veterinary, v. 12, n. 1 , p. 105-15, 1990.

VAN DE WEIL, D.F.M.; BOOMAN, P.; WILLEMSE, A.H.; BEVERS, M.M. Relevance of prolactin to lactational and post-weaning anoestrus in the pig. In: Endocrine causes of seasonal and lactational anestrus in farm animals. Dordrecht, Martinus Nijhoff, 1985. p. 154-64.

VAN DE WEIL, D.F.M.; KOOPS, J.; VOS, E.; VAN LANDEGHEM, A.A.J. Perioestrus and midluteal time courses of circulating $\mathrm{LH}, \mathrm{FSH}$, prolactin, estradiol-17 $\beta$ and progesteron in the domestic pig. Biology of Reproduction, v. 24, n. 2, p. 223-33, 1981.

VARLEY, M.A.; FOXCROFT, G.R. Endocrinology of the lactating and weaned sow. Journal of Reproduction and Fertility, Supl. 40, p. 47-61, 1990.

VESSEUR, P.C.; KEMP, B.; HARTOG, L.A. The effect of the weaning to oestrus interval on litter size, live born piglets and farrowing rate in sows. Journal of Animal Physiology and Animal Nutrition, v. 71, n. 1, p. 30-8, 1994a.

VESSEUR, P.C.; KEMP, B.; HARTOG, L.A. Factors affecting the weaning to oestrus interval in the sow. Journal of Animal Physiology and Animal Nutrition, v. 72, n. 4, p. 225-33, 1994b.

VESSEUR, P.C.; KEMP, B.; HARTOG, L.A. Factors influencing the proportion of offspring from a second insemination in sows. Animal Reproduction Science, v. 41, n. 3, p. 255-65, 1996.

WABERSKI, D.; WEITZE, K.F.; GLEUMES, T.; SCHWARS, M.; WILLMEN, T.; PETZOLDT, R. Effect of time of insemination relative to ovulation on fertility with liquid and frozen boar semen. Theriogenology, v. 42, n. 5, p. 831-40, 1994a. 
WABERSKI, D.; WEITZE, K.F.; LIETMANN, C.; LÜBERT zUr LAGE, W.; BORTOLOZZO, F.P.; WILLMEN, T.; PETZOLDT, R. The initial fertilizing capacity of longterm-stored liquid boar semen following pre- and postovolatory insemination. Theriogenology, v. 41, n. 7, p. 1367-77, 1994b.

WALTON, J.S. Effect of boar presence before and after weaning on oestrus and ovulation in sows. Journal of Animal Science, v. 62, n. 1, p. 9-15, 1986.

WEITZE, K.F.; HABECK, O.; WILLMEN, T.; RATH, D. Detection of ovulation in sow using transcutaneous sonography. Zuchthygiene, v. 24, n. 1, p. 40-2, 1989.

WEITZE, K.F.; RABELER, J.; WILLMEN, T.; WABERSKI, D. Interaction between inseminate, uterine and ovarial function in the sow: I. Influence of seminal plasma and oestrogens in the inseminate on intragenital sperm transport, time of ovulation and fertility results in gilts. Reproduction in Domestic Animals, v. 25, n. 4, p. 191-6, 1990.

WEITZE, K.F.; WAGNER-RIETSCHEL, H.; WABERSKI, D.; RICHTER, L.; KRIETER, J. The onset of heat after weaning, heat duration, and ovulation as major factors in IA timing in sows. Reproduction in Domestic Animals, v. 29, n. 7, p. 433-43, 1994.

WENTZ, I.; MARTINI, R.L.; BORTOLOZZO, F.P.; HECK, A.; STAHLBERG, R.; UEMOTO, D.A.; NAGAE, R.; GUIDONI, A.L. Avaliação da duração do estro e momento da ovulação em leitoas com auxílio da ultra-sonografia. In: CONGRESSO BRASILEIRO DE VETERINÁRIOS ESPECIALISTAS EM SUÍNOS, 8. Foz do Iguaçu, 1997. Anais. Foz do Iguaçu: Associação Brasileira de Veterinários Especialistas em Suínos, 1997. p.331-2.

ZIECIK, A.; TILTON, J.E.; WEIGL, R.; WILLIAMS, G.L. Plasma luteinizing hormone during pregnancy in the pig. Animal Reproduction Science, v. 5, n. 3, p. 213-8, 1982.

ZIMMERMAN, D.R.; NABER,C. The influence of mating on ovulation time in the pig. Journal of Animal Science, v. 33, n. 1, p. 273, 1971. 